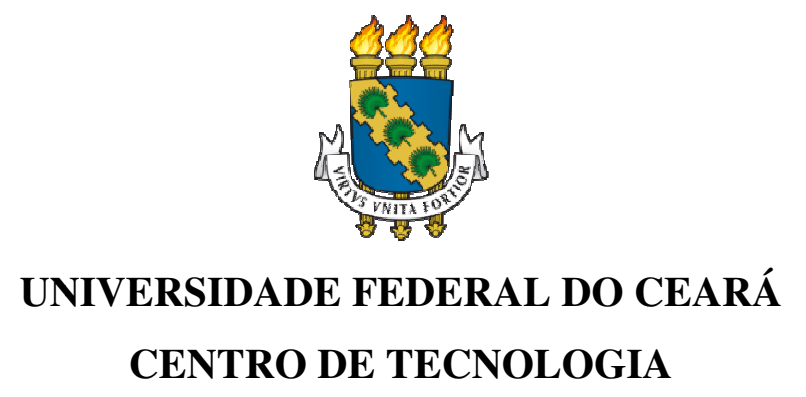

DEPARTAMENTO DE ENGENHARIA ESTRUTURAL E CONSTRUÇÃO CIVIL PROGRAMA DE PÓS-GRADUAÇÃO EM ENGENHARIA CIVIL: ESTRUTURAS E CONSTRUÇÃO CIVIL

NERTAN FONSECA BARROSO FILHO

UM ESTUDO COMPARATIVO DE PROCEDIMENTOS DE ANÁLISE ESTRUTURAL PARA TORRES EÓLICAS DE CONCRETO ARMADO

FORTALEZA

2018 
UM ESTUDO COMPARATIVO DE PROCEDIMENTOS DE ANÁLISE ESTRUTURAL PARA TORRES EÓLICAS DE CONCRETO ARMADO

Dissertação apresentada ao Programa de PósGraduação em Engenharia Civil: Estruturas e Construção Civil da Universidade Federal do Ceará, como requisito parcial à obtenção do título de mestre Engenharia Civil. Área de Concentração: Estruturas.

Orientador: Prof. Dr. Antônio Macário Cartaxo de Melo

Coorientadora: Profa. Dra. Tereza Denyse Pereira de Araújo 
Dados Internacionais de Catalogaçăo na Publicação

Universidade Federal do Ceará

Biblioteca Universitária

Gerada automaticamente pelo módulo Catalog, mediante os dados fomecidos pelo(a) autor(a)

B285e Barroso Filho, Nertan Fonseca.

Um estudo comparativo de procedimentos de análise estrutural para torres eólicas de concreto armado /

Nertan Fonseca Barroso Filho, - 2018

$108 \mathrm{f}$ : : il. color.

Dissertação (mestrado) - Universidade Federal do Ceará, Centro de Tecnologia, Programa de PósGraduaçăo em Engenharia Civil: Estruturas e Construção Civil, Fortaleza, 2018.

Orientação: Prof. Dr. Antônio Macírio Cartaxo de Melo.

Coorientaçāo: Profa. Dra. Tereza Denyse Pereira de Araújo.

1. Torre eólica. 2. Concreto armado. 3. Elementos finitos. L. Titulo.

CDD 624.1 


\title{
UM ESTUDO COMPARATIVO DE PROCEDIMENTOS DE ANÁLISE ESTRUTURAL PARA TORRES EÓLICAS DE CONCRETO ARMADO
}

\begin{abstract}
Dissertação apresentada ao Programa de PósGraduação em Engenharia Civil: Estruturas e Construção Civil da Universidade Federal do Ceará, como requisito parcial à obtenção do título de mestre Engenharia Civil. Área de Concentração: Estruturas.
\end{abstract}

Aprovada em: 28/08/2018.

\author{
BANCA EXAMINADORA
}

Prof. Dr. Antônio Macário Cartaxo de Melo (Orientador) Universidade Federal do Ceará (UFC)

Profa. Dra. Tereza Danyse Pereira de Araújo Universidade Federal do Ceará (UFC)

Prof. Dr. João Batista Marques de Sousa Junior Universidade Federal do Ceará (UFC)

Prof. Dr. Francisco Alex Correira Monteiro

Instituto Tecnológico de Aeronáutica (ITA) 


\section{AGRADECIMENTOS}

Agradeço ao meu orientador Professor Antônio Macário Cartaxo de Melo e minha co-orientadora Professora Tereza Denyse Pereira de Araújo, que foram cruciais na elaboração da minha dissertação.

Agradeço a todos meus colegas do mestrado em Engenharia Civil, cujo incentivo e companheirismo estiveram presentes em todos os momentos.

Agradeço a minha família, pela compreensão, ao serem privados da minha presença em muitos momentos. 
"Tudo deveria se tornar o mais simples possível, mas não simplificado."

(Albert Einstein) 


\section{RESUMO}

O estudo de soluções econômicas para estruturas de aerogeradores eólicos tem despertado o interesse devido ao apelo ambiental desta fonte de energia renovável. Particularmente, as torres eólicas de aço têm sido bastante estudadas tanto no que concerne à análise quanto à otimização estrutural. Em geral minimiza-se o consumo de material que está diretamente relacionado ao custo. Entretanto, limitações nas dimensões devidas ao transporte tem sido um fator importante para o emprego de torres de concreto armado. $\mathrm{Na}$ otimização, um passo crítico é o processo de análise. Nas análises buscam-se, em geral, respostas em termos de resistência, estabilidade, rigidez e frequência fundamental. Os recursos computacionais modernos têm permitido a aplicação de procedimentos numéricos refinados de análise estrutural. Entretanto, o uso destes recursos em um modelo de otimização pode tornar o processo computacionalmente caro. O emprego de modelos substitutos tem sido bastante estudado, mas uma alternativa é a adoção de procedimentos simplificados, em geral conservadores, e muito usados em projetos preliminares. A torre eólica considerada nesse trabalho possui $100 \mathrm{~m}$ de altura com uma turbina de 3,6 MW, cujas ações foram obtidas da literatura. Pretende-se, neste trabalho, estudar e comparar modelos de análise de torres eólicas de concreto armado. Os modelos serão comparados através dos métodos dos elementos finitos com consideração dos elementos finitos unidimensionais e bidimensionais. A modelagem da ação do vento ao longo da torre será tratada como estática. Serão avaliadas as influências de não linearidades física e geométrica, interação solo-estrutura e o seu efeito nos deslocamentos e nas frequências naturais da torre. O modelo de viga é validado para aplicação em modelos de otimização.

Palavras-chave: Análise. Torre eólica. Concreto armado. Elementos finitos. 


\begin{abstract}
The study of economic solutions for wind turbine structures has attracted interest due to the environmental appeal of this renewable energy source. Particularly, steel wind towers have been well studied both in terms of analysis and structural optimization. In general, the consumption of material that is directly related to the cost is minimized. However, limitations in the dimensions due to transport have been an important factor for the use of reinforced concrete towers. In optimization, a critical step is the process of analysis. In the analysis, we generally seek answers in terms of resistance, stability, rigidity and fundamental frequency. Modern computational resources have allowed the application of refined numerical structural analysis procedures. However, using these features in an optimization model can make the process computationally expensive. The use of substitute models has been well studied, but an alternative is the adoption of simplified procedures, generally conservative, and much used in preliminary projects. The wind tower considered in this work is $100 \mathrm{~m}$ high with a turbine of 3.6 MW, whose actions were obtained from the literature. In this work, we intend to study and compare models of analysis of wind-powered reinforced concrete towers. The models will be compared through finite element methods with consideration of one-dimensional and twodimensional finite elements. Wind modeling along the tower will be treated as static. The influence of physical and geometric nonlinearities, soil-structure interaction and their effect on the tower natural frequencies and its displacements, as well as its natural frequencies will be evaluated. The beam model is validated for application in optimization models.
\end{abstract}

Keywords: Analysis. Wind tower. Reinforced concret. Finite elements. 


\section{LISTA DE FIGURAS}

Figura 1 - Capacidade global acumulada de energia eólica instalada (GWEC, 2016)

Figura 2 - Componentes do aerogerador..................................................... 20

Figura 3 - $\quad$ Aerogerador de eixo vertical e horizontal.................................... 20

Figura 4 - $\quad$ Painéis curvos de concreto............................................................. 24

Figura 5 - Distribuição de pressão para cilindros com diferentes números de

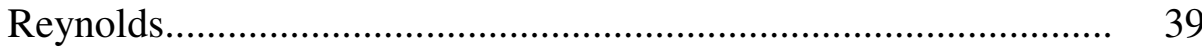

Figura 6 - $\quad$ Nomenclatura do coeficiente de pressão externa............................. 39

Figura 7 - Esquematização da torre.................................................................. 53

Figura 8 - Dimensões da fundação............................................................ 57

Figura 9 - Curva de Thorenfeldt................................................................ 57

Figura 10 - Curva Exponencial.............................................................. 58

Figura 11 - Idealmente plástico................................................................................... 58

Figura 12 - Modos de vibração considerando o modelo de viga com a base engastada e o concreto não fissurado................................................ 67

Figura 13 - Modos de vibração considerando o modelo de casca com a base engastada e o concreto não fissurado.

Figura 14 - Modos de vibração considerando o modelo de casca com a fundação engastada e o concreto não fissurado.

Figura 15 - Variação da frequência natural da torre no estado não fissurado com a rigidez

Figura 16 - Modos de vibração considerando o modelo de viga com a base apoiada na areia fina e o concreto não fissurado

Figura 17 - Detalhe da armadura da torre de concreto.

Figura 18 - Modos de vibração considerando o modelo de casca com a base engastada e o concreto armado não fissurado

Figura 19 - Modos de vibração considerando o modelo de casca com a fundação engastada e o concreto armado não fissurado.

Figura 20 - Máxima deflexão em função da carga de vento aplicada no ELU.... 85

Figura 21 - Máxima deflexão em função do fator de carga do vento no ELS.... 86

Figura 22 - Variação da frequência da torre no estado não fissurado com a resistência do concreto. 
Figura 23 - Variação do deslocamento no topo da torre no estado não fissurado com a resistência do concreto......................................... 88

Figura 24 - Variação da frequência da torre com a espessura da parede........... $\quad 90$

Figura 25 - Variação do deslocamento no topo da torre no estado fissurado com a espessura da parede........................................................... 90

Figura 26 - Variação da frequência da torre com o diâmetro externo................. 92

Figura 27 - Variação do deslocamento no topo da torre no estado fissurado com o diâmetro externo............................................................... 92 


\section{LISTA DE TABELAS}

Tabela 1 - Classes de turbinas éólicas padrão..................................................... 33

Tabela 2 - Constantes do vento.................................................................. 38

Tabela 3 - Coeficiente de pressão externa......................................................... 40

Tabela 4 - $\quad$ Especificações da Turbina................................................................... 40

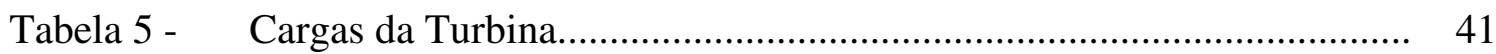

Tabela 6 - Coeficientes de ponderação das resistências dos materiais.................. 42

Tabela 7 - Frequência de trabalho da turbina...................................................... 42

Tabela 8 - $\quad$ Parâmetros meteorológicos referentes à classe II............................... 44

Tabela 9 - Distribuição das pressões externas em edificações cilíndricas de seção circular................................................................................... 45

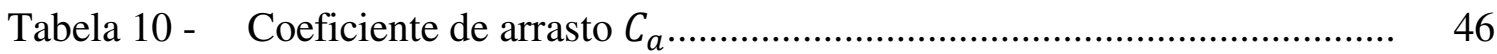

Tabela 11 - Coeficiente $\gamma_{f}=\gamma_{f 1} \cdot \gamma_{f 3}$ para combinações de ações normais........... 47

Tabela 12 - Valores do coeficiente $\gamma_{f 2}$ para ações do vento................................. 47

Tabela 13 - Combinações últimas normais.............................................................. 49

Tabela 14 - Combinações de serviço........................................................................ 50

Tabela 15 - Propriedades de concreto obtidas usando o Model Code CEB-FIB

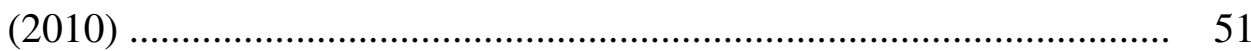

Tabela 16 - Propriedades da armadura............................................................... 52

Tabela 17 - Rigidez do solo para fundações circulares......................................... 56

Tabela 18 - Coeficientes de profundidade de embutimento.................................... 56

Tabela 19 - Deflexão no topo da torre para o ELS (mm) …................................... 62

Tabela 20 - Deflexão no topo da torre para o ELU $(\mathrm{mm})$....................................... 63

Tabela 21 - Deflexão no topo da torre para o ELU considerando os efeitos de $2^{\mathrm{a}}$

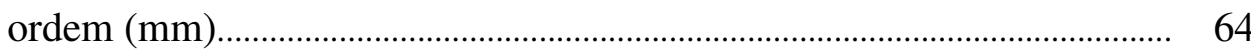

Tabela 22 - Momento na base da torre para o ELU considerando os efeitos de $2^{\text {a }}$ ordem $(\mathrm{MNm})$...................................................................... 65

Tabela 23 - Análise de vibração livre da torre para o estado não fissurado e fissurado do concreto $(\mathrm{Hz})$........................................................................... 66

Tabela 24 - Frequência para os 6 primeiros modos considerando a base engastada e o concreto não fissurado.

Tabela 25 - Limites para deslocamentos de aceitabilidade sensorial...................... 69 
Tabela 26 - Deflexão no topo da torre para o ELS (mm) considerando a ABNT NBR 6118 (2014) e ABNT NBR 6123 (1988)

Tabela 27 - Deflexão no topo da torre para o ELU (mm) considerando a ABNT NBR 6118 (2014) e ABNT NBR 6123 (1988)

Tabela 28 - Deflexão no topo da torre para o ELS (mm), considerando os efeitos de $2^{\mathrm{a}}$ ordem de acordo com a ABNT NBR 6118 (2014) e ABNT NBR $6123(1988)$

Tabela 29 - Deflexão no topo da torre para o ELU (mm), considerando os efeitos de $2^{\mathrm{a}}$ ordem de acordo com a ABNT NBR 6118 (2014) e ABNT NBR $6123(1988)$ 71

Tabela 30 - Frequência natural da torre/engastada/NBR's para o ELU (Hz).......... 71

Tabela 31 - Frequência natural da torre/engastada/NBR's para o ELS (Hz)........... 72

Tabela 32 - Propriedades de solos típicos......................................................................... 72

Tabela 33 - Redução da frequência fundamental $(\mathrm{Hz})$ da torre devida a diferentes tipos de solos.

Tabela 34 - Influência da fissuração do concreto na frequência $(\mathrm{Hz})$ da torre para diferentes tipos de solos no ELS

Tabela 35 - Influência da fissuração do concreto na frequência $(\mathrm{Hz})$ da torre para diferentes tipos de solos no ELU.....

Tabela 36 - Deflexão (mm) no topo da torre para diferentes tipos de solos, considerando o concreto fissurado

Tabela 37 - Deflexão (mm) no topo da torre para diferentes tipos de solos: concreto fissurado e efeitos de $2^{\mathrm{a}}$ ordem.

Tabela 38 - Análise paramétrica da frequência da torre engastada de Zyl (2014) no estado não fissurado, em função da resistência do concreto $(\mathrm{Hz})$

Tabela 39 - Análise paramétrica da torre de acordo com o modelo de Zyl (2014) com a base engastada considerando a variação da espessura da parede 89

Tabela 40 - Análise paramétrica da torre de acordo com o modelo de Zyl (2014) com a base engastada considerando a variação do diâmetro externo 


\section{LISTA DE ABREVIATURAS E SIGLAS}

ABEEólica Associação Brasileira de Energia Eólica

ABNT Associação Brasileira de Normas Técnicas

ACI American Concrete Insttitute

ANSI American National Standards Institute

ASCE American Society of Civil Engineers

ECD Extreme Coherent Gust with Direction Change

EDC Extreme Direction Change

EOG Extreme Operating Gust

ETM Extreme Turbulence Model

EWM Extreme Wind Model

EWS Extreme Wind Shear

GWEC Global Wind Energy Council

GWR Global Wind Report

GWS Global Wind Statistic

IEC International Electrotechnical Commission

LWST Low Wind Speed Turbine

NBR Norma Brasileira

NREL National Renewable Energy Laboratory

NTM Normal Turbulence Model

NWP Normal Wind Profile

SANS South African National Standards

SABS South African Bureau of Standards

SINAPI Sistema Nacional de Preços e Índices para a Construção Civil

TNO The Netherlands Organisation

WTG Wind turbine generator 


\section{SUMÁRIO}

$1 \quad$ INTRODUÇÃO

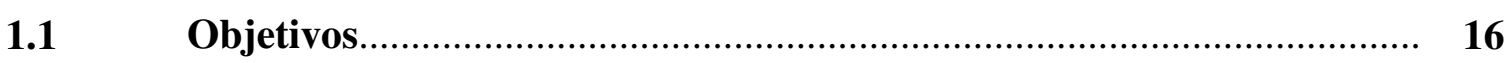

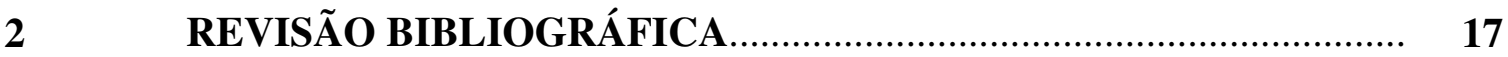

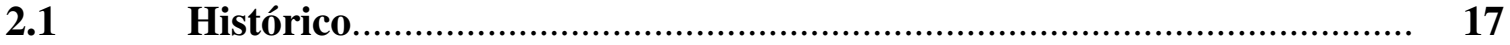

$2.2 \quad$ Vantagens e desvantagens das torres de concreto................................ 18

$2.3 \quad$ Tipos de turbinas eólicas e seus componentes...................................... 19

$2.4 \quad$ Torre

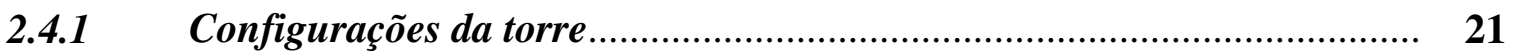

2.5 Técnicas para execução de torre eólica de concreto............................. 22

2.5.1 Fôrma deslizante ........................................................................ 23

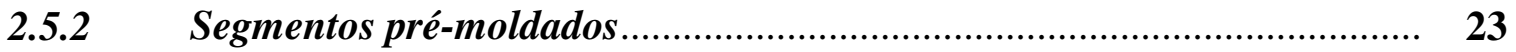

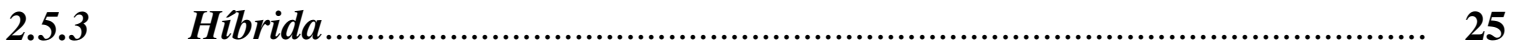

2.6 Modelos de análise estrutural........................................................... 25

2.6.1 Solução analítica $x$ Método dos elementos finitos.................................... 25

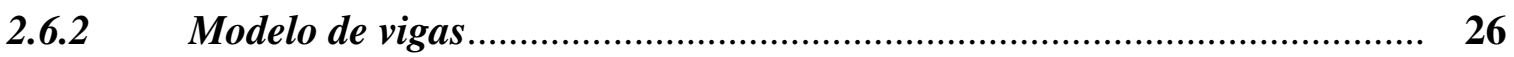

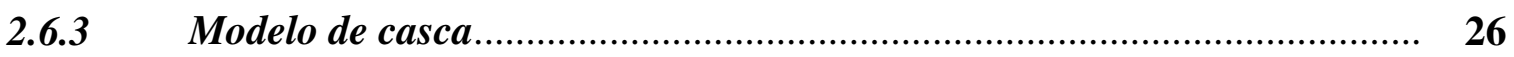

2.7 Trabalhos precedentes................................................................. 27

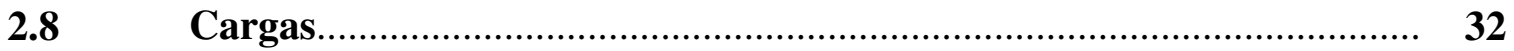

2.8.1 Pressão direta do vento - Modelo de Zyl............................................. 32

2.8.1.1 Velocidade básica do vento.......................................................................... 32

2.8.1.2 Pressão do vento..................................................................................... 36

2.8.1.3 Distribuição de pressão circunferencial................................................... 39

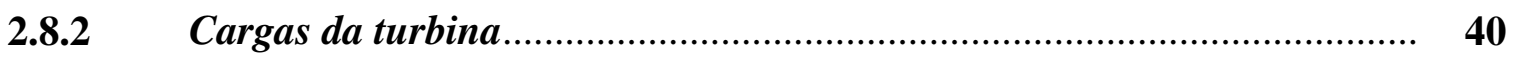

2.9 Coeficientes parciais e combinações de carga de acordo com o modelo

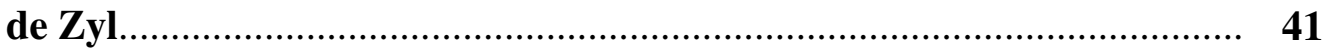

2.10 Coeficientes de ponderação das resistências dos materiais de acordo

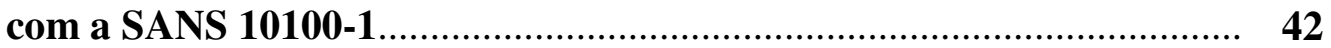

2.11 Frequência de trabalho da turbina de 3,6 MW .................................. 42

2.12 Ações do Vento de acordo com a ABNT NBR 6123 .............................. 42

2.13 Ações de acordo com a ABNT NBR 6118.......................................... 46

2.13.1 Coeficientes de ponderação das açães no ELU ....................................... 46 
2.13.2 Coeficientes de ponderação das ações no ELS..................................... 47

2.14 Combinações de ações de acordo com a ABNT NBR 6118................... 48

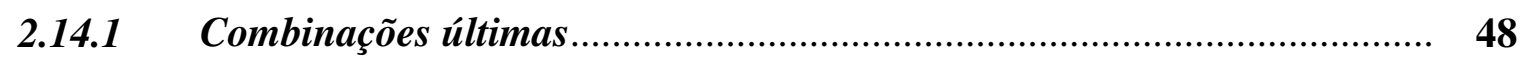

2.14.2 Combinações de serviço..................................................................... 50

2.15 Combinação de carga de acordo a ABNT NBR 6118.......................... 51

2.16 Propriedades dos materiais utilizados na modelagem de Zyl.............. 51

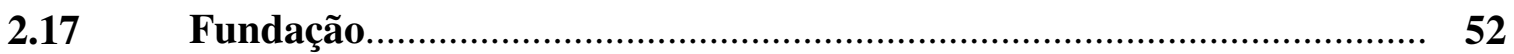

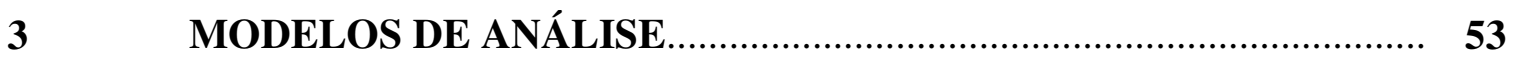

3.1 Modelo de viga a ser utilizado nesta pesquisa................................... 54

3.2 Modelo de casca a ser utilizado nesta pesquisa................................... 54

3.3 Efeito P-Delta de acordo com o SAP2000 ........................................... 55

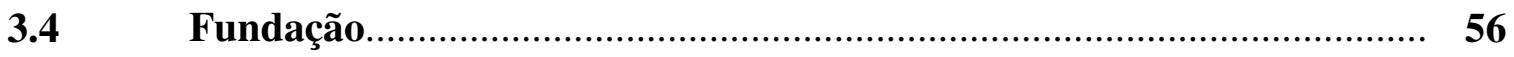

3.5 Modelos dos materiais utilizados no modelo de Zyl com a

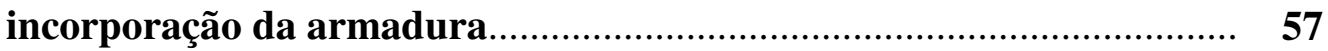

3.6 Avaliação analítica da frequência fundamental da torre...................... 58

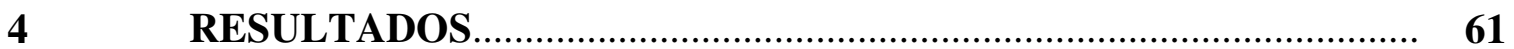

4.1 Torre engastada e modelo de Zyl................................................... 61

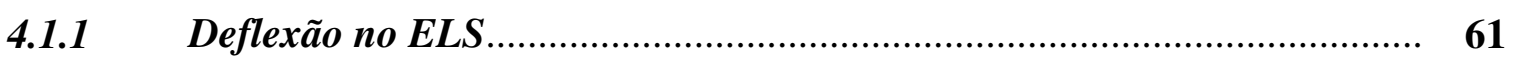

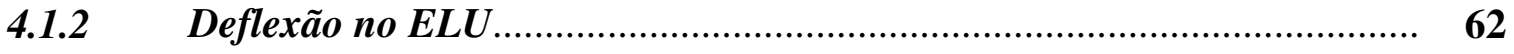

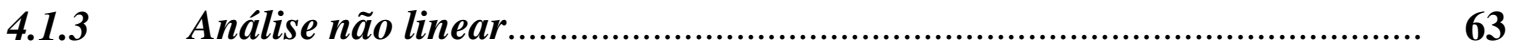

4.1.3.1 Deflexão no ELU................................................................................. $\mathbf{6 4}$

4.1.3.2 Momento no ELU.................................................................................... 64

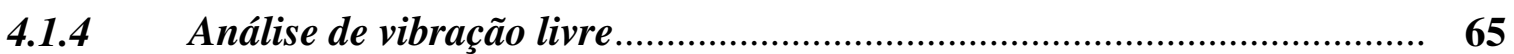

4.2 Torre engastada e modelo da ABNT NBR 6118 e ABNT NBR 6123.... 68

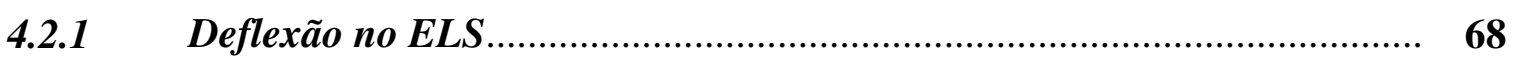

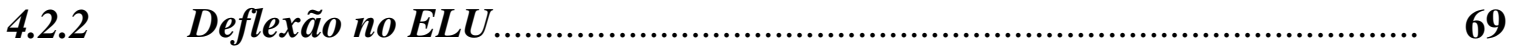

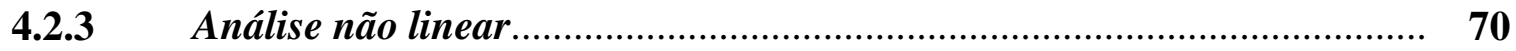

4.2.3.1 Deflexão no ELS............................................................................... 70

4.2.3.2 Deflexão no ELU ................................................................................. 71

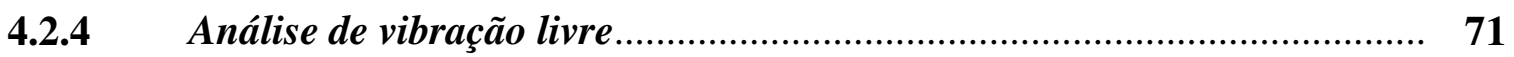

4.3 Torre com interação solo-estrutura e modelo de Zyl........................... 72

4.3.1 Análise de vibração livre - concreto não fissurado................................. 72

4.3.2 Análise de vibração livre no ELS - concreto fissurado........................... 78 
4.3.3 Análise de vibração livre no ELU - concreto fissurado

4.4 Torre com interação solo-estrutura e modelo da ABNT NBR 6118 e ABNT NBR 6123

4.4.1 Deflexão no ELS - concreto fissurado 79

4.4.2 Deflexão no ELS - concreto fissurado e efeitos de segunda ordem......... 80

4.5 Torre engastada e modelo de $\mathrm{Zyl}$ incorporando a armadura................ 80

4.5.1 Deflexão, análise de vibração livre e efeitos de segunda ordem no ELU 82

4.5.2 Deflexão no ELS........................................................................... 85

5

ANÁLISE PARAMÉTRICA 87

5.1 Variação da resistência característica do concreto à compressão. 87

5.2 Variação da espessura. 89

5.3 Variação do diâmetro externo 91

6 COMENTÁRIOS FINAIS. 93 REFERÊNCIAS. 95

APÊNDICE A - MANUAL DE UTILIZAÇÃO DE ELEMENTOS SHELL NO SOFTWARE SAP2000. 99 APÊNDICE B - PROCEDIMENTO DE PROJETO PARA DETERMINAÇÃO DA CARGA DO VENTO 105 


\title{
1 INTRODUÇÃO
}

\begin{abstract}
O movimento mundial para gerar grandes quantidades de eletricidade com turbinas eólicas levou a um aumento significativo na capacidade das turbinas eólicas. A capacidade das turbinas aumentaram de um par de $\mathrm{kW}$ na década de 1970 para qualquer coisa entre 2000 e $7500 \mathrm{~kW}$ atualmente. Um método de aumentar a capacidade das turbinas eólicas é aumentar a velocidade média anual do vento que a turbina estará exposta. Isto pode ser conseguido escolhendo um local com uma alta velocidade média anual do vento, assim como aumentando a altura do rotor da turbina. O efeito da rugosidade da superfície diminui com a altura, assim uma velocidade mais constante do vento pode ser conseguida colocando a turbina mais alta. (ZYL, 2014, p. 2, tradução nossa).
\end{abstract}

As torres de aço com altura de 80-90 m não é mais adequada se a capacidade da turbina for aumentanda, pois as limitações de diâmetro as tornam antieconômicas em alturas de rotores maiores que aproximadamente 80-90 m (ZYL,2014). O diâmetro máximo da base da torre de aço tubular, por questões de transporte, não pode exceder os 4,30 metros, o que representa um obstáculo insuperável para o aumento da altura da torre (CHASTRE; LÚCIO, 2014). Uma solução para a limitação de altura é usar torres de turbinas eólicas de concreto, pois não apresenta limitação no diâmetro e, portanto, não há limitação na altura que é possível (ZYL, 2014).

O projeto da torre pode ser obtido pela aplicação de técnicas numéricas de otimização. Nessa estratégia, um passo crítico é o processo de análise que pode ser computacionalmente caro. Nas análises buscam-se, em geral, respostas em termos de resistência, estabilidade, rigidez e frequência fundamental. Os recursos computacionais modernos têm permitido a aplicação de procedimentos numéricos refinados de análise estrutural. Uma alternativa é a adoção de procedimentos simplificados, em geral conservadores, e muito usados em projetos preliminares.

Vários aspectos merecem destaque e carecem de estudos na análise das torres de concreto armado, tais como: tipo de elemento finito usado (viga e casca); modelagem da ação do vento (estática e dinâmica); consideração das não linearidades física e geométrica; e modelagem da interação solo-estrutura. O principal interesse tem sido a avaliação do efeito desses elementos nas deflexões e frequências naturais de vibração.

Pretende-se, neste trabalho, estudar e comparar modelos de análise de torres eólicas de concreto armado. Os modelos serão comparados com relação ao tipo de elemento, às não linearidades e à interação solo-estrutura. 


\subsection{Objetivos}

O objetivo deste trabalho é comparar modelos de análise estrutural de torres eólicas de concreto armado, principalmente no que concerne ao tipo de elemento usado, às não linearidades e à interação solo-estrutura.

Os objetivos específicos são:

a) Conhecer o estado da arte dos procedimentos de análise de torres de concreto armado;

b) Estudar a modelagem do vento de acordo com modelo proposto na literatura por Zyl (2014);

c) Estudar a modelagem do vento de acordo com a norma brasileira de vento (ABNT NBR 6123/1988);

d) Comparar a aplicação do elemento finito de viga (1D) com o elemento de casca (2D) ao modelo proposto por Zyl (2014) e ao modelo da ABNT 6118 (2014) e ABNT NBR 6123 (1988);

e) Analisar o efeito da interação solo-estrutura no comportamento;

f) Estudar o efeito da fissuração no comportamento da torre;

g) Estudar o comportamento da torre para variações em alguns de seus parâmetros (estudo paramétrico);

h) Validar o elemento de viga para sua utilização num modelo de otimização. 


\section{REVISÃO BIBLIOGRÁFICA}

Este capítulo contempla o referencial bibliográfico relacionado ao assunto análise estrutural para torres eólicas de concreto armado.

\subsection{Histórico}

Nos últimos anos, com o avanço das ciências e técnicas sobre o meio natural foi possível perceber o alto nível de desgaste em que o planeta se encontrava, o que gerou uma crescente preocupação mundial com questões ambientais. Com esse entendimento, foram realizadas várias conferências em diferentes países para tratar deste problema, gerando acordos mundiais de proteção à natureza, tais como o Protocolo de Montreal em vigor a partir de 1989, que impõe metas de diminuição de gases que afetem negativamente a camada de ozônio, e o Protocolo de Kyoto em 2005, onde foram definidas metas de redução de poluentes que causam o efeito estufa e geram o aquecimento global (SOUSA, 2016).

O Global Wind Energy Council (GWEC) prevê que, até 2035, as energias renováveis gerarão mais de $25 \%$ das necessidades mundiais de eletricidade, sendo que um quarto delas será proveniente da energia eólica (GLOBAL WIND REPORT, 2013). Na Figura 1 é mostrada a capacidade global acumulada de energia eólica instalada.

Figura 1 - Capacidade global acumulada de energia eólica instalada (GWEC, 2016)

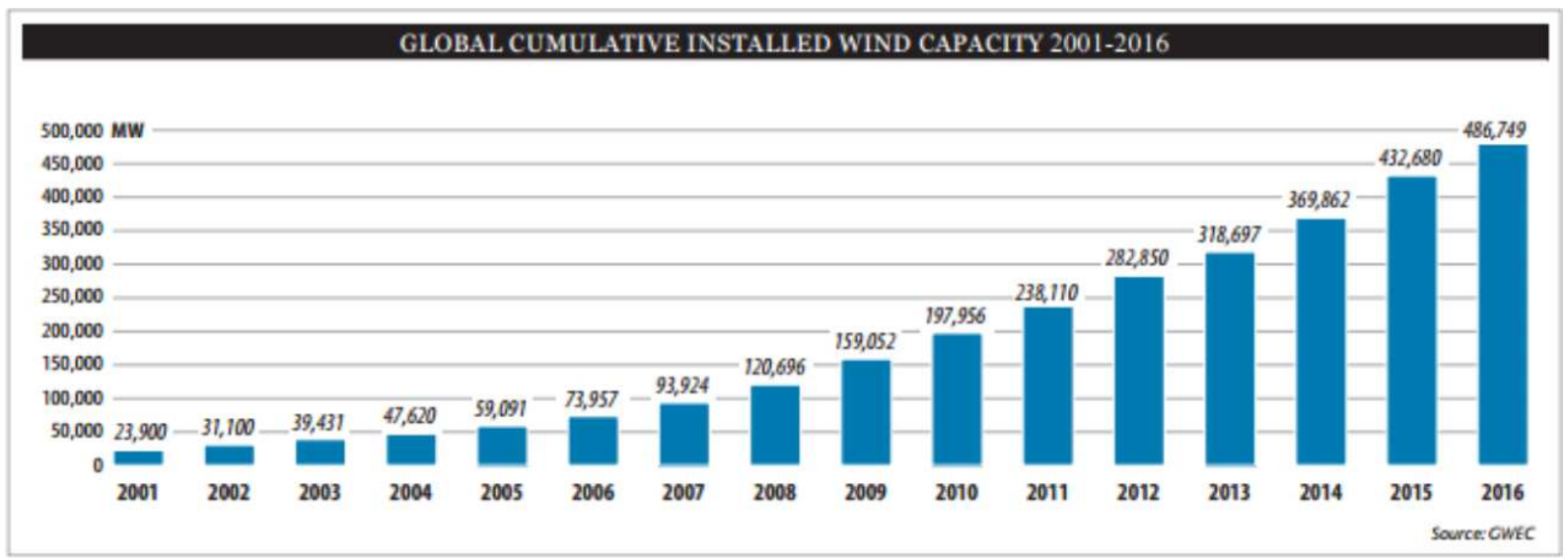

Fonte: Brasil... (2017)

O Brasil subiu uma posição, passando o Canadá, e agora ocupa o oitavo lugar no ranking mundial que afere a capacidade instalada de produção de energia eólica, segundo o Global Wind Statistic (2017) e Nascimento (2018), documento anual com dados mundiais de energia eólica produzido pela Global Wind Energy Council (GWEC). 
Em 2017, o país conseguiu "adicionar 52,57 GW de potência eólica à produção mundial, totalizando 539,58 GW de capacidade instalada", informou a Associação Brasileira de Energia Eólica (ABEEólica) apud Nascimento (2018, não paginado), que reúne empresas do setor.

Em 2016, o Brasil ultrapassou a Itália no ranking e passou ocupar a $9^{a}$ posição. Atualmente, o país conta com $12,76 \mathrm{GW}$ de capacidade de energia instalada, contra os 12,39 GW do Canadá. A China ocupa a primeira posição, com 188,23 GW; seguida pelos Estados Unidos, com 89,07 GW, e a Alemanha, com 56,132 GW de capacidade instalada. A Índia, a Espanha, o Reino Unido e a França completam o ranking dos sete primeiros. (NASCIMENTO, 2018, não paginado).

Os números apontam para um crescimento da matriz de energia eólica no país. O segmento já é responsável por 8,3\% da energia produzida no Brasil, percentual ainda distante dos 60,9\% produzido pelas hidrelétricas, mas já próximo dos 9,3\% da produção das usinas de biomassa, que ocupam o segundo posto no ranking nacional. A energia produzida pelas usinas eólicas chegou a ser responsável por $64 \%$ da energia consumida na Região Nordeste, no dia 14 de setembro do ano passado. A ABEEólica estima que o Brasil, cuja capacidade instalada é $12 \mathrm{GW}$, tenha potencial eólico superior a $500 \mathrm{GW}$. (NASCIMENTO, 2018, não paginado).

A Região Nordeste aparece na frente na capacidade de produção de energia a partir dos ventos. Com 135 parques, o Rio Grande do Norte é o estado que mais produziu energia usando a força dos ventos. São 3678,85 MW de capacidade instalada. Em seguida, com 93 parques e 2410,04 MW de capacidade instalada vem à Bahia. Em terceiro lugar vem o Ceará, que conta com 74 parques e tem 1935,76 MW de capacidade instalada. (NASCIMENTO, 2018, não paginado).

Em quarto lugar aparece o Rio Grande do Sul. O estado tem 80 parques e 1831,87 MW de capacidade instalada. Em seguida vem o Piauí, com 52 parques e 1443,10 MW instalados, e Pernambuco com 34 parques e 781,99 MW de capacidade instalada. (NASCIMENTO, 2018, não paginado).

\subsection{Vantagens e desvantagens das torres de concreto}

As principais vantagens das torres de concreto:

a) Capacidade para atingir grandes alturas e suportar aerogeradores de grandes dimensões, quer onshore, quer offshore (CHASTRE; LÚCIO, 2014);

b) Melhoria do comportamento dinâmico, reduzindo a fadiga, aumentando a vida útil do equipamento e reduzindo a manutenção (CHASTRE; LÚCIO, 2014);

c) Excelente resposta as ações sísmicas, graças a elevada ductilidade e amortecimento estrutural, contrastando com as torres de aço (CHASTRE; LÚCIO, 2014);

d) Menor necessidade de manutenção em contraste com as torres aço, especialmente em ambiente offshore (CHASTRE; LÚCIO, 2014);

e) Maior durabilidade destas estruturas de concreto em relação as torres de aço, em particular em ambientes marinhos (CHASTRE; LÚCIO, 2014); 
f) Menor ruído gerado pelo efeito de amortecimento do concreto (CHASTRE; LÚCIO, 2014);

g) Redução das emissões de $\mathrm{CO}_{2}$ na fabricação da torre (entre 55 e $65 \%$ das emissões envolvidas na fabricação de uma torre de aço) (CHASTRE; LÚCIO, 2014);

h) O material das torres é totalmente reciclável (CHASTRE; LÚCIO, 2014);

i) A durabilidade do concreto das torres é muito mais elevada que a dos aerogeradores (CHASTRE; LÚCIO, 2014);

j) Maior resistência ao fogo devido às espessuras das paredes e seus recobrimentos necessários, as armaduras estão melhor protegidas do grande gradiente térmico que ocorre por ocasião de um acidente com incêndio (DUARTE, 2014);

k) Devido à ausência da oxidação não há necessidade de pintura anticorrosiva de proteção (DUARTE, 2014);

1) Fundações mais econômicas, em relação às estruturas de aços tradicionais (CHASTRE; LÚCIO, 2014);

m) Menor custo relativo entre as soluções de concreto armado/protendido em relação às soluções de aço estrutural (DUARTE, 2014);

n) Grande facilidade de industrialização das peças de concreto (DUARTE, 2014);

o) Ausência do problema de flambagem localizada (DUARTE, 2014);

p) A torre de concreto com a mesma altura que a torre de aço apresenta um maior rendimento de energia por fazer funcionar o aerogerador com ventos maiores e por mais tempo (DUARTE, 2014).

A principal desvantagem da torre de concreto é a inexistência de uma norma de projeto específica.

\subsection{Tipos de turbinas eólicas e seus componentes}

Os componentes gerais da turbina eólica são a torre, rotor, nacele e pás. Uma visão mais detalhada é apresentada na Figura 2. A produção de energia se dá quando o vento passa pelas pás, fazendo-as girarem, o que movimenta o rotor e em seguida aciona o gerador, que tem a função de converter a energia mecânica de rotação em energia elétrica. 
Figura 2 - Componentes do aerogerador

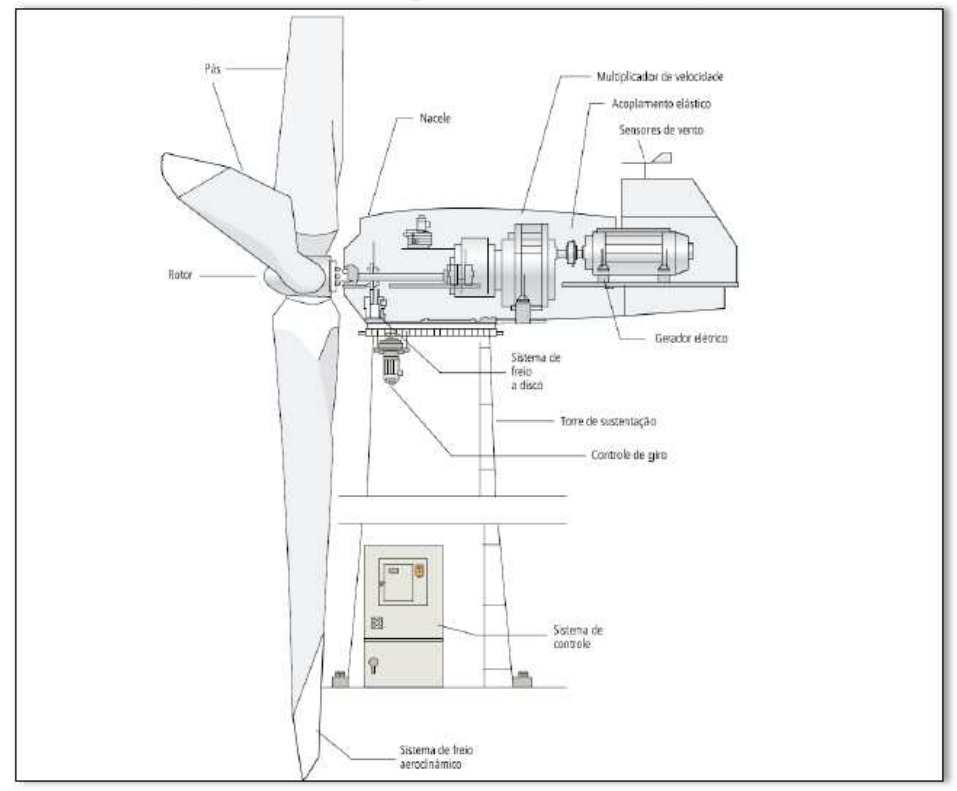

Fonte: Energias Renováveis (2017)

Os aerogeradores são comumente classificados quanto a orientação de seu eixo de rotação, que são de dois tipos: vertical (Figura 3) e horizontal (Figura 3). O primeiro tem como vantagem a produção de energia sem precisar de reorientação independente da direção do vento no momento, porém tem um rendimento menor de potência. Já os de eixo horizontal precisam ser reorientados em função do vento, mas geram um melhor aproveitamento de energia desta forma e por isso é mais utilizado (SOUSA, 2016), sendo considerado nesta dissertação.

Figura 3 - Aerogerador de eixo vertical e horizontal

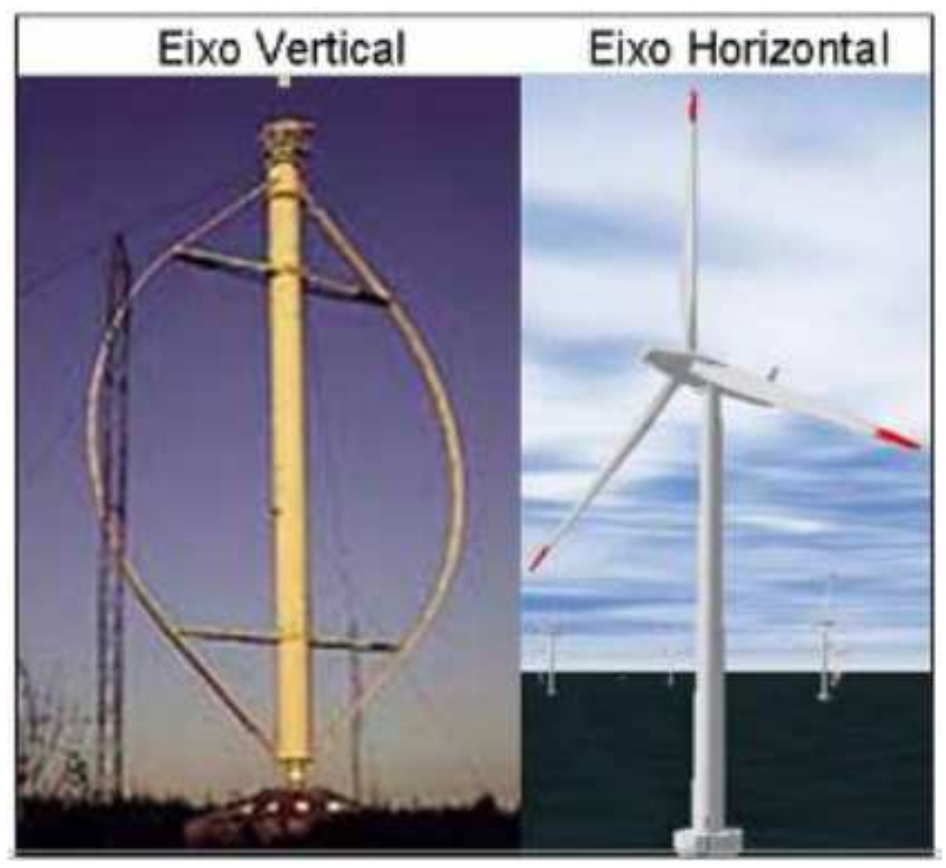

Fonte: [Aerogerador...] (2012). 


\subsection{Torre}

A torre é um componente essencial da turbina de eixo horizontal. O custo da torre é representativo e pode chegar a até 30\% do custo total do sistema (HAU, 2013). Quando a altura da torre aumenta, o transporte, a montagem, a ereção da torre e a manutenção dos componentes também aumentam, se tornando cada vez mais difícil e caro. Por outro lado, a energia específica de rendimento do rotor também aumenta com a altura da torre. Teoricamente, a altura ideal da torre encontra-se no ponto onde as funções de crescimento do custo de construção e o rendimento energético se cruzam (HAU, 2013). Infelizmente, este ponto de interseção não pode ser especificado em qualquer formulário de aplicação geral. Nas turbinas maiores, os custos de construção aumentam mais rapidamente com o aumento da altura da torre do que em turbinas pequenas. Um papel ainda mais importante é observado pela escolha do local. Em terrenos irregulares, ou seja, nas regiões com um elevado grau de rugosidade da superfície, a velocidade do vento aumenta mais devagar com a altura do que em terrenos planos. Em terrenos irregulares, grandes aerogeradores com altura de torre de 80 m ou mais apresentam um fator econômico decisivo da utilização potencial do vento.

Depois da altura, o segundo parâmetro de projeto mais importante de uma torre é sua rigidez. Estabelecer a primeira frequência de flexão natural de maneira correta é uma tarefa importante no projeto. Isso determina o material necessário e, em última instância, o custo da construção. O objetivo do projeto da torre é conseguir a altura da torre desejada com a rigidez necessária ao menor custo de construção possível.

O transporte e o procedimento de ereção está se tornando um problema crescente para a última geração de turbinas eólicas de vários megawatts. Alturas de torre entre 80 e 90 m e pesos de várias centenas de toneladas apresentam diâmetro maiores que 4,30 metros, como conseqüência o transporte rodoviário não é viável. Isto torna-se um forte incentivo para encontrar soluções no projeto de torres eólicas de concreto.

\subsubsection{Configurações da torre}

Os tipos mais antigos de "turbinas eólicas", os moinhos de vento, não tinham torres mas "casas de moinhos". Estas foram construídas com baixa altura em relação ao diâmetro do rotor e com construção volumosa em função do seu espaço de trabalho, assegurando assim a rigidez necessária. Logo, entretanto, a vantagem do aumento da altura foi reconhecida e os moinhos tornaram-se mais esbeltos e mais semelhantes a uma torre. Mas é 
apenas nas construções dos dias modernos, primeiro nas pequenas turbinas eólicas norteamericanas e, posteriormente, nas primeiras usinas de energia eólica que eram usados "mastros" ou "torres. Como uma consequência deste desenvolvimento, projetos e materiais para torres aumentaram em variedade. $\mathrm{O}$ aço e o concreto tomaram o lugar da construção de madeira das casas de moinhos. As primeiras torres foram construídas com metodologia de experimentação e teste, como os moinhos de vento, gradualmente essas torres foram sendo concebidas através de modelos de análise estrutural e dimensionamento bem definidos.

Quanto ao tipo de sistema estrutural, três tipos principais têm sido usados:

As torres estaiadas são usualmente empregadas em torres de pequeno porte e têm como vantagem o aumento da rigidez da torre, gerando a possibilidade de torres mais finas. Entretanto necessitam de grande espaço para colocação dos suportes dos estais e têm acesso dificultado para manutenção da torre.

As treliçadas têm como ponto positivo uma estrutura mais leve e uma redução no efeito da carga de vento, porém geram uma agressividade visual e, devido ao grande número de elementos, geram variadas frequências naturais, dificultando o cálculo da estrutura, o que fazem muitos descartarem essa opção.

As torres tubulares são as mais comuns, são rápidas para serem executadas e possuem boa rigidez. Em relação aos tipos anteriores sua desvantagem é ter um peso relativamente maior e, consequentemente, custo mais elevado. Neste trabalho, será estudado as deste último tipo.

Classificação das torres quanto ao material:

Os materiais disponíveis para a construção de torres eólicas são concreto, aço ou ambos (híbrida).

\subsection{Técnicas para execução de torre eólica de concreto}

Atualmente existem três técnicas principais para execução de torres de concreto. Elas são:

- Fôrma deslizante;

- Segmentos pré-fabricados;

- Híbrida. 


\subsubsection{Fôrma deslizante}

A fôrma deslizante é um método para a construção de estruturas de concreto vertical usando um sistema de içamento do sistema de fôrmas.

Em construções com fôrma deslizante, o sistema de fôrmas está em constante movimento para cima à medida que a estrutura é moldada. O concreto é assim moldado até atingir a altura desejada.

As vantagens do método executivo da fôrma deslizante de acordo com Zyl (2014):

a) Não há necessidade de transporte das unidades pré-fabricadas;

b) Estruturas monolíticas de concreto sem juntas frias;

c) Custos de guindastes e problemas logísticos são reduzidos;

d) Construção em áreas remotas é possível.

As desvantagens do método executivo da fôrma deslizante de acordo com Zyl (2014):

a) Período de construção mais longo do que na construção pré-fabricada (taxa de construção de aproximadamente $250 \mathrm{~mm}$ por hora);

b) Pode ocorrer custo maior do que na construção pré-fabricada dependendo do local específico da construção;

c) Sistemas de formas customizados são necessários para cada torre se mais de uma torre é construída simultaneamente;

A principal desvantagem da construção forma deslizante é o tempo de construção. A uma taxa de $250 \mathrm{~mm}$ por hora leva-se 16,7 dias para completar uma torre de 100 metros, se a construção for ininterrupta 24 horas por dia. O número de torres construídas simultaneamente pode ser aumentado pelo aumento do número de plataformas de fôrma deslizante, mas isso irá aumentar o custo significativamente (ZYL, 2014).

\subsubsection{Segmentos pré-moldados}

O concreto pré-moldado não é um conceito novo e tem sido usado há anos na construção de lajes, escadas, muros de contenção e vários outros elementos estruturais. Existem principalmente dois tipos de construção pré-moldada usados para torres de turbinas eólicas. A torre pode ser construída usando grandes segmentos com altura de 20-25 m ou pequenos segmentos de anel com aproximadamente $3 \mathrm{~m}$ de altura (ZYL, 2014). 
O conceito de grandes segmentos pré-moldados envolve o uso de painéis curvos de concreto longo (Figura 4). O diâmetro da torre é dividido em segmentos para reduzir o tamanho dos painéis. Normalmente, para grandes torres a base é dividida em três painéis, com 120 graus cada. Isso garante que os segmentos possam ser transportados em estradas normais sem exceder o limite de altura (ZYL, 2014).

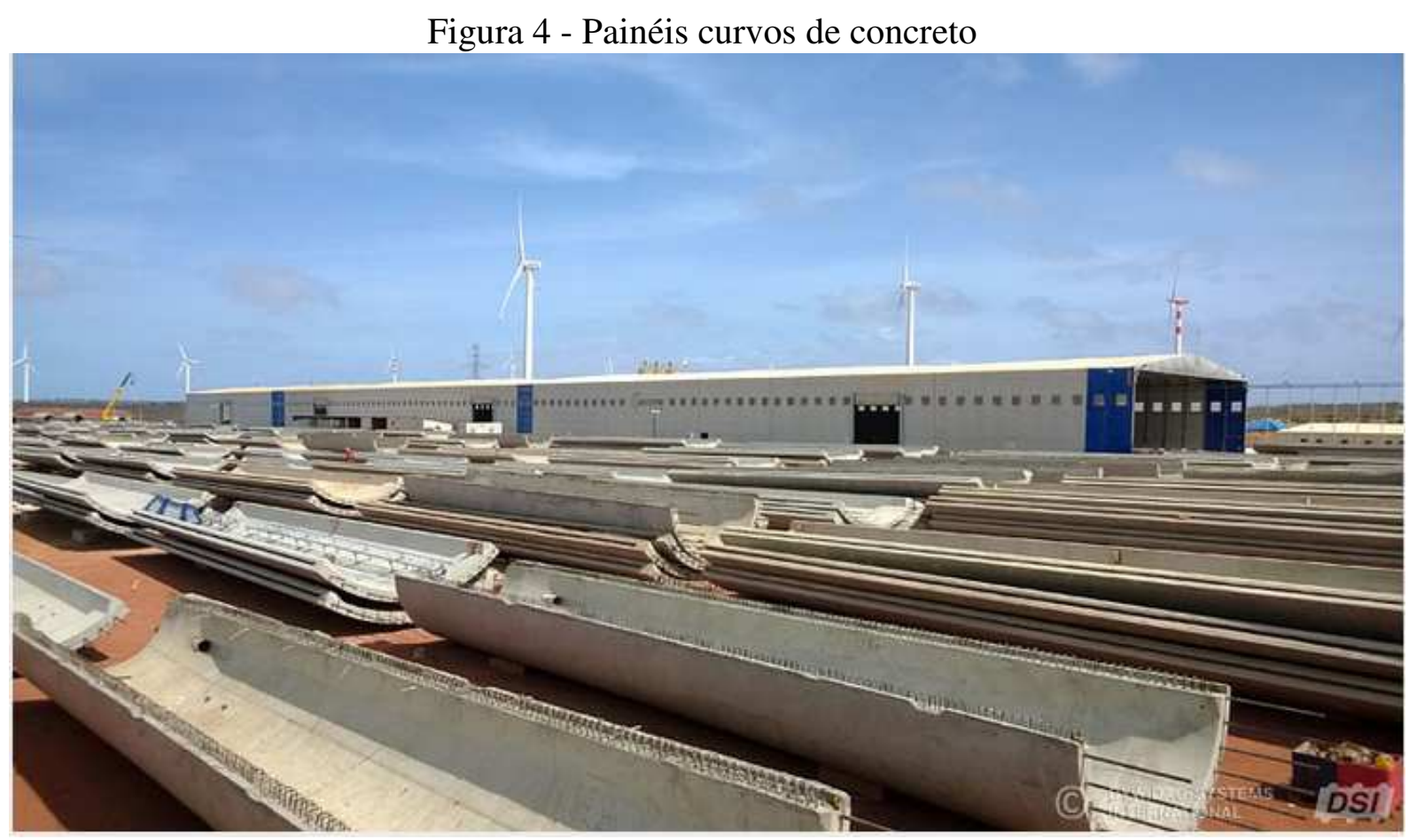

Fonte: Protendidos Dywidag (2018)

Uma das vantagens dos pequenos segmentos é que podem ser transportados em caminhões normais e levantados no lugar com guindastes relativamente pequenos. $\mathrm{O}$ grande número de segmentos aumenta significativamente o número de juntas, o que por sua vez aumenta o custo. A escolha entre grandes e pequenos segmentos pré-moldados será fortemente influenciada pelo local específico.

$\mathrm{O}$ custo de transporte dos segmentos da torre pode representar uma grande porcentagem do custo total da torre, particularmente quando os parques eólicos são remotos ou servidos por redes de transporte precárias. Algumas empresas usam fábricas de concreto pré-moldados no próprio local para a produção de segmentos de torre. Isto tem duas vantagens, em primeiro lugar o custo de transporte é reduzido significativamente e, em segundo lugar, a mão-de-obra local pode ser utilizada.

As vantagens e desvantagens da construção pré-moldada segmentada de acordo com Zyl (2014) são apresentadas a seguir:

Vantagens: 
a) Produção rápida devido ao processo de produção industrializado;

b) Alta qualidade devido ao eficiente controle de qualidade;

c) Não há necessidade de transporte anormal para o canteiro de obra;

d) O tempo de construção é equivalente ao das torres de aço, conforme relato das empresas.

Desvantagens:

a) Guindaste grande é necessário para a montagem final;

b) Fábrica pré-moldada é necessária;

c) O projeto da conexão pode ser complexo.

\subsubsection{Híbrida}

O terceiro conceito de torre atualmente utilizado pela indústria eólica é de torres híbridas. Torres híbridas combinam torres de concreto e aço. Conforme mencionado anteriormente, a altura das torres de aço é limitada pela logística de transporte da base da torre. As torres híbridas superam este problema usando uma base de concreto com uma peça de aço tubular normal montada no topo do concreto. A torre, portanto, não tem limite de altura, pois a base de concreto pode ser feita para qualquer diâmetro. Torres híbridas podem atingir alturas de $140 \mathrm{~m}$ ou mais (ZYL, 2014). A solução híbrida é muito mais leve que as torres de concreto e em alguns casos esta solução pode ser benéfica. $O$ tempo de construção das torres híbridas pode ser menor que o das torres de concreto, dependendo da altura da torre e da localização. A principal desvantagem das torres híbridas de acordo com Zyl (2014) é o uso de seções tubulares de aço que devem ser fabricadas em uma usina siderúrgica. Isto resulta em seções de aço a serem transportadas a longas distâncias e, portanto, aumenta o custo da torre.

\subsection{Modelos de análise estrutural}

A concepção de uma estrutura como um modelo estrutural é uma etapa fundamental do projeto estrutural, pois é o modelo que efetivamente é dimensionado.

\subsubsection{Solução analítica $x$ Método dos elementos finitos}

Soluções analíticas permitem avaliar a resposta do modelo de forma exata para os deslocamentos, deformações e tensões na estrutura em todos os seus pontos. Porém, estas 
soluções são conhecidas para alguns casos, que dependem da geometria da estrutura, do tipo de carregamento e das condições de contorno.

Os métodos dos elementos finitos permitem o cálculo da resposta aproximada dos deslocamentos, deformações e tensões na estrutura em todos os seus pontos, em caráter geral, independente da forma da estrutura, das condições de apoio e da condição de carregamento, dentro da precisão aceitável do problema de engenharia.

Assim, esquematicamente os dois grandes caminhos que podem ser percorridos na solução de problemas de estruturas simples e complexas são: em estruturas com geometria, carregamento e condição de apoio simples, soluções exatas podem ser obtidas; em estruturas complexas, soluções aproximadas com a utilização, por exemplo, do método dos elementos finitos podem ser obtidas.

\subsubsection{Modelo de vigas}

A consideração da torre como uma viga é atrativa pela simplicidade do modelo e pode ser aplicada com resultados aceitáveis em alguns casos como Feijó (2010), Lima (2011) e Souza (2016). A aplicação deste modelo é adequado a uma torre tubular cilíndrica prismática, pois a torre é tratada como uma viga engastada na base e livre no topo sujeita ao peso próprio, carga de vento e cargas da turbina. Para a torre tubular cilíndrica prismática, soluções analíticas podem ser facilmente obtidas.

A aplicação do modelo de viga em uma torre composta por segmentos de tronco de cone com a obtenção de expressões analíticas para os deslocamentos e esforços solicitantes, considerando a variação da geometria e a ação do vento, não é tão simples. Neste caso, é mais adequado realizar a análise por elementos finitos para determinação dos deslocamentos e esforços solicitantes.

\subsubsection{Modelo de casca}

A aplicação do modelo de casca por elementos finitos apresenta um custo computacional mais elevado que o modelo de viga, mas tem como vantagem a modelagem do efeito da distribuição da pressão circunferencial do vento e a incorporação da armadura ao modelo. 


\subsection{Trabalhos precedentes}

Vários trabalhos relacionados com torres de aço têm sido desenvolvidos nos últimos anos como os de Feijó (2010), Lima (2011) e Souza (2016), mas a revisão bibliográfica a seguir se restringe às torres de concreto, objeto deste trabalho.

Brasil et al (2003) avaliaram o efeito do vento sobre uma torre de telecomunicações cilíndrica de concreto pré-moldado com altura de $60 \mathrm{~m}$, diâmetro externo de $1 \mathrm{~m}$ e espessura da parede variando entre 10 e $12 \mathrm{~cm}$, usando um modelo de vigas, aplicando o método estático, o método dinâmico proposto na ABNT NBR 6123 (1988) e o método do vento sintético. Como resultado das análises baseadas ABNT NBR 6123 (1988), chegaram à conclusão que os carregamentos previstos pela análise elástica produzem esforços solicitantes maiores que aqueles devidos às cargas pseudo-estáticas originadas da análise dinâmica com modelo discreto.

O método do vento sintético permitiu um enfoque estocástico coerente com a aleatoriedade dos efeitos do vento. O método do vento sintético é uma simulação do tipo Monte Carlo que adota um espectro de velocidades de vento para gerar séries de carregamentos temporais superpondo funções harmônicas (BRASIL et al, 2003).

LaNier (2005) analisou torres de turbinas eólicas híbridas (concreto e aço) e de concreto protendido com altura de $100 \mathrm{~m}$, cujas ações das cargas da turbina foram obtidas da literatura e o carregamento do vento tratado como estático equivalente de acordo com disposições normativas do International Standard IEC 61400-1 (2005) e da American Concrete Insttitute (ASCE) 7 (1998), tendo como objetivo abordar as questões econômicas da viabilidade dessas torres quando utilizadas como elemento do projeto em locais de vento de baixa velocidade (Low Wind Speed Turbine - LWST).

Zyl (2014) analisou uma torre tronco de cone de $100 \mathrm{~m}$ de altura, tendo diâmetro externo na base igual a 7,10 m e no topo igual a 4,00 m, e espessura da parede na base igual a $0,40 \mathrm{~m}$ e no topo igual a $0,30 \mathrm{~m}$. Tanto a espessura da parede como o diâmetro da torre variam linearmente com a altura. Um anel de aço é colocado no topo da torre para simular o efeito do enrijecimento provocado pela estrutura de aço da turbina que se conecta à torre neste ponto, evitando a ovalização do topo da torre e formando uma plataforma na qual as cargas da turbina podem ser aplicadas. $\mathrm{O}$ anel, com altura de $0,5 \mathrm{~m}$, tem diâmetro e espessura de parede igual ao da torre no topo. O programa de elementos finitos Diana (THE NETHERLANDS ORGANISATION, TNO, 2012), especializada na análise não-linear de estruturas de concreto e 
alvenaria foi utilizado na análise da torre. A torre e a metodologia usadas por Zyl (2014) serão referidas nessa dissertação como modelo de Zyl.

A ação direta do vento atuando sobre a torre é calculada usando três normas diferentes. A IEC (International Electrotechnical Commission) 61400-1 (2005) para o cálculo da velocidade básica do vento; a ASCE (American Society of Civil Engineers) 7-10 (2010) para o cálculo da pressão do vento; e finalmente a SANS (South African National Standards) 10160-3 (2011) para o cálculo da distribuição da pressão circunferencial.

A velocidade de referência do vento e a intensidade de turbulência são usadas em modelos de vento para descrever diferentes condições de vento. O regime de vento para considerações de carga e segurança é dividido em condições normais de vento, que ocorrerão frequentemente durante o funcionamento normal de uma turbina eólica e condições extremas de vento que são definidas como tendo um período de recorrência de um ano ou 50 anos.

O International Standard IEC 61400-1 (2005) especifica 8 situações de projeto diferentes que representam as significantes condições que a torre pode estar sujeita durante a sua vida útil. Para a simulação da ação do vento, ela especifica 8 modelos, a saber: perfil de vento normal (NWP: Normal Wind Profile), modelo de turbulência normal (NTM: Normal Turbulence Model), modelo de vento extremo (EWM: Extreme Wind Model), Rajada extrema de operação (EOG: Extreme Operating Gust), modelo de turbulência extrema (ETM: Extreme Turbulence Model), mudaça de direção extrema (EDC: Extreme Direction Change), rajada extrema com mudança de direção (ECD: Extreme Coherent Gust with Direction Change), e vento cisalhante extremo (EWS: Extreme Wind Shear). Para cada situação de projeto, a combinação de modelos de vento com outras condições, em geral associadas a falhas ou condições extremas, geram vários casos de carga de projeto. Atualmente, os fabricantes de turbinas apenas fornecem as cargas da turbina para os modelos EWM e EOG (GAMA, 2015; JAMMES, 2009; LEWIN, 2010; ZYL, 2014;). Além das cargas EWM e EOG provenientes do vento, a torre também é analisada para fadiga.

A torre tem um perfil tronco de cone, com o diâmetro e a espessura da parede reduzindo com a altura, devido ao fato dos esforços solicitantes estarem com o valor máximo ao nível da fundação e irem reduzindo para o topo, em consequência ocorre a diminuição do peso e dos custos.

O concreto de alta resistência utilizado foi limitado à classe de resistência C80/95 e as suas propriedades físicas foram baseadas nas recomendações do Model Code CEB-FIB (2010) da International Federation for Structural Concrete. O concreto de alta resistência é conhecido por ser um material frágil e a curva de Thorenfeldt foi escolhida para representar o 
comportamento de compressão do concreto através do pacote de elementos finitos do Diana (THE NETHERLANDS ORGANISATION, 2012). O modelo de Thorenfeldt reduz rapidamente a rigidez do material quando a tensão principal atinge a máxima resistência à compressão, descrevendo com precisão o comportamento do concreto de alta resistência e a curva exponencial representa a resistência do concreto à tração.

Existem basicamente três modelos disponíveis no Diana para descrever o comportamento de tensão-deformação da armadura passiva. Eles são: elástico linear, idealmente plástico e rígido-plástico. O modelo idealmente plástico é utilizado neste projeto. Do ponto de vista de projeto, não será conservador levar em conta o encruamento (endurecimento por deformação plástica) da armadura. As propriedades do aço de reforço da torre são citadas na dissertação. A quantidade de armadura é mantida constante através da altura da torre. Para fins de otimização, a quantidade de armadura pode ser reduzida com a altura em função da redução dos esforços.

As cargas da turbina são aplicadas no anel de aço no topo da torre no nível de 100,50 m em relação à base da torre. A força de impulso e o peso da turbina são aplicados como uma série de cargas pontuais em cada nó do anel. Ambos os momentos de tombamento e de torção são aplicados como uma série de forças conjugadas em cada nó do anel. A ação direta do vento é aplicada como uma pressão em toda a torre. A pressão em cada elemento é calculada de acordo com a altura do elemento acima do solo, bem como a sua posição radial. Assim, todos os 7200 elementos de casca do modelo utilizado, estão sujeitos a uma pressão de vento distinta de acordo com a sua posição.

Dois elementos de casca quadriláteros curvos, com oito e quatro nós, respectivamente, são usados para modelar a torre e os resultados são comparados. A estabilidade da torre é verificada usando a análise de estabilidade de Euler.

A fundação é tratada como rígida e a interação com o solo é modelada com molas lineares usando o método apresentado por Gazetas (1983). A rigidez do solo é decomposta em componentes desacopladas vertical, horizontal, oscilatório e torcional. Uma vez que o movimento oscilatório (pêndulo) é dominante, a fundação é representada por molas verticais com rigidezes que fornecem a mesma rigidez à rotação do método de Gazetas. O efeito da rigidez do solo sobre a frequência fundamental da torre é avaliado para alguns tipos de solo.

As deflexões são tradicionalmente calculadas para o ELS. Grandes deflexões no topo da torre no ELS farão com que a eficiência da turbina diminua e portanto essas deflexões devem ser limitadas. Não há limite de deflexão para o estado limite último (ELU) desde que a estrutura tenha resistência suficiente para evitar o colapso. Os fabricantes de turbinas eólicas 
geralmente especificam a deflexão máxima da torre sob cargas de serviço. Como estes limites não puderem ser obtidos junto dos fabricantes, a norma ACI 307-98 é utilizada.

Zyl (2014) verificou que a formação de fissuras afetou muito a rigidez da estrutura e que a redução da rigidez aumentou significativamente a deflexão. Zyl (2014) também verificou que uma estrutura que tem resistência suficiente para resistir às cargas no estado lime último pode não necessariamente cumprir o limite máximo das deflexões para o ELS. A classe de resistência do concreto requerida não foi determinada apenas pelo esforço de compressão máximo que o concreto experimentaria, mas também pela rigidez necessária para assegurar que a frequência da torre estivesse dentro da frequência de trabalho da turbina.

Estruturas delgadas que sofrem deformações relativamente grandes são propensas a efeito de segunda ordem. Um dos efeitos de segunda ordem mais comuns é o efeito P-Delta, que ocorre em todas as estruturas que são submetidas a cargas axiais. $\mathrm{O}$ efeito é geralmente insignificante (muito pequeno) em estruturas rígidas e é assim ignorado na análise da estrutura.

Quando uma estrutura sofre grandes deformações, a carga axial tem uma excentricidade e faz surgir momentos de segunda ordem. Esses momentos podem ser significativos em estruturas esbeltas submetidas a grandes forças axiais. Contanto uma análise não-linear da torre é necessária devido ao peso da turbina no topo da torre e ao peso próprio. No modelo de Zyl (2014) o acréscimo do momento de tombamento devido ao efeito P-Delta foi de $7,71 \%$.

A vida de fadiga da torre é avaliada de acordo com o Model Code CEB-FIB da International Federation for Structural Concrete (2010), sendo a faixa de tensão de fadiga da armadura e do concreto determinada pelo MEF. A torre é primeiro analisada sob as cargas de serviço para permitir a ocorrência de fissuras. Em seguida, são extraídas as cargas variáveis da turbina responsáveis pela fadiga e a estrutura é analisada novamente usando o estado final da análise anterior no ELS, como um estado inicial. A diferença de tensão entre as duas análises é então comparada para determinar a faixa de tensão máxima no concreto e na armadura.

Analisando os resultados, Zyl (2014) observou que o estado limite de fadiga não é crítico para o projeto, entretanto as cargas da turbina usadas foram determinadas por um um estudo feito por engenheiros de Berger-Abam para o Laboratório Nacional de Energia Renovável (NREL: National Renewable Energy Laboratory) no Colorado, através do uso da dinâmica de fluidos computacional, porque as cargas reais da turbina são protegidas por 
direitos autorais. A vida de fadiga real da torre só pode ser determinada com precisão se as cargas de fadiga reais de uma turbina específica forem fornecidas pelo fabricante da turbina.

O comportamento dinâmico da torre também foi afetado pela formação de fissuras. A frequência fundamental da torre foi reduzida em $46 \%$ após a aplicação das cargas no ELS. Zyl (2014) verificou que o tipo de solo influencia a rigidez adotada na análise.

Gama (2015) trabalhou com uma torre protendida de concreto de $100 \mathrm{~m}$ de altura provida de uma turbina de $5 \mathrm{MW}$, cujas ações foram obtidas da literatura. O carregamento do vento ao longo da torre foi tratado como estático equivalente de acordo com disposições normativas do International Standard IEC 61400-1 (2005) e da ASCE 7 (1998). Os esforços e deslocamentos na torre foram obtidos pelo método dos elementos finitos com discretização em elementos finitos unidimensionais, considerando as não linearidades físicas e geométricas por intermédio do programa de elementos finitos SAP2000 com algoritmo desenvolvido no MATLAB. Foram realizadas análises paramétricas com as variáveis sendo os raios externos (base e topo da torre), as espessuras (base, meio e topo da torre), as resistências características do concreto, a forma da torre (tronco de cone e parabólica), os espaçamentos entre barras de aço tanto da armadura passiva como ativa e a disposição dos cabos da armadura ativa ao longo da torre. Dentre as restrições se encontram as restrições geométricas da torre e as restrições de comportamento referente ao deslocamento e a frequência natural. Comparações foram feitas entre os dimensionamentos possíveis da estrutura, a partir do custo do material, a fim de identificar o dimensionamento mais econômico. Em relação aos custos dos materiais foram utilizados para os concretos, os valores fornecidos Sistema Nacional de Pesquisa de Custos e Índices da Construção Civil (SINAPI, 2014) do estado de São Paulo, no qual já consta o serviço de bombeamento. Os demais valores foram obtidos da revista "Construção Mercado" (PINI, 2015) do estado de São Paulo. Uma das principais conclusões é que a otimização da área de aço passivo ocorre de forma sistemática para as torres de frequência natural mais baixa, tornando indispensável o uso de um modelo não linear para o correto dimensionamento.

Além disso, as torres obtidas foram comparadas através do custo do material total, constatando-se que as torres mais econômicas possuíam variação parabólica. Isso permitiu aferir um valor inicial para o qual o uso do concreto de ultra-alto desempenho reforçado com fibras em torres eólicas passaria a ser competitivo.

Brasil e Silva (2016) analisaram uma torre de telecomunicação cilíndrica de concreto armado pré-moldado com altura de 40 metros, diâmetro externo de 1 metro e espessura da parede de 12 centímetros através de um modelo dinâmico não linear discretizado 
em elementos de área. A estrutura foi submetida a uma carga de vento sintético, que foi proposto por Franco (1993) com o objetivo de permitir um enfoque estocástico coerente com a aleatoriedade dos efeitos do vento, e a análise do concreto armado foi realizada de acordo com a Associação Brasileira de Normas Técnicas NBR 6118 (2014). A partir da análise realizada, pôde-se observar que a análise dinâmica não-linear para estruturas esbeltas, como é o caso das torres de telecomunicação em concreto armado, é essencial pois leva a deslocamentos, e portanto esforços na estrutura, até três vezes maiores do que aqueles obtidos pela simples análise estática linear da estrutura. Esta diferença pode ser relacionada ao fato de que os deslocamentos e a frequência natural da estrutura isostática estudada são consideravelmente sensíveis à diminuição do produto de rigidez dos segmentos inferiores da torre.

\subsection{Cargas}

As torres de turbinas eólicas são estruturas que apresentam cargas acidentais insignificantes e carregamento dominado pela carga do vento e pelo peso próprio da estrutura que é benéfico para resistir às cargas do vento (ZYL, 2014). Como mencionado anteriormente, não existe atualmente nenhuma norma descrevendo o processo de projeto de torres de turbinas eólicas de concreto armado, portanto este item descreve o processo seguido no Modelo de Zyl para obter as cargas de vento impostas à estrutura da torre.

\subsubsection{Pressão direta do vento - Modelo de Zyl}

Esta seção descreve o método utilizado por Zyl (2014) para calcular a pressão direta do vento numa torre de turbina eólica de concreto armado. A pressão direta do vento atuando sobre a torre, é calculada usando três normas diferentes. A velocidade básica do vento é calculada de acordo com a IEC 61400-1 (2005). A pressão do vento é então calculada usando a ASCE 7-10 (2010) e finalmente, a distribuição da pressão circunferencial é calculada de acordo com o SANS 10160-3 (2011).

\subsubsection{Velocidade básica do vento}

A IEC 61400-1 é uma norma de projeto publicado pela Comissão Eletrotécnica Internacional (2005). A norma é útil para obter a velocidade de projeto do vento e o modelo de vento adequado para um gerador de turbinas eólicas (WTG: Wind turbine generator). Isto 
é feito categorizando turbinas eólicas em três classes (classe I, II, III), baseado no ambiente típico do vento a que serão expostas. Dependendo do local específico, as classes podem ser ainda subdivididas em categorias A (maior turbulência), B (turbulência média) e C (turbulências mais baixas) de acordo com as características de turbulência do vento. As classes de turbinas não descrevem um local específico, mas sim descrevem um tipo genérico de local para um tipo específico de turbina. Além das três classes padrão de turbinas eólicas, é especificada uma quarta classe, denominada S. Esta classe deve ser usada quando a turbina é exposta a condições de vento não cobertas pelo padrão, como furacões. As classes padrão de turbinas eólicas são apresentadas na Tabela 1.

$\mathrm{A} \mathrm{V}_{\text {ref }}$ é a velocidade média de referência do vento com duração de 10 minutos para um período de retorno de 50 anos e a $\mathrm{I}_{\text {ref }}$ é o valor esperado da intensidade de turbulência para ventos de $15 \mathrm{~m} / \mathrm{s}$. A intensidade de turbulência é definida como a relação entre o desvio padrão da velocidade do vento e a velocidade média do vento, determinado a partir de um conjunto de dados de amostras medidos da velocidade do vento, e tomados durante um período de tempo especificado.

Tabela 1 - Classes de turbinas eólicas padrão

\begin{tabular}{|c|c|c|c|c|}
\hline $\begin{array}{c}\text { Classe da turbina } \\
\text { eólica }\end{array}$ & I & II & III & $\mathrm{S}$ \\
\hline $\mathrm{V}_{\text {ref }}(\mathrm{m} / \mathrm{s})$ & 50 & 42,5 & 37,5 & \multirow{4}{*}{$\begin{array}{l}\text { Valores } \\
\text { especificados pelo } \\
\text { projetista }\end{array}$} \\
\hline $\mathrm{I}_{\mathrm{ref}}-\mathrm{A}$ & & 0,16 & & \\
\hline $\mathrm{I}_{\mathrm{ref}}-\mathrm{B}$ & & 0,14 & & \\
\hline $\mathrm{I}_{\mathrm{ref}}-\mathrm{C}$ & & 0,12 & & \\
\hline
\end{tabular}

* Todos os valores se aplicam na altura do cubo.

Fonte: International Electrotechnical Commission (2005)

A velocidade referência do vento e a intensidade de turbulência são então usadas em modelos de vento para descrever as diferentes condições de vento. O regime de vento para considerações de carga e segurança é dividido em condições normais de vento, que ocorrerão frequentemente durante o funcionamento normal de uma turbina eólica e as condições de vento extrema que são definidas como tendo um período de recorrência de 1 ano ou 50 anos. A International Electrotechnical Commission (IEC) 61400-1 (2005) descreve 8 diferentes modelos de vento como citado anteriormente, mas atualmente, os fabricantes de turbinas apenas fornecem cargas da turbina para o modelo EWM e EOG. Os modelos de vento EWM e EOG, e os modelos NWP e NTM, necessários para o entendimento dos primeiros, serão discutidos a seguir. 


\section{Modelo de perfil de vento normal (NWP)}

A IEC 61400-1 (2005) usa a lei de potência para descrever a variação da velocidade média do vento com a altura.

$$
V(z)=\mathrm{V}_{\text {cubo }}\left(\frac{\mathrm{z}}{\mathrm{z}_{\text {cubo }}}\right)^{\alpha}
$$

onde:

$\mathrm{V}_{\text {cubo }}$ é a velocidade de corte do vento, especificada pelos fabricantes de turbinas;

$\mathrm{Z}_{\text {cubo }}$ é a altura do cubo;

z é a altura de interesse;

$\alpha$ é o expoente da lei de potência que é uma função da rugosidade do solo. A IEC 61400-1 (2005) utiliza uma potência de 0,11 para condições extremas e 0,2 para condições normais.

\section{Modelo de turbulência normal (NTM)}

O valor representativo do desvio padrão de turbulência, $\sigma_{1}$, é dado por $90 \%$ da quantidade dada para a velocidade do vento na altura do cubo (INTERNATIONAL ELECTROTECHNICAL COMMISSION, 2005). O desvio padrão de turbulência para as classes de turbina padrão é dado pela seguinte equação:

$$
\sigma_{1}=I_{\text {ref }}\left(0,75 V_{c u b o}+b\right)
$$

onde:

$\mathrm{b}=5,6 \mathrm{~m} / \mathrm{s}$;

Iref é a intensidade de turbulência dada na Tabela 1.

\section{Modelo de velocidade extrema do vento (EWM)}

O modelo EWM é uma condição não operacional, portanto a turbina está parada e pode ser aplicado a vento estável ou turbulento. O modelo de vento turbulento é usado quando uma análise dinâmica é necessária. As velocidades constantes do vento extremo $\mathrm{Ve}_{50} \mathrm{e} \mathrm{Ve}_{1}$, 
com períodos de recorrência de 50 anos e 1 ano respectivamente são calculadas pelas seguintes equações:

$$
\begin{gathered}
V_{e 50}(z)=1,4 V_{\text {ref }}\left(\frac{z}{Z_{r e f}}\right)^{0,11} \\
V_{e 1}(z)=0,8 V_{e 50}(z)
\end{gathered}
$$

onde:

$\mathrm{V}_{\text {ref }}$ é a velocidade média de referência do vento com duração de 10 minutos para um período de retorno de 50 (Tabela 1);

z é a altura de interesse;

As velocidades de vento $\mathrm{V}_{\mathrm{e} 50}$ e $\mathrm{V}_{\mathrm{e} 1}$ são velocidades de rajada do vento de 3 segundos.

\section{Rajada de operação extrema (EOG)}

A magnitude da rajada na altura do cubo $\mathrm{V}_{\text {gust }}$ é dada para as classes de turbinas eólicas, fornecidas pela norma IEC 61400-1 (2005), através da seguinte relação:

$$
V_{\text {gust }}=\operatorname{Min}\left\{\begin{array}{c}
1,35\left(V_{e 1}-V_{c u b o}\right) \\
3,3\left(\frac{\sigma_{1}}{1+0,1\left(\frac{D}{\Lambda_{1}}\right)}\right)
\end{array}\right.
$$

onde:

$\sigma_{1}$ é dado na Equação (2);

$\Lambda_{1}$ é o parâmetro da escala de turbulência longitudinal e assume-se que é $42 \mathrm{~m}$ quando $\mathrm{z}_{\text {cubo }} \geq 60 \mathrm{~m}$;

$D$ é o diâmetro do rotor da turbina.

A velocidade do vento é então definida pela seguinte equação:

$$
V(z, t)=\left\{\begin{array}{c}
V(z)-0,37 V_{\text {gust }} \sin \left(\frac{3 \Pi t}{T}\right)\left(1-\cos \left(\frac{2 \Pi t}{T}\right)\right) \text { para } 0 \leq t \leq T \\
V(z) \quad t>T
\end{array}\right.
$$

onde:

$V(z)$ é definido na Equação (1);

$\mathrm{T}=10,5 \mathrm{~s}$. 
O modelo EOG pode ser usado como um modelo estático usando o valor de pico máximo obtido pela Equação (6). O valor obtido é a velocidade do vento de rajada estática de 3 segundos para o modelo EOG.

\subsubsection{Pressão do vento}

A pressão dinâmica do vento na torre será calculada de acordo com a American Society Of Civil Engineers 7-10 (2010) que é uma norma de projeto credenciada pelo Instituto Nacional de Normas Americanas (ANSI: American National Standards Institute) que leva em consideração a interação dinâmica entre uma estrutura esbelta e o vento. A norma classifica as estruturas como rígidas com frequência natural maior que $1 \mathrm{~Hz}$ e estruturas esbeltas com frequência natural menor de $1 \mathrm{~Hz}$. A velocidade do vento de referência calculada usando a IEC 61400-1 (2005) é uma velocidade de vento de rajada de 3 segundos à altura do cubo e, portanto, tem de ser convertida para uma velocidade de vento a $10 \mathrm{~m}$ para ser utilizada no cálculo da pressão dinâmica do vento de acordo com a ASCE 7-10 (2010).

O processo apresentado pela ASCE 7-10 (2010) para calcular a pressão de vento de projeto na torre de turbina eólica é descrito abaixo.

Pressão dinâmica do vento em função da altura da torre é dada por:

$$
q_{(z)}(z)=0,613 K_{z} K_{z t} K_{d} V^{2} I G
$$

onde $\mathrm{K}_{\mathrm{z}}$ é um coeficiente de exposição e é função da rugosidade da superfície e da altura da estrutura.

$$
K_{z}=\left\{\begin{array}{lr}
2,01\left(\frac{z}{z_{g}}\right)^{\frac{2}{\alpha}} & \text { para } 4,01<z<z_{g} \\
2,01\left(\frac{4,6}{z_{g}}\right)^{\frac{2}{\alpha}} & \text { para } z<4,6
\end{array}\right.
$$

onde $\mathrm{z}$ é a altura de interesse, $\alpha=11,5$ de acordo com a Tabela 2 e $\mathrm{z}_{\mathrm{g}}=213,36 \mathrm{~m}$.

A categoria de exposição D da ASCE 7-10 (2010), adotada por Zyl (2014), é utilizada para terreno plano, sem obstáculos e superfícies aquáticas fora de regiões sujeitas a furações.

$\mathrm{O}$ fator topográfico $\mathrm{K}_{\mathrm{zt}}=1,0$ para terrenos planos e abertos, o fator de direcionalidade do vento $K_{d}=0,95$ para torre circular e o fator de importância $I=1,0$, porque as turbinas de vento são construídas geralmente em áreas rurais abertas onde os seres 
humanos não estão nas proximidades da estrutura. A velocidade básica do vento $V$ corresponde a velocidade de rajada de $3 \mathrm{~s}$ a altura de $10 \mathrm{~m}$.

Para estruturas flexíveis ou dinamicamente sensíveis, o fator de efeito de rajada $G_{f}$ será calculado por:

$$
G_{f}=0,925\left(\frac{1+1,7 I_{\bar{z}} \sqrt{g_{Q}^{2} Q^{2}+g_{R}^{2} R^{2}}}{1+1,7 g_{v} I_{\bar{z}}}\right)
$$

$g_{Q}=3,4$ (fator de pico para resposta de fundo);

$g_{v}=3,4$ (Fator de pico para a resposta do vento).

A intensidade da turbulência na altura $\bar{z}$ é dada por:

$$
\begin{gathered}
I_{\bar{z}}=c\left(\frac{10}{\bar{z}}\right)^{\frac{1}{6}} \\
Q=\sqrt{\frac{1}{1+0,63\left(\frac{B+h}{L_{\bar{z}}}\right)^{0,63}}} \\
L_{\bar{z}}=l\left(\frac{\bar{z}}{10}\right)^{\bar{\epsilon}}
\end{gathered}
$$

O fator de pico para a ressonância $g_{R}$ é dado por:

$$
g_{R}=\sqrt{2 \ln \left(3600 n_{1}\right)}+\frac{0,577}{\sqrt{2 \ln \left(3600 n_{1}\right)}}
$$

onde $\mathrm{n}_{1}$ é a frequência fundamental da torre em $\mathrm{Hz}$.

$\mathrm{O}$ fator de resposta ressonante $\mathrm{R}$ é dado por:

$$
R=\sqrt{\frac{1}{\beta} R_{n} R_{h} R_{B}\left(0,53+0,47 R_{L}\right)}
$$




$$
\begin{aligned}
& R_{n}=\frac{7,47 N_{1}}{\left(1+10,3 N_{1}\right)^{\frac{5}{3}}} \\
& N_{1}=\frac{n_{1} L_{\bar{z}}}{\bar{V}_{\bar{z}}} \\
& \bar{V}_{\bar{z}}=\bar{b}\left(\frac{\bar{z}}{10}\right)^{\bar{\alpha}} V . \\
& R_{h}=\frac{1}{4,6 n_{1} \frac{h}{\bar{V}_{\bar{z}}}}-\frac{\left(1-e^{-2\left(4,6 n_{1} \frac{h}{\bar{V}_{\bar{z}}}\right)}\right)}{2\left(4,6 n_{1} \frac{h}{\bar{V}_{\bar{Z}}}\right)^{2}} \\
& R_{B}=\frac{1}{4,6 n_{1} \frac{B}{\bar{V}_{\bar{Z}}}}-\frac{\left(1-e^{-2\left(4,6 n_{1} \frac{B}{\bar{V}_{\bar{Z}}}\right)}\right)}{2\left(4,6 n_{1} \frac{B}{\bar{V}_{\bar{Z}}}\right)^{2}} \\
& R_{L}=\frac{1}{15,4 n_{1} \frac{L}{\bar{V}_{\bar{Z}}}}-\frac{\left(1-e^{-2\left(15,4 n_{1} \frac{L}{\bar{V}_{\bar{z}}}\right)}\right)}{2\left(15,4 n_{1} \frac{L}{\bar{V}_{\bar{z}}}\right)^{2}}
\end{aligned}
$$

$\bar{z}=0,6 h$

$\mathrm{h}=$ altura da torre;

V é a velocidade básica do vento $(\mathrm{m} / \mathrm{s})$;

B é a largura da torre medida perpendicularmente à direção do vento;

L é a dimensão da torre paralela a direção do vento.

Todas as constantes utilizadas são dadas na Tabela 2.

Tabela 2 - Constantes do vento

\begin{tabular}{ccccccccccc}
\hline Exposição & $\mathrm{A}$ & $z_{g}(m)$ & $\hat{a}$ & $\hat{b}$ & $\bar{a}$ & $\bar{b}$ & $c$ & $l(m)$ & $\bar{\epsilon}$ & $z_{\min }(m)$ \\
\hline $\mathrm{B}$ & 7,0 & 365,76 & $\frac{1}{7}$ & 0,84 & $\frac{1}{4,0}$ & 0,45 & 0,30 & 97,54 & $\frac{1}{3,0}$ & 9,14 \\
\hline $\mathrm{C}$ & 9,5 & 274,32 & $\frac{1}{9,5}$ & 1,00 & $\frac{1}{6,5}$ & 0,65 & 0,20 & 152,40 & $\frac{1}{5,0}$ & 4,57 \\
\hline $\mathrm{D}$ & 11,5 & 213,36 & $\frac{1}{11,5}$ & 1,07 & $\frac{1}{9,0}$ & 0,80 & 0,15 & 198,12 & $\frac{1}{8,0}$ & 2,13 \\
\hline
\end{tabular}

Fonte: American Society Of Civil Engineers (2010) 


\subsubsection{Distribuição de pressão circunferencial}

A distribuição da pressão circunferencial será calculada de acordo com a norma SANS 10160-3 (2011) que é publicada pelo Departamento de Normas da África do Sul (SABS: South African Bureau of Standards). A torre de turbina eólica utilizada nesta pesquisa é baseada numa rugosidade equivalente de $\mathrm{k} / \mathrm{b}<5 \times 10^{-4}$ (Figura 5), onde k é a rugosidade de protrusão e b o diâmetro do cilindro. Os coeficientes de pressão crítica da Figura 5 são apresentados na Tabela 3. A nomenclatura, do coeficiente de pressão externa, utilizada nesta pesquisa é apresentada na Figura 6.

Figura 5 - Distribuição de pressão para cilindros com diferentes números de Reynolds
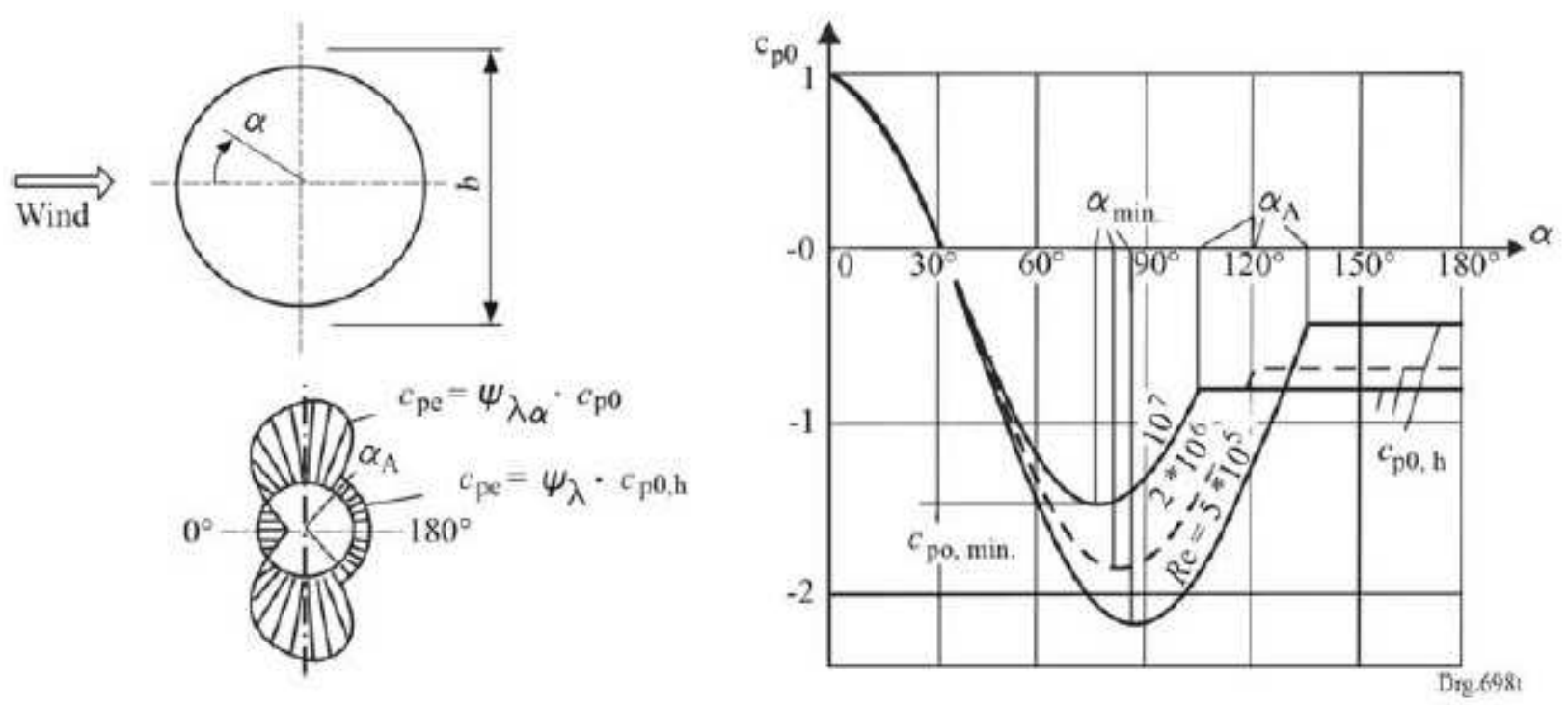

Fonte: SANS 10160-3 (2011)

Figura 6 - Nomenclatura do coeficiente de pressão externa

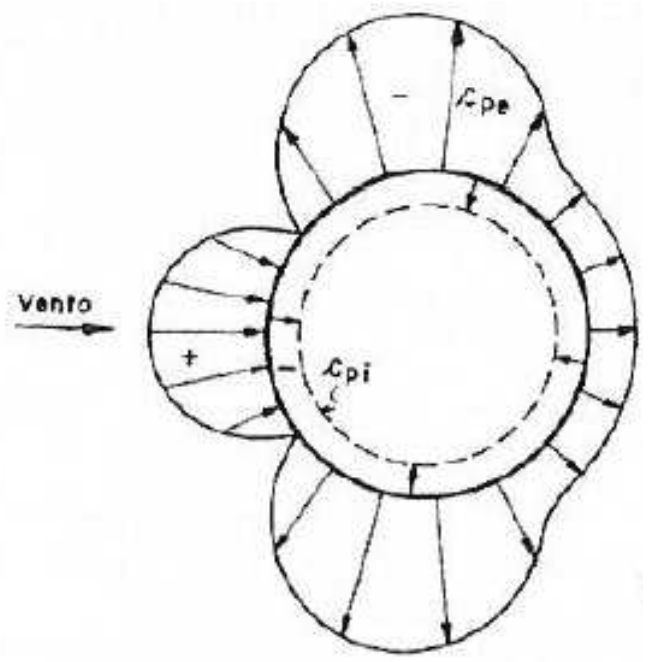

Fonte: Blessmann (1983) 
Tabela 3 - Coeficiente de pressão externa

\begin{tabular}{ccccc}
\hline 1 & 2 & 3 & 4 & 5 \\
\hline $\operatorname{Re}$ & $\alpha_{\min }^{a}$ & $C_{p 0, \min }^{b}$ & $\alpha_{A}^{c}$ & $C_{p 0, h}^{d}$ \\
\hline $5 \times 10^{5}$ & 85 & $-2,2$ & 135 & $-0,4$ \\
\hline $2 \times 10^{6}$ & 80 & $-1,9$ & 120 & $-0,7$ \\
\hline $10^{7}$ & 75 & $-1,5$ & $-0,8$ \\
\hline$\alpha_{\text {min }}^{a}$ é a posição da pressão mínima, expressa em graus. & & \\
$C_{p 0, \text { min }}^{b}$ é o valor do coeficiente de pressão mínimo. & & \\
$\alpha_{A}^{c}$ é a posição da separação de fluxo, expressa em graus. \\
$C_{p 0, h}^{d}$ é o coeficiente de pressão base.
\end{tabular}

Fonte: SANS 10160-3 (2011)

\subsubsection{Cargas da turbina}

As cargas da turbina usadas por Zyl (2014) foi determinado por um um estudo feito por engenheiros de Berger-Abam para o Laboratório Nacional de Energia Renovável (NREL: National Renewable Energy Laboratory) no Colorado, através do uso da dinâmica de fluidos computacional, porque as cargas reais da turbina são protegidas por direitos autorais. A Tabela 4 apresenta as especificações da turbina utilizadas pelo Laboratório Nacional de Energia Renovável (NREL: National Renewable Energy Laboratory) e a Tabela 5 apresenta as cargas da turbina na altura do cubo de $100 \mathrm{~m}$ para duas condições de vento IEC, a saber: EWM e EOG com velocidades de vento de $59,5 \mathrm{~m} / \mathrm{s}$ e $35,0 \mathrm{~m} / \mathrm{s}$, respectivamente para rajada de $3 \mathrm{~s}$.

Tabela 4 - Especificações da Turbina

\begin{tabular}{ll}
\hline Potência & $3,6 \mathrm{MW}$ \\
\hline Velocidade do rotor & $13,2 \mathrm{rpm}$ \\
\hline Diâmetro do rotor & $108,4 \mathrm{~m}$ \\
\hline Massa da turbina (incluindo nacelle, cubo e pás) & $314912 \mathrm{~kg}$ \\
\hline Altura do cubo & $100 \mathrm{~m}$ \\
\hline Classe IEC & IIB \\
\hline
\end{tabular}

Fonte: LaNier (2005) 
Tabela 5 - Cargas da Turbina

\begin{tabular}{lcccc}
\hline & $\begin{array}{c}\text { Força de impulso } \\
(\mathrm{kN})\end{array}$ & $\begin{array}{c}\text { Momento de } \\
\text { tombamento } \\
(\mathrm{kNm})\end{array}$ & $\begin{array}{c}\text { Força de compressão axial na } \\
\text { torre } \\
(\mathrm{kN})\end{array}$ & $\begin{array}{c}\text { Momento } \\
\text { torçor }\end{array}$ \\
\hline EWM & 1086 & 16767 & 3155 & 5961 \\
\hline EOG & 1199 & 9913 & 3129 & 1597 \\
\hline
\end{tabular}

Fonte: LaNier (2005)

\subsection{Coeficientes parciais e combinações de carga de acordo com o modelo de Zyl}

Ações provenientes do vento que atuam tanto na turbina eólica quanto diretamente na torre possuem a mesma origem. Deste modo, as ações presentes nas turbinas eólicas e nas torres eólicas podem ser classificadas basicamente em ações permanentes e ações variáveis (GAMA, 2015). Como é visto em Zyl (2014) o método dos estados limites é usado para o projeto da torre, sendo os coeficientes de carga parciais no ELU prescritos pela ASCE, mas são feitas modificações para atender a IEC. O modelo EWM é utilizado na análise do ELU.

O ELS para uma turbina eólica deve ser uma condição de operação sob condições de vento normais, contanto o modelo EOG é o único modelo de vento operacional para o qual estão disponíveis as cargas da turbina. O modelo simula uma condição extrema com um período de recorrência de 1 ano. Os fabricantes de turbinas recomendam que na ausência de cargas operacionais, $60 \%$ da carga característica extrema possa ser usada, pois o modelo EOG superestimará consideravelmente as cargas operacionais normais da turbina e levará a um projeto antieconômico (ZYL, 2014).

Estado limite último (ELU):

$$
0,9 \mathrm{D}+1,6 \mathrm{~W}+1,35 \mathrm{TWL}
$$

Estado limite de serviço (ELS):

$$
0,6(1,0 \mathrm{D}+1,0 \mathrm{~W}+1,0 \mathrm{TWL})
$$

onde:

D é a carga permanente;

W é a carga direta do vento na torre; 
TWL é a carga de turbina induzida pelo vento.

\subsection{Coeficientes de ponderação das resistências dos materiais de acordo com a SANS 10100-1}

Os coeficientes de ponderação das resistências para os materiais concreto e aço de acordo com a SANS 10100-1 (2000), são apresentados na Tabela 6.

Tabela 6 - Coeficientes de ponderação das resistências dos materiais

\begin{tabular}{lcc}
\hline \multicolumn{1}{c}{ Estado limite } & Concreto & Aço \\
\hline Último: flexão e axial & 1,50 & 1,15 \\
\hline \multicolumn{1}{c}{ Cortante } & 1,40 & 1,15 \\
\hline \multicolumn{1}{c}{ Aderência } & 1,40 & \\
\hline Serviço & 1,00 & 1,00 \\
\hline Fonte: SANS 10100-1 (2000) & &
\end{tabular}

\subsection{Frequência de trabalho da turbina de 3,6 MW}

A frequência de trabalho da turbina é projetada para uma estrutura com frequência fundamental entre os intervalos da freqüência de rotação da lâmina (1P) e freqüência de passagem da lâmina (3P), classificada como estrutura flexível-rígida. A estrutura flexívelrígida é a mais econômica para torres de turbinas eólicas (ZYL, 2014). Devido a incerteza no cálculo da frequência da estrutura na fase de projeto, a frequência da torre é mantida fora de \pm $10 \%$ dos intervalos de frequência 1P e 3P (DNV / RISO, 2002). A frequência de trabalho da turbina utilizada nesta pesquisa é apresentada na Tabela 7.

Tabela 7 - Frequência de trabalho da turbina

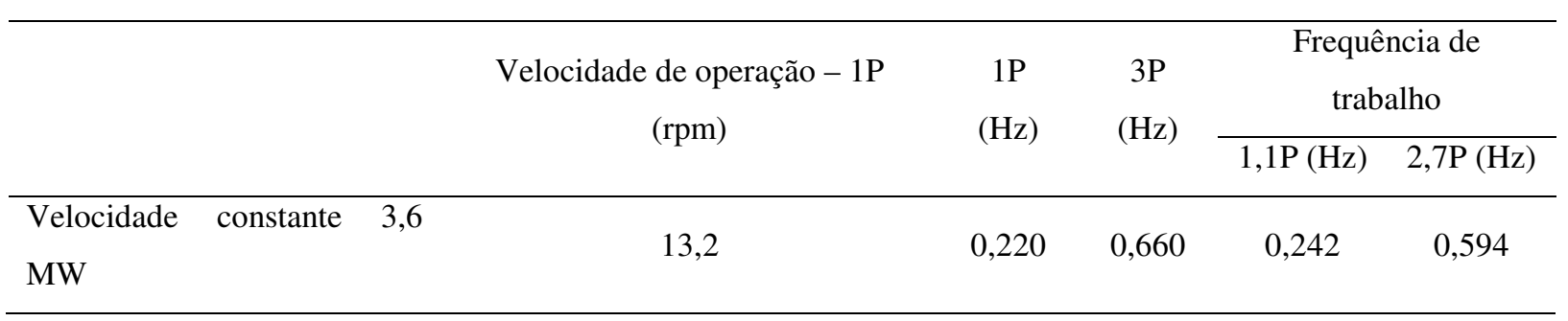

Fonte: Zyl (2014)

\subsection{Ações do Vento de acordo com a ABNT NBR 6123}

A análise da torre é feita usando a norma brasileira ABNT NBR 6123 (1988), considerando o vento como uma carga estática. Para tanto, identifica-se a velocidade básica do vento $\left(V_{o}\right)$, relativa ao local onde a estrutura será instalada. A velocidade básica do vento é 
definida como a velocidade de uma rajada de três segundos de duração, excedida em média uma vez em 50 anos, a dez metros acima do terreno, em campo aberto e plano (BLESSMANN, 1989 apud FEIJÓ, 2010). Em seguida multiplica-se a velocidade básica por três coeficientes de ponderação $\left(S_{1}, S_{2}, S_{3}\right)$, e encontra-se a velocidade característica do vento $\left(V_{K}\right)$, conforme Equação (23).

$$
V_{K}=V_{o} \cdot S_{1} \cdot S_{2} \cdot S_{3}
$$

A velocidade básica do vento $V_{o}$ é extraída do mapa das isopletas (que reúne as velocidades do vento no Brasil) e, para a região de Fortaleza (CE), é igual a $30 \mathrm{~m} / \mathrm{s}$ (108 $\mathrm{km} / \mathrm{h}$ ).

O fator $S_{1}$ é definido como Fator Topográfico, e leva em consideração as variações do relevo do terreno nos arredores de onde a estrutura está localizada. Para terrenos planos ou fracamente acidentados, $S_{1}=1,0$. Quando se tem taludes ou morros, o fator $S_{1}$ varia em função da altura medida a partir da superfície do terreno no ponto considerado e da inclinação do morro ou talude. Para vales profundos protegidos de ventos de qualquer direção, $\mathrm{S}_{1}$ assume o valor de 0,9 .

$\mathrm{O}$ fator $\mathrm{S}_{2}$ combina os efeitos da rugosidade do terreno, da variação da velocidade do vento com a altura acima do terreno e das dimensões da estrutura. Quanto à rugosidade do terreno, esta é dividida em cinco categorias. A categoria II, adotada nesta pesquisa, é utilizada para terrenos abertos em nível ou aproximadamente em nível, com poucos obstáculos isolados, sendo a cota média no topo dos obstáculos inferior ou igual a 1,0 m;

No que diz respeito às dimensões da edificação, a ABNT NBR 6123 (1988) apresenta três classes. A Classe C, adotada nesta pesquisa, é utilizada quando a maior dimensão horizontal ou vertical da superfície frontal exceda 50,0 m.

$\mathrm{O}$ fator $\mathrm{S}_{2}$ é definido de acordo com a expressão:

$$
\mathrm{S}_{2}=b F_{r}\left(\frac{\mathrm{z}}{10}\right)^{p}
$$

onde, $F_{r}$ é o fator de rajada e sempre correspondente à categoria II; $z$ é a altura do nível geral do terreno; $b$ e $p$ são parâmetro meteorológicos, de acordo com a categoria de rugosidade e a classe de dimensão, conforme Tabela 8. 
Tabela 8 - Parâmetros meteorológicos referentes à classe II

\begin{tabular}{cccccc}
\hline \multirow{2}{*}{ Categoria } & \multirow{2}{*}{$\begin{array}{l}\mathrm{Z}_{\mathrm{g}} \\
(\mathrm{m})\end{array}$} & & Parâmetro & \multicolumn{3}{c}{ Classe } \\
\cline { 4 - 6 } & & & $\mathrm{A}$ & $\mathrm{B}$ & $\mathrm{C}$ \\
\hline \multirow{2}{*}{ II } & \multirow{2}{*}{300} & $b$ & 1,00 & 1,00 & 1,00 \\
\cline { 3 - 6 } & & $F_{r}$ & 1,00 & 0,98 & 0,95 \\
\cline { 3 - 6 } & & $p$ & 0,085 & 0,09 & 0,10
\end{tabular}

Fonte: ABNT NBR 6123 (1988)

O terceiro e último fator para se determinar a velocidade característica do vento, é o fator $\mathrm{S}_{3}$, denominado de Fator Estatístico. Como o próprio nome diz, este fator é baseado em conceitos estatísticos, considerando o grau de segurança requerido e a vida útil da edificação. A norma ABNT NBR 6123 (1988) divide o fator $S_{3}$ em cinco grupos.

O Grupo 1 é utilizado para edificações consideradas imprescindíveis em situações de emergência, ou seja, cuja ruína total ou parcial pode afetar a segurança ou possibilidade de socorro à população. São elas: hospitais, quartéis de bombeiros e de forças de segurança, centrais de comunicação, etc. $O$ fator estatístico utilizado neste grupo é $S_{3}=1,10$.

No Grupo 2 estão enquadrados os hotéis, residências, comércio e indústria com alto fator de ocupação. Neles é utilizado um fator $S_{3}=1,00$. Já no Grupo 3, estão enquadradas as edificações e instalações industriais com baixo fator de ocupação, sendo utilizado um fator $S_{3}=0,95$.

O Grupo 4 é relativo aos elementos de vedação como telhas, vidros, etc. $\left(S_{3}=\right.$ 0,88) e para o Grupo 5 estão contemplados as edificações temporárias, ou seja, todas as edificações pertencentes aos grupos 1,2 e 3 durante suas construções $\left(S_{3}=0,83\right)$.

Após definidos todos os coeficientes, calcula-se a velocidade característica do vento $\left(V_{K}\right)$ ao longo da altura da estrutura, conforme a Equação (23). Em seguida encontra-se a pressão característica do vento (q), conforme a Equação (25).

$$
\mathrm{q}=0,613 \cdot \mathrm{V}_{\mathrm{k}}^{2}
$$

Para a determinação das pressões externas em uma edificação cilíndrica de seção circular, devem ser usados os valores de $C_{p e}$ dados na Tabela 9. Estes coeficientes aplicam-se somente em fluxo acima da região crítica, isto é, para número de Reynolds maiores que 4,20 x $10^{5}$ e com vento incidindo perpendicularmente ao eixo do cilindro, de diâmetro d. O número de Reynolds é determinado pela expressão: 


$$
\operatorname{Re}(\mathrm{z})=7000 \cdot \mathrm{V}_{\mathrm{K}} \cdot \mathrm{d}
$$

sendo $V_{K}$ em metros por segundo e d em metros.

Tabela 9 - Distribuição das pressões externas em edificações cilíndricas de seção circular

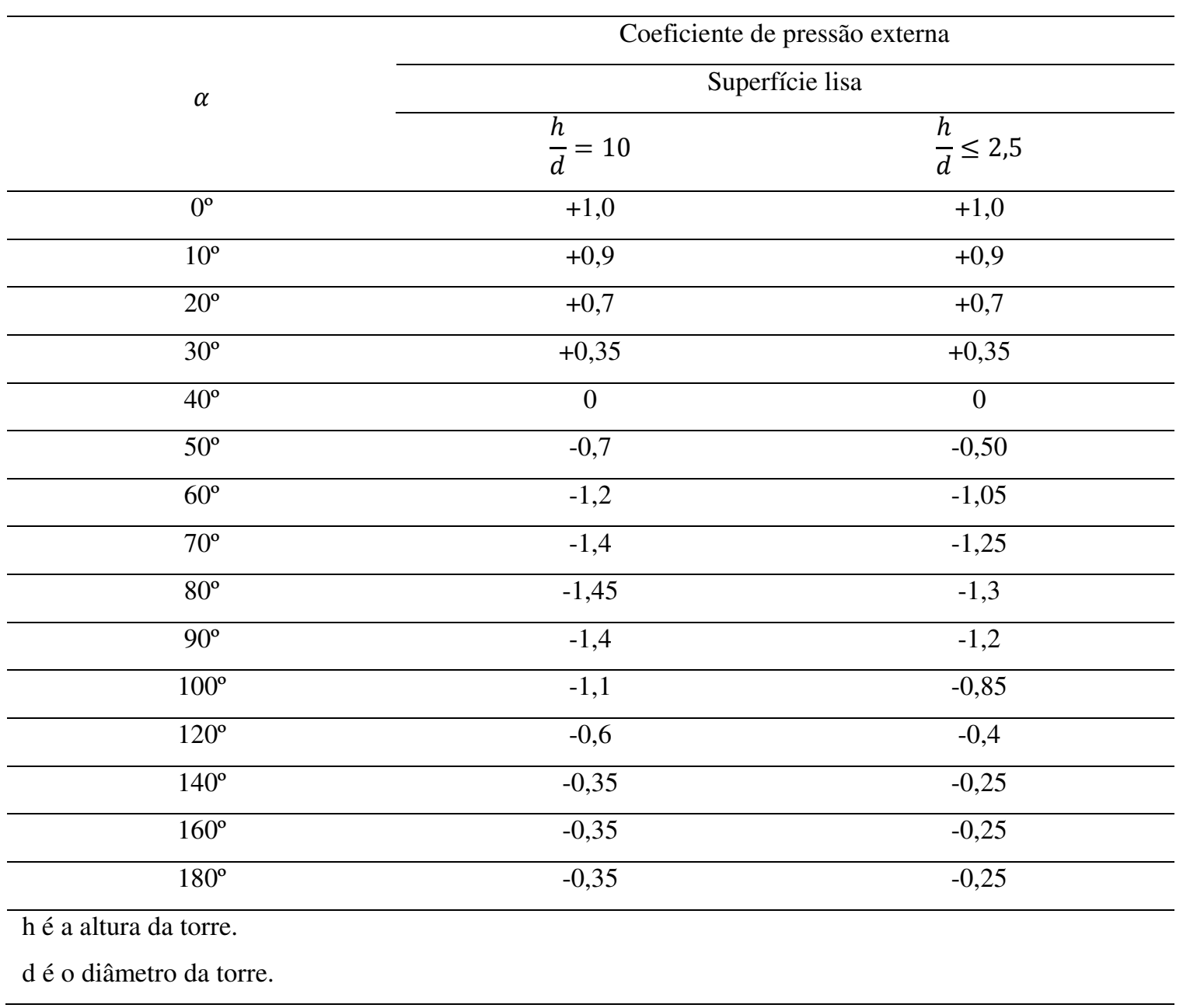

Fonte: ABNT NBR 6123 (1988)

Para se determinar a força de arrasto resultante da ação do vento $\left(\mathrm{f}_{\mathrm{a}}\right)$, utiliza-se a equação abaixo:

$$
f_{a}=C_{a} \cdot q \cdot A_{e}
$$

sendo: $C_{a}$ o coeficiente de arrasto; $A_{e}$ a área frontal efetiva correspondendo a projeção ortogonal sobre um plano perpendicular à direção do vento.

Para as barras prismáticas de seção circular, lisas (metal, concreto, alvenaria rebocada), o coeficiente de arrasto $\left(C_{a}\right)$ é apresentado na Tabela 10 , conforme a relação da altura com o diâmetro e dependem do número de Reynolds apresentado na Equação (26). 
Tabela 10 - Coeficiente de arrasto $C_{a}$

\begin{tabular}{|c|c|c|c|c|c|c|c|}
\hline \multirow{2}{*}{$\operatorname{Re} \times 10^{-5}$} & \multicolumn{7}{|c|}{$\frac{\mathrm{h}}{\mathrm{d}}$} \\
\hline & $\frac{1}{2}$ & 1 & 2 & 5 & 10 & 20 & $\infty$ \\
\hline$\leq 3,5$ & 0,7 & 0,7 & 0,7 & 0,8 & 0,9 & 1,0 & 1,2 \\
\hline$\geq 4,2$ & 0,7 & 0,5 & 0,5 & 0,5 & 0,5 & 0,6 & 0,6 \\
\hline
\end{tabular}

h é a altura da torre.

d é o diâmetro da torre.

Fonte: ABNT NBR 6123 (1988)

Considerando um comprimento unitário da torre, a força por unidade de comprimento torna-se

$$
w=C_{a} \cdot q \cdot d
$$

\subsection{Ações de acordo com a ABNT NBR 6118}

As ações a considerar classificam-se em permanentes, variáveis e excepcionais. As ações permanentes, divididas em diretas e indiretas, atuam durante toda a vida da construção com valores que variam pouco, devendo-se considerar os valores representativos mais desfavoráveis. As ações variáveis, divididas em diretas e indiretas, sendo as diretas constituídas pelas cargas acidentais previstas para o uso da construção, pela ação do vento e da água, e as indiretas constituídas pelas variações de temperatura e pelas ações dinâmicas.

\subsubsection{Coeficientes de ponderação das ações no ELU}

As ações devem ser majoradas pelo coeficiente $\gamma_{\mathrm{f}}$ que é considerado como:

$$
\gamma_{f}=\gamma_{f 1} \cdot \gamma_{f 2} \cdot \gamma_{f 3}
$$

Os valores dos coeficientes de ponderação das ações no ELU utilizados nesta pesquisa são os apresentados na Tabela 11 e na Tabela 12, para $\gamma_{\mathrm{f} 1} \cdot \gamma_{\mathrm{f} 3}$ e $\gamma_{\mathrm{f} 2}$, respectivamente. 
Tabela 11 - Coeficiente $\gamma_{f}=\gamma_{f 1} \cdot \gamma_{f 3}$ para combinações de ações normais

\begin{tabular}{|c|c|c|c|c|c|c|c|c|}
\hline \multirow{3}{*}{ Combinações de ações } & \multicolumn{8}{|c|}{ Ações } \\
\hline & \multicolumn{2}{|c|}{$\begin{array}{c}\text { Permanentes } \\
\text { (g) }\end{array}$} & \multicolumn{2}{|c|}{$\begin{array}{c}\text { Variáveis } \\
\text { (q) }\end{array}$} & \multicolumn{2}{|c|}{$\begin{array}{l}\text { Protensão } \\
\text { (p) }\end{array}$} & \multicolumn{2}{|c|}{ Recalques de apoio e retração } \\
\hline & $\mathrm{D}$ & $\mathrm{F}$ & G & $\mathrm{T}$ & $\mathrm{D}$ & $\mathrm{F}$ & $\mathrm{D}$ & $\mathrm{F}$ \\
\hline Normais & $1,4^{\mathrm{a}}$ & 1,0 & 1,4 & 1,2 & 1,2 & 0,9 & 1,2 & 0 \\
\hline \multicolumn{9}{|l|}{ onde } \\
\hline \multicolumn{9}{|c|}{ D é desfavorável, F é favorável, G representa as cargas variáveis em geral e T é a temperatura. } \\
\hline
\end{tabular}

Fonte: ABNT NBR 6118 (2014)

Tabela 12 - Valores do coeficiente $\gamma_{f 2}$ para ações do vento

\begin{tabular}{|c|c|c|c|c|}
\hline & \multirow{2}{*}{ Ações } & \multicolumn{3}{|c|}{$\gamma_{f 2}$} \\
\hline & & $\psi_{0}$ & $\psi_{1}^{\mathrm{a}}$ & $\psi_{2}$ \\
\hline Vento & Pressão dinâmica do vento nas estruturas em geral & 0,6 & 0,3 & 0 \\
\hline
\end{tabular}

Fonte: ABNT NBR 6118 (2014)

O valor do coeficiente de ponderação de cargas permanentes de mesma origem, em um dado carregamento, deve ser o mesmo ao longo de toda a estrutura. A única exceção é o caso da verificação da estabilidade como corpo rígido.

\subsubsection{Coeficientes de ponderação das ações no ELS}

Em geral, o coeficiente de ponderação das ações para estados limites de serviço é dado pela expressão:

$$
\gamma_{f}=\gamma_{f 2}
$$

onde:

$\gamma_{f 2}$ tem valor variável conforme a verificação que se deseja fazer (ver Tabela 12);

$\gamma_{f 2}=1$ para combinações raras;

$\gamma_{f 2}=\psi_{1}$ para combinações frequentes;

$\gamma_{f 2}=\Psi_{2}$ para combinações quase permanentes. 


\subsection{Combinações de ações de acordo com a ABNT NBR 6118}

Um carregamento é definido pela combinação das ações que têm probabilidades não desprezíveis de atuarem simultaneamente sobre a estrutura, durante um período preestabelecido.

A combinação das ações deve ser feita de forma que possam ser determinados os efeitos mais desfavoráveis para a estrutura; a verificação da segurança em relação aos estados limites último e aos estados limites de serviço deve ser realizada em função de combinações últimas e de combinações de serviço, respectivamente.

\subsubsection{Combinações últimas}

Uma combinação última pode ser classificada como normal, especial ou de construção e excepcional. Na combinação última normal devem estar incluídas as ações permanentes e a ação variável principal, com seus valores característicos e as demais ações variáveis, consideradas secundárias, com seus valores reduzidos de combinação. As combinações últimas usuais estão dispostas na Tabela 13. 
Tabela 13 - Combinações últimas normais

\begin{tabular}{|c|c|c|}
\hline $\begin{array}{l}\text { Combinações } \\
\text { últimas (ELU) }\end{array}$ & Descrição & Cálculo das solicitações \\
\hline \multirow{3}{*}{ Normais } & $\begin{array}{l}\text { Esgotamento da } \\
\text { capacidade } \\
\text { resistente para } \\
\text { elementos } \\
\text { estruturais de } \\
\text { concreto armado } \\
\end{array}$ & $F_{d}=\gamma_{g} F_{g k}+\gamma_{\varepsilon g} F_{\varepsilon g k}+\gamma_{q}\left(F_{q 1 k}+\Sigma \psi_{0 \mathrm{j}} \mathrm{F}_{\mathrm{qjk}}\right)+\gamma_{\varepsilon q} \psi_{0 \varepsilon} F_{\varepsilon q k}$ \\
\hline & $\begin{array}{l}\text { Esgotamento da } \\
\text { capacidade } \\
\text { resistente para } \\
\text { elementos } \\
\text { estruturais } \\
\text { de concreto } \\
\text { protendido } \\
\end{array}$ & $\begin{array}{l}\text { Deve ser considerada, quando necessário, a força de protensão } \\
\text { como carregamento externo com os valores máximo e mínimo para } \\
\text { a força desfavorável e favorável, respectivamente. }\end{array}$ \\
\hline & $\begin{array}{l}\text { Perda do } \\
\text { equilíbrio } \\
\text { como corpo } \\
\text { rígido }\end{array}$ & $\begin{array}{c}S\left(F_{s d}\right) \geq S\left(F_{n d}\right) \\
F_{s d}=\gamma_{g s} G_{s k}+R_{d} \\
F_{n d}=\gamma_{g n} G_{n k}+\gamma_{q} Q_{n k}-\gamma_{q s} Q_{s}, \text { min, onde }: Q_{n k}=Q_{1 k}+\Sigma \psi_{0 j} Q_{j k}\end{array}$ \\
\hline
\end{tabular}

Onde

$\mathrm{F}_{\mathrm{d}}$ é o valor de cálculo das ações para combinação última;

$\mathrm{F}_{\mathrm{gk}}$ representa as ações permanentes diretas;

$\mathrm{F}_{\varepsilon \mathrm{k}}$ representa as ações indiretas permanentes como a retração $\mathrm{F}_{\varepsilon \mathrm{gk}}$ e variáveis como a Temperatura $\mathrm{F}_{\varepsilon q \mathrm{k}}$;

$\mathrm{F}_{\mathrm{qk}}$ representa as ações variáveis diretas das quais $\mathrm{F}_{\mathrm{q} 1 \mathrm{k}}$ é escolhida principal;

$\gamma_{\mathrm{g}}, \gamma_{\varepsilon \mathrm{g}}, \gamma_{\mathrm{q}}, \gamma_{\varepsilon \mathrm{q}}$ ver Tabela 11

$\psi_{0 j}, \psi_{0 \varepsilon}$ ver Tabela 12 ;

$\mathrm{F}_{\mathrm{nd}}$ representa as ações não estabilizantes;

$\mathrm{G}_{\text {sk }}$ é o valor característico da ação permanente estabilizante;

$\mathrm{R}_{\mathrm{d}}$ é o esforço resistente considerado estabilizante, quando houver;

$\mathrm{G}_{\mathrm{nk}}$ é o valor característico da ação permanente variáveis instabilizante;

$\mathrm{G}_{\mathrm{nk}}=\mathrm{Q}_{1 \mathrm{k}}+\sum_{\mathrm{j}=2}^{\mathrm{m}} \Psi_{0 \mathrm{j}} \mathrm{Q}_{\mathrm{jk}}$

$\mathrm{Q}_{\mathrm{nk}}$ é o valor característico das ações variáveis instabilizantes;

$\mathrm{Q}_{1 \mathrm{k}}$ é o valor característico da ação variável instabilizante considerada principal;

$\Psi_{0 \mathrm{j}}$ e $Q_{\mathrm{jk}} \mathrm{são}$ as demais ações variáveis instabilizantes, consideradas com seu valor reduzido;

$\mathrm{Q}_{\mathrm{s} \text {,mín }}$ é o valor característico mínimo da ação variável estabilizante que acompanha obrigatoriamente uma ação variável instabilizante.

${ }^{a}$ No caso geral, devem ser consideradas inclusive combinações onde o efeito favorável das cargas permanentes seja reduzido pela consideração de $\gamma_{\mathrm{g}}=1,0$. No caso de estruturas usuais de edifícios, essas combinações que consideram $\gamma_{\mathrm{g}}$ reduzido $(1,0)$ não precisam ser consideradas.

${ }^{\mathrm{b}}$ Quando $\mathrm{F}_{\mathrm{q} 1 \mathrm{k}}$ ou $\mathrm{F}_{\mathrm{q} 1 \text { exc }}$ atuarem em tempo muito pequeno ou tiverem probabilidade de ocorrência muito baixa, $\Psi_{0 \mathrm{j}}$ pode ser substituído por $\Psi_{2 \mathrm{j}}$. Este pode ser o caso para ações sísmicas e situação de incêndio.

Fonte: ABNT NBR 6118 (2014) 


\subsubsection{Combinações de serviço}

São classificadas de acordo com sua permanência na estrutura e devem ser verificadas como estabelecido a seguir:

a) quase permanentes: podem atuar durante grande parte do período de vida da estrutura, e sua consideração pode ser necessária na verificação do estado-limite de deformações excessivas;

b) frequentes: repetem-se muitas vezes durante o período de vida da estrutura, e sua consideração pode ser necessária na verificação dos estados-limites de formação de fissuras, de abertura de fissuras e de vibrações excessivas. Podem também ser consideradas para verificações de estados-limites de deformações excessivas decorrentes de vento ou temperatura que podem comprometer as vedações;

c) raras: ocorrem algumas vezes durante o período de vida da estrutura, e sua consideração pode ser necessária na verificação do estado-limite de formação de fissuras.

As combinações de serviço usuais estão dispostas na Tabela 14.

Tabela 14 - Combinações de serviço

\begin{tabular}{|c|c|c|}
\hline $\begin{array}{c}\text { Combinações } \\
\text { de serviço } \\
\text { (ELS) }\end{array}$ & Descrição & Cálculo das solicitações \\
\hline $\begin{array}{l}\text { Combinações } \\
\text { quase } \\
\text { permanentes } \\
\text { de serviço } \\
\text { (CQP) }\end{array}$ & $\begin{array}{l}\text { Nas combinações quase permanentes } \\
\text { de serviço, todas as ações variáveis são } \\
\text { consideradas com seus valores quase } \\
\text { permanentes } \Psi_{2} \mathrm{~F}_{\mathrm{qk}}\end{array}$ & $F_{d, s e r}=\Sigma \mathrm{F}_{g \mathrm{i}, \mathrm{k}}+\Sigma \Psi_{2 \mathrm{j}} \mathrm{F}_{\mathrm{qj}, \mathrm{k}}$ \\
\hline $\begin{array}{l}\text { Combinações } \\
\text { frequentes de } \\
\text { serviço }(\mathrm{CF})\end{array}$ & $\begin{array}{c}\text { Nas combinações frequentes de serviço, } \\
\text { a ação variável principal } \mathrm{F}_{\mathrm{q} 1} \text { é tomada com seu } \\
\text { valor frequente } \psi_{1} \mathrm{~F}_{\mathrm{q} 1 \mathrm{k}} \text { e todas as demais ações } \\
\text { variáveis } \\
\text { são tomadas com seus valores quase } \\
\text { permanentes } \psi_{2} \mathrm{~F}_{\mathrm{qk}}\end{array}$ & $F_{d, s e r}=\Sigma \mathrm{F}_{g \mathrm{ik}}+\psi_{1} \mathrm{~F}_{\mathrm{q} 1 \mathrm{k}}+\sum \psi_{2 \mathrm{j}} \mathrm{F}_{\mathrm{qjk}}$ \\
\hline $\begin{array}{l}\text { Combinações } \\
\text { raras de } \\
\text { serviço }(\mathrm{CR})\end{array}$ & $\begin{array}{l}\text { Nas combinações raras de serviço, a ação } \\
\text { variável principal } \mathrm{F}_{\mathrm{q} 1} \text { é tomada com seu valor } \\
\text { característico } \mathrm{F}_{\mathrm{q} 1 \mathrm{k}} \text { e todas as demais ações são } \\
\text { tomadas com seus valores frequentes } \psi_{1} \mathrm{~F}_{\mathrm{qk}}\end{array}$ & $F_{d, s e r}=\Sigma F_{g i k}+F_{q 1 k}+\Sigma \psi_{1 j} F_{q j k}$ \\
\hline \multicolumn{3}{|l|}{ onde } \\
\hline \multicolumn{3}{|c|}{$\mathrm{F}_{\mathrm{d} \text {,serv }}$ é o valor de cálculo das ações para combinação de serviço; } \\
\hline \multicolumn{3}{|c|}{$\mathrm{F}_{\mathrm{q} 1 \mathrm{k}}$ é o valor característico das ações variáveis principais diretas; } \\
\hline \multicolumn{3}{|c|}{$\Psi_{1}$ é o fator de redução de combinação frequente para ELS; } \\
\hline$\Psi_{2}$ é o fator de & ão de combinação quase permanente para ELS. & \\
\hline
\end{tabular}

Fonte: ABNT NBR 6118 (2014) 


\subsection{Combinação de carga de acordo a ABNT NBR 6118}

A combinação de carga de acordo com a ABNT NBR 6118 (2014) a ser utilizado nesta pesquisa é apresentado abaixo.

Estado limite último (ELU):

$$
1,0 \mathrm{D}+1,4 \mathrm{~W}+1,4 \mathrm{TWL}
$$

Estado limite de serviço (ELS):

$$
1,0 \mathrm{D}+0,3 \mathrm{~W}+0,3 \mathrm{TWL}
$$

onde:

D é a carga permanente;

W é a carga direta do vento na torre;

TWL é a carga de turbina induzida pelo vento.

\subsection{Propriedades dos materiais utilizados na modelagem de $\mathrm{Zyl}$}

As características do concreto utilizadas no modelo de Zyl estão resumidas na Tabela 15.

Tabela 15 - Propriedades de concreto obtidas usando o Model Code CEB-FIB (2010)

\begin{tabular}{cc}
\hline $\mathrm{f}_{\mathrm{ck}}$ & $80 \mathrm{MPa}$ \\
\hline $\mathrm{f}_{\mathrm{ctk}, \min }$ & $3,4 \mathrm{MPa}$ \\
\hline $\mathrm{E}_{\mathrm{ci}}$ & $44,4 \mathrm{GPa}$ \\
\hline$v_{\mathrm{c}}$ & 0,2
\end{tabular}

Fonte: Zyl (2014)

onde:

$f_{c k}$ é a resistência característica à compressão (MPa);

$\mathrm{f}_{\mathrm{ctk} \text {,min }}$ é o limite inferior para a resistência característica à tração;

$\mathrm{E}_{\mathrm{ci}}$ é o módulo de elasticidade do concreto com 28 dias em MPa;

$v_{c}$ é o coeficiente de Poisson.

As características da armadura utilizadas na torre modelada por Zyl (2014) estão resumidas na Tabela 16. 
Tabela 16 - Propriedades da armadura

\begin{tabular}{cc}
\hline Densidade & $7850 \mathrm{~kg} / \mathrm{m}^{3}$ \\
\hline Módulo de elasticidade & $200 \mathrm{GPa}$ \\
\hline Coeficiente de Poisson & 0,3 \\
\hline Resistência ao escoamento & $450 \mathrm{MPa}$ \\
\hline Modelo do material & Idealmente plástico \\
\hline Armadura vertical & $5068 \mathrm{~mm}^{2} / \mathrm{m}$ por camada \\
\hline Armadura horizontal & $1636 \mathrm{~mm}^{2} / \mathrm{m}$ por camada \\
\hline Quantidade de camadas horizontal & 2 \\
\hline Quantidade de camadas vertical & 2 \\
\hline Recobrimento do concreto & $0,04 \mathrm{~m}$ \\
\hline
\end{tabular}

Fonte: Zyl (2014)

\subsection{Fundação}

Embora a fundação não faça parte do presente estudo, vale destacar a sua importância no comportamento da torre. Considerar a torre engastada na base pode resultar em diferenças da ordem de $20 \%$ na frequência fundamental da torre (DNV; RISO, 2002 apud ZYL, 2014). No cálculo da frequência pode-se considerar que a torre não é engastada na base, incluindo no modelo a própria fundação e a sua interação com o solo, sendo o efeito da rigidez do solo mais significante que a da fundação, segundo DNV e RISO (2002 apud ZYL, 2014).

A rigidez do solo e a sua interação com a fundação podem ser modeladas por meio de elementos finitos para representar o solo e elementos de interface para a sua interação com a fundação. Uma alternativa, computacionalmente menos onerosa, envolve o uso de molas lineares para representar a rigidez do solo. 


\section{MODELOS DE ANÁLISE}

Uma torre da literatura (ZYL, 2014) em formato de tronco de cone com $100 \mathrm{~m}$ de altura, tendo o diâmetro externo na base $7,10 \mathrm{~m}$, o diâmetro externo no topo 4,00 m, a espessura na base 0,40 m e a espessura no topo 0,30 m é analisada nesta pesquisa (Figura 7). A escolha se deve ao fato da torre estar dentro dos padrões atuais de torre de turbinas eólicas e à disponibilidade das cargas devidas à turbina. Tanto a espessura da parede quanto o diâmetro da torre variam linearmente com a altura. Um anel de aço é colocado no topo da torre para simular o efeito do enrijecimento provocado pela estrutura de aço da turbina que se conecta à torre neste ponto.

Dois modelos de elementos finitos serão utilizados para análise da torre usando o programa SAP2000, um com elementos de viga e outro com elementos de casca.

Figura 7 - Esquematização da torre

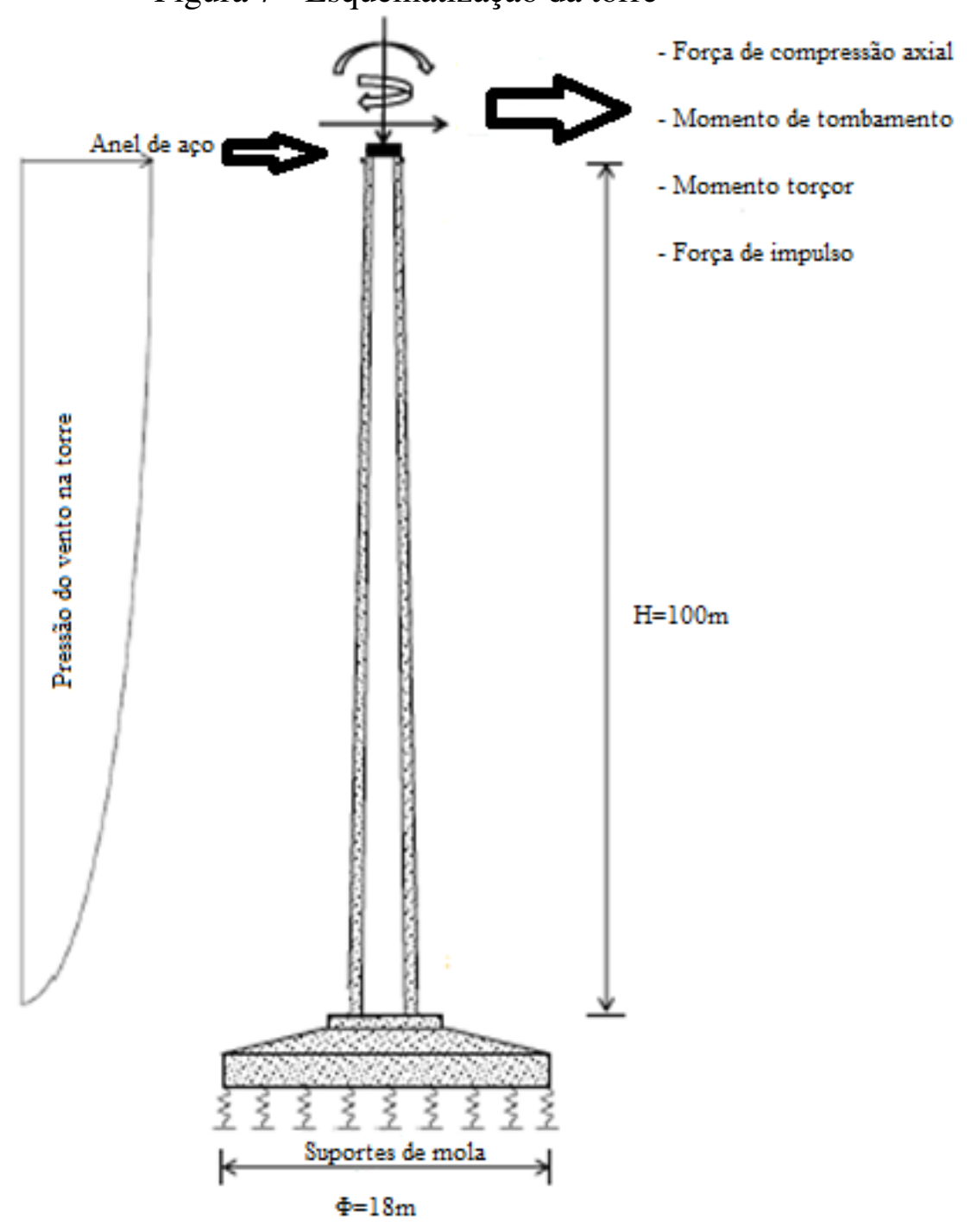

Fonte: Adaptado de Zyl (2014) 


\subsection{Modelo de viga a ser utilizado nesta pesquisa}

O modelo de viga a ser utilizado nesta pesquisa será modelado através do programa de análise estrutural SAP2000 (COMPUTERS \& STRUCTURES INC, 2005) com 200 elementos de $0,50 \mathrm{~m}$. Em relação à modelagem do vento será considerado a força de arrasto resultante, conforme apresentado no Apêndice B.

O elemento de viga do SAP2000 possui seis graus de liberdade em ambas as articulações e usa uma formulação tridimensional de viga-coluna que inclui os efeitos de flexão biaxial, torção, deformação axial e deformações de cisalhamento biaxial, onde cada elemento possui seu próprio sistema de coordenadas local para definir as propriedades da seção e cargas, e para interpretar os resultados.

\subsection{Modelo de casca a ser utilizado nesta pesquisa}

O modelo de casca a ser utilizado nesta pesquisa será modelado através do programa de análise estrutural SAP2000 com tamanho de malha de 0,5 m na direção vertical e um ângulo interno $10^{\circ}$ na direção circunferencial, sendo composto de 7236 elementos de casca. Em relação à modelagem do vento será considerado o efeito da pressão circunferencial, conforme apresentado no Apêndice B.

O software SAP2000 dispõe de elemento de casca de três ou quatro nós que combinam os comportamentos de membrana e de flexão de placa.

O comportamento de membrana utiliza uma formulação isoparamétrica que inclui componentes de rigidez de translação no plano e uma componente de rigidez de rotação na direção normal ao plano do elemento.

O comportamento de flexão da placa inclui componentes de rigidez de rotação de placas bidirecionais fora do plano e uma componente de rigidez de translação na direção normal ao plano do elemento.

Por padrão, é utilizada uma formulação de placa fina (Kirchhoff) que negligencia a deformação de cisalhamento transversal. Opcionalmente, você pode escolher uma formulação de placa espessa (Mindlin / Reissner) que inclui os efeitos da deformação de cisalhamento transversal. Nesta pesquisa será utilizada a formulação de placa espessa (Reissner/Mindlim).

Estruturas que podem ser modeladas com este elemento incluem:

a. Cascas tridimensionais, como tanques e cúpulas; 
b. Estruturas de placas, tais como lajes;

c. Estruturas de membrana, tais como paredes cisalhante.

Para cada elemento de casca na estrutura, você pode optar por modelar a membrana pura, a placa pura ou o comportamento de casca completo. Recomenda-se geralmente que você use o comportamento de casca completo, a menos que toda a estrutura seja plana e adequadamente contida.

Cada elemento de casca tem seu próprio sistema local de coordenadas para definir propriedades do material e cargas e para interpretar os resultados. São permitidas propriedades de material ortotrópico dependentes da temperatura. Cada elemento pode ser carregado por gravidade e cargas uniformes em qualquer direção; pressão superficial nas faces superior, inferior e lateral; e cargas devidas à mudança de temperatura.

Para a rigidez da casca é utilizada uma forma de integração numérica variável de quatro a oito pontos. Tensões, forças internas e momentos, no sistema de coordenadas local do elemento, são avaliados nos pontos de integração de Gauss de 2 por 2 e extrapolados para os nós do elemento. Um erro aproximado nas tensões do elemento ou forças internas pode ser estimado a partir da diferença de valores calculados a partir de diferentes elementos ligados a uma articulação comum. Isto dará uma indicação da precisão de uma dada aproximação por elementos finitos e pode então ser usado como base para a seleção de uma nova e mais precisa malha de elementos finitos.

\subsection{Efeito P-Delta de acordo com o SAP2000}

Nas estruturas com cargas laterais ou assimetrias geométricas, de rigidez ou massa, produzem-se deslocamentos laterais. As cargas verticais geram momentos adicionais iguais a soma da carga vertical "P" multiplicada pelos deslocamentos laterais "Delta". Razão pela qual o efeito é conhecido como "P-Delta". Estes esforços adicionais são chamados de segunda ordem, pois são calculados na configuração deformada da estrutura.

O SAP2000 realiza uma análise iterativa baseado na utilização da matriz de rigidez geométrica para determinar as forças axiais provenientes do efeito P-Delta em estruturas reticuladas. As forças axiais são estimadas mediante uma análise preliminar da estrutura e resolução das equações de equilíbrio, podendo este processo criar variações nas forças axiais. Devem-se realizar iterações adicionais até que as forças axiais e as deflexões laterais convirjam, atendendo a uma tolerância preestabelecida. 


\subsection{Fundação}

O método de Gazetas (1983) será utilizado para representar a rigidez do solo por meio de molas lineares, assumindo a fundação como rígida. Este método é simples e econômico para simular o efeito da rigidez do solo sobre o comportamento dinâmico da torre. A rigidez do solo é desacoplada numa componente de rigidez vertical, horizontal, rotacional e torcional e as suas equações num semi-espaço homogêneo são apresentadas na Tabela 17.

Estando a fundação enterrada no solo, as rigidezes das molas podem ser multiplicadas por coeficientes, ditos de embutimento e dados na Tabela 18, para considerar a profundidade de embutimento. Entretanto, esse aumento de rigidez requer a hipótese de que há contato completo entre os lados da fundação e o solo. Sendo mais conservador, Zyl (2014) não considerou o embutimento em razão da falta de compactação do solo e a redução volumétrica do concreto devido à retração, que podem influenciar o contato da fundação com o solo.

A rigidez do solo obtida pelas equações da Tabela 17 foi utilizada para todos os cálculos da fundação e as dimensões para a fundação utilizada são apresentadas na Figura 8.

Tabela 17 - Rigidez do solo para fundações circulares

\begin{tabular}{cc}
\hline Modo de movimento & Rigidez da fundação circular \\
\hline Vertical & $K_{v}=\frac{4 G R}{1-v}$ \\
\hline Horizontal & $K_{H}=\frac{8 G R}{2-v}$ \\
\hline Oscilatório (pêndulo) & $K_{R}=\frac{8 G R^{3}}{3(1-v)}$ \\
\hline Torção & $K_{T}=\frac{16 G R^{3}}{3}$ \\
\hline
\end{tabular}

R é o raio da fundação

G é o módulo de cisalhamento dinâmico do solo

$v$ é o coeficiente de Poisson do solo

Fonte: Gazetas (1983)

Tabela 18 - Coeficientes de profundidade de embutimento

\begin{tabular}{cc}
\hline Modo de movimento & Rigidez da fundação circular \\
\hline Vertical & $\eta_{v}=1+0,6(1-v)\left(\frac{h}{R}\right)$ \\
\hline Horizontal & $\eta_{H}=1+0,55(2-v)\left(\frac{h}{R}\right)$ \\
\hline Oscilatório (pêndulo) & $\eta_{R}=1+1,2(1-v)\left(\frac{h}{R}\right)+0,2(2-v)\left(\frac{h}{R}\right)^{3}$ \\
\hline Torção & - \\
\hline
\end{tabular}


onde:

h é a profundidade de embutimento.

Figura 8 - Dimensões da fundação

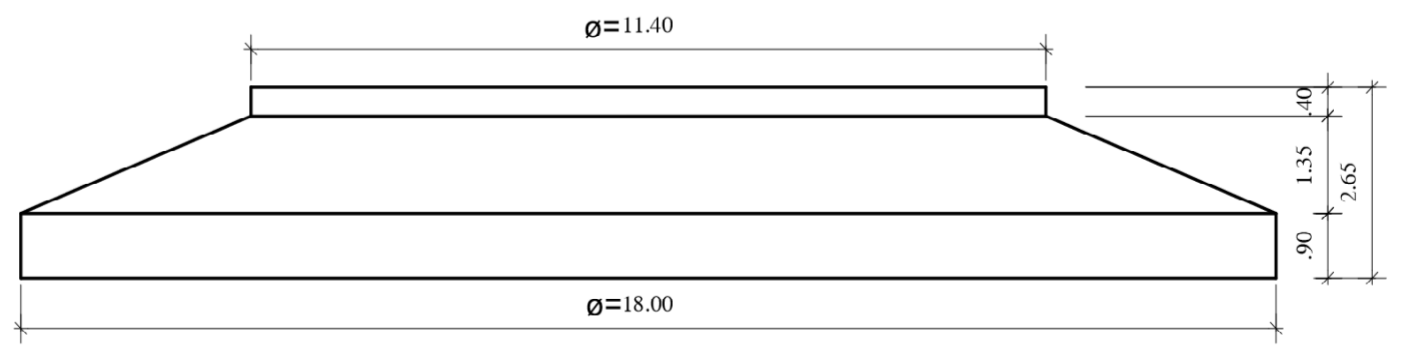

Fonte: Autor

3.5 Modelos dos materiais utilizados no modelo de Zyl com a incorporação da armadura

A curva de Thorenfeldt (Figura 9) e a curva exponencial (Figura 10) foram escolhidas para representar o comportamento de compressão do concreto e a resistência do concreto à tração, respectivamente.

Figura 9 - Curva de Thorenfeldt

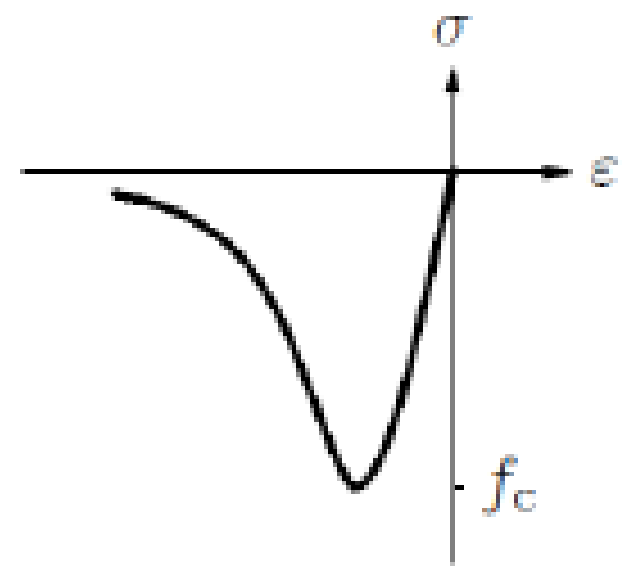

Fonte: Zyl (2014) 
Figura 10 - Curva Exponencial

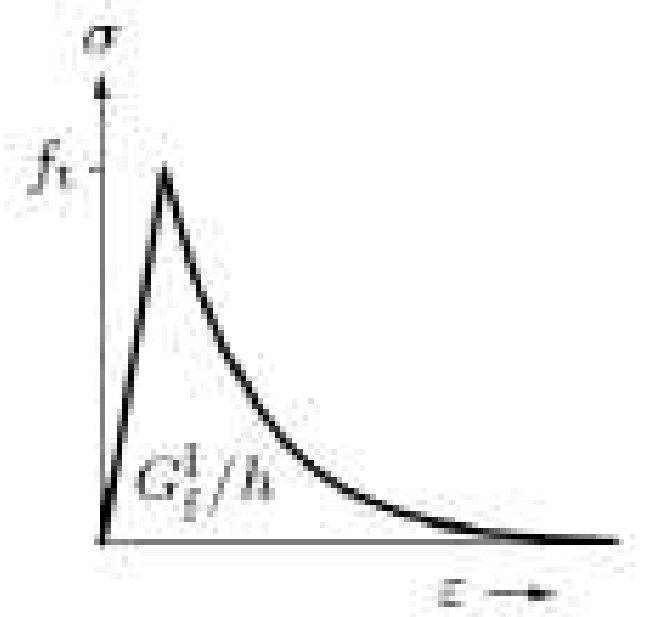

Fonte: Zyl (2014)

O modelo idealmente plástico é utilizado neste projeto para representar o comportamento da armadura (Figura 11).

Figura 11 - Idealmente plástico

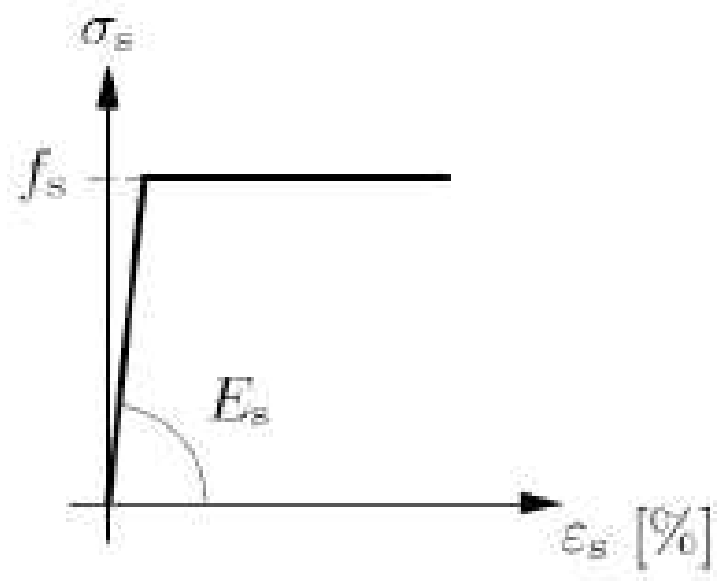

Fonte: Zyl (2014)

\subsection{Avaliação analítica da frequência fundamental da torre}

O Princípio dos Deslocamentos Virtuais (PDV) é um dos métodos utilizados para determinar a equação de movimento de um sistema. Neste princípio, o trabalho virtual de forças reais e das forças de inércia deve ser nulo, ou seja,

$$
\delta W_{n c}-\delta V_{c}+\delta W_{i n}=0
$$


em que, $\delta W_{n}$ é o trabalho virtual das forças não conservativas, $\delta V_{c}$ é a variação da energia potencial das forças conservativas e $\delta W_{i n}$ é o trabalho virtual das forças de inércia.

A torre, nesse caso, é considerada como uma viga engastada na base e livre no topo, com suas respectivas cargas aplicadas, cujos graus de liberdade são infinitos. $\mathrm{Na}$ aproximação por um único grau de liberdade, a deflexão $v(z, t)$ da viga é separada no espaço e no tempo na forma

$$
v(z, t)=\varphi(z) w(t)
$$

A função $w(t)$ é a coordenada generealizada que representa a amplitude do movimento para o sistema de um grau de liberdade e $\varphi(z)$ é a função de forma que aproxima a deformação do sistema contínuo ao longo do eixo longitudinal da viga (eixo-z), sendo dada por:

$$
\varphi(z)=1-\cos \left(\frac{\pi z}{2 L}\right)
$$

em que, $\rho$ é a altura da torre. Então, a redução do sistema para um sistema de um grau de liberdade é realizada aplicando o PDV, que resulta numa massa generalizada $\left(m_{g}\right)$ e um coeficiente de rigidez generalizado $\left(k_{g}\right)$, dados, respectivamente, por:

$$
\begin{gathered}
m_{g}=\int_{0}^{L} \rho A(z)[\varphi(z)]^{2} d z+M_{t} \\
k_{g}=\int_{0}^{L} E I(z)\left[\varphi^{\prime \prime}(z)\right]^{2} d z
\end{gathered}
$$

em que $\rho$ e $E$ são a densidade específica e o módulo de elasticidade do concreto, respectivamente. $A(z)$ e $I(z)$ são a área e o momento de inércia da seção transversal da torre, respectivamente, ambos em função da coordenada $z$. Essas propriedades geométricas são dadas por:

$$
A(z)=\pi\left(r_{\text {ext }}^{2}-r_{\text {int }}^{2}\right)
$$




$$
I(z)=\frac{\pi}{4}\left(r_{\text {ext }}^{4}-r_{\text {int }}^{4}\right)
$$

Onde $r_{\text {ext }}$ e $r_{\text {int }}$ são os raios externo e interno da seção da torre, respectivamente, funções de $z$. Essas grandezas são descritas pelas seguintes equações:

$$
\begin{gathered}
r_{\text {ext }}=r_{\text {ext-base }}+\frac{\left(r_{\text {ext-topo }}-r_{\text {ext-base }}\right)}{L} z \\
r_{\text {int }}=r_{\text {int-base }}+\frac{\left(r_{\text {int-topo }}-r_{\text {int-base }}\right)}{L} z
\end{gathered}
$$

Assim, a frequência fundamental da torre, em $\mathrm{Hz}$, é obtida por:

$$
f=\frac{1}{2 \pi} \sqrt{\frac{k_{g}}{m_{g}}}
$$




\section{RESULTADOS}

Neste capítulo são discutidos os resultados da análise da torre obtidos com o programa de análise estrutural SAP2000 e comparados com os resultados do modelo de Zyl. A torre será também analisada à luz das normas ABNT NBR 6118 (2014) e ABNT NBR 6123 (1988). Inicialmente nos itens 4.1 a 4.4 o concreto será tratado como material homogêneo e no item 4.5 o concreto será tratado como material heterogêneo. Não foram considerados efeitos de fadiga na análise da torre.

\subsection{Torre engastada e modelo de Zyl}

Nesta seção será modelada a torre através de um modelo de viga e de casca no programa de análise estrutural SAP2000 e será feito a comparação com o modelo de Zyl.

\subsubsection{Deflexão no ELS}

As deflexões são verificadas no ELS. Grandes deflexões no topo da torre no ELS farão com que a eficiência da turbina diminua e, portanto, essas deflexões devem ser limitadas. Os fabricantes de turbinas eólicas geralmente especificam a deflexão admissível da torre sob cargas de serviço, mas esta informação, assim como outras, tem acesso restrito. Zyl usou o ACI 307-98, que especifica para a deflexão lateral máxima permitida no topo da torre de concreto, sem os coeficientes de carga, o seguinte valor:

$$
Y_{M A X}=3,33 h(\mathrm{~mm})
$$

onde $\mathrm{h}$ é a altura da torre em $\mathrm{m}$.

A deflexão máxima no ELS para a situação de projeto de desligamento normal e caso de carga de projeto 4.2 de acordo com a norma IEC 61400-1 (2005) é apresentada Tabela 19 para dois níveis de carregamento. O primeiro corresponde ao momento em que o concreto começa a fissurar. Este é um parâmetro importante, porque, até este ponto, o concreto armado se comporta como um material homogêneo. À medida que o concreto fissura, sua resistência à tração é reduzida e o material deixa de se comportar como um material homogêneo. $\mathrm{O}$ segundo é quando $100 \%$ da carga de serviço é aplicada e os modelos de casca e de viga, por adotarem comportamento elástico linear, não capturam este efeito e fornecem deslocamentos cerca de $60 \%$ menores, o que já era esperado. 
Tabela 19 - Deflexão no topo da torre para o ELS (mm)

\begin{tabular}{ccccccc}
\hline \multirow{2}{*}{ Carga } & Zyl (2014) & & & \multicolumn{3}{c}{ Diferença (\%) } \\
& Casca & Casca ${ }^{* *}$ & Viga $^{* *}$ & & \multicolumn{3}{c}{ Casca/Zyl } & Viga/Zyl & Viga/Casca \\
\hline $\begin{array}{l}75 \%-\text { início da } \\
\text { fissuração }\end{array}$ & 168 & 177 & 169 & 5,36 & 0,60 & $-4,52$ \\
\hline $100 \%$ & $549^{*}$ & 236 & 225 & $-57,01$ & $-59,02$ & $-4,66$ \\
\hline $100 \%$ e $0,41 E_{c}$ & - & 575 & 548 & 4,74 & $-0,18$ & $-4,69$ \\
\hline
\end{tabular}

"Considera a fissuração da seção. ${ }^{* *}$ Análise elástica linear (sem fissuração)

Fonte: Autor

A rigidez de uma seção de concreto completamente fissurada no seu lado tracionado é reduzida drasticamente, variando, segundo McCormac e Brown (2014), entre um terço e três quartos da rigidez da seção bruta não fissurada. Observando o gráfico da carga de vento aplicada $\times$ deflexão máxima para o ELS apresentado em Zyl (2014), concluímos que o módulo de elasticidade secante que fornece na análise elástica linear o mesmo resultado de Zyl (2014) é da ordem de 0,41 do módulo de elasticidade na origem. Resultado este confirmado dividindo o deslocamento no elemento de viga com $100 \%$ da carga $(225 \mathrm{~mm})$ pelo deslocamento de Zyl com 100\% da carga (549 mm), obtendo 0,41 do módulo de elasticidade na origem. Resultados da análise linear com este módulo de elasticidade são mostrados na última linha da Tabela 19. O módulo de elasticidade secante poderia ser calibrado considerando a resposta do elemento de casca, mas, pensando na otimização, usouse o de viga.

Observa-se que a deflexão obtida, tanto no modelo de casca como de viga, excede a deflexão lateral máxima prescrita pelo ACI 307-98, que é $333 \mathrm{~mm}$, quando se considera $100 \%$ da carga e a rigidez de $0,41 E c$.

\subsubsection{Deflexão no ELU}

Não há limite de deflexão para o ELU, desde que a estrutura tenha resistência suficiente para evitar o colapso.

Analisando a Tabela 20, calculamos o módulo de elasticidade secante que fornece na análise elástica linear o mesmo resultado de Zyl (2014). Resultado este obtido dividindo o 
deslocamento no elemento de viga com $100 \%$ da carga $(560 \mathrm{~mm})$ pelo deslocamento de Zyl com $100 \%$ da carga (1808 mm), obtendo 0,31 do módulo de elasticidade na origem.

A torre é analisada para a situação de projeto estacionada (turbina parada ou em marcha lenta) e caso de carga de projeto 6.1 de acordo com a norma IEC 61400-1 (2005), sendo os resultados para a deflexão no topo dos elementos de casca e viga para o ELU apresentados na Tabela 20, juntamente com o de Zyl (2014) para comparação. Os dois elementos forneceram resultados da mesma magnitude com $100 \%$ da carga, mas, como era esperado, da ordem de $70 \%$ do valor de Zyl, pelo fato deste considerar a fissuração. Entretanto se for adotado $31 \%$ da rigidez original, a deflexão no ELU é calculada com diferença de $5,75 \%$ para o elemento de casca e $-0,06 \%$ para o elemento de viga em relação ao resultado de Zyl (2014). O valor de $31 \%$ é obtido a partir da relação entre as flechas do elemento de viga e de Zyl para 100\% da carga (560/1808).

Tabela 20 - Deflexão no topo da torre para o ELU (mm)

\begin{tabular}{|c|c|c|c|c|c|c|}
\hline \multirow{2}{*}{ Carga } & \multirow{2}{*}{$\begin{array}{c}\text { Zyl (2014) } \\
\text { Casca }\end{array}$} & \multirow{2}{*}{ Casca $^{* *}$} & \multirow{2}{*}{ Viga $^{* *}$} & \multicolumn{3}{|c|}{ Diferença $(\%)$} \\
\hline & & & & Casca/Zyl & Viga/Zyl & Viga/Casca \\
\hline $\begin{array}{l}30 \% \text { - início da } \\
\text { fissuração }\end{array}$ & 155 & 178 & 168 & 14,84 & 8,39 & $-5,62$ \\
\hline $100 \%$ & $1808^{*}$ & 593 & 560 & $-67,20$ & $-69,03$ & $-5,56$ \\
\hline $100 \%$ e $0,31 \mathrm{Ec}$ & - & 1912 & 1807 & 5,75 & $-0,06$ & $-5,49$ \\
\hline
\end{tabular}

*Considera a fissuração da seção. ** Análise elástica linear

Fonte: Autor

\subsubsection{Análise não linear}

Estruturas delgadas que sofrem deformações relativamente grandes são propensas ao efeito de segunda ordem. Um dos efeitos de segunda ordem mais comuns é o efeito PDelta, que ocorre em todas as estruturas que são submetidas a cargas axiais de compressão. Quando uma estrutura sofre grandes deformações, a carga axial pode apresentar excentricidades, dando origem a momentos ditos de segunda ordem. Esses momentos podem ser significativos em estruturas esbeltas submetidas a grandes forças axiais. Uma torre de turbina eólica é delgada e é submetida a uma grande força axial, causada pelo peso da turbina no topo da torre. O peso próprio da torre de concreto também causará momentos de segunda ordem no estado deformado. 
O momento de tombamento adicional do peso da turbina e do peso próprio da torre é calculado usando a deflexão máxima da torre e a curva de deflexão da torre. Matematicamente, esse momento pode ser calculado pela seguinte equação:

$$
M_{a d d}=\int_{0}^{h} w(y) \Delta(y) d y+P \Delta
$$

onde, $\mathrm{w}(\mathrm{y})$ é a função que descreve o peso próprio da torre, $\Delta(\mathrm{y})$ é a função de deflexão, $\mathrm{P}$ é o peso da turbina e $\Delta$ é a deflexão no topo da torre $(y=h)$.

\subsubsection{Deflexão no ELU}

A magnitude dos efeitos de segunda ordem na torre é determinada pelo efeito PDelta considerando a não-linearidade geométrica.

Os resultados para a deflexão no topo da torre para os modelos de casca e de viga são apresentados na Tabela 21 para a situação de projeto estacionada e caso de carga de projeto 6.1 de acordo com a norma IEC 61400-1 (2005), juntamente com o de Zyl (2014) para comparação. Os dois elementos forneceram resultados da mesma magnitude, mas, como era esperado, da ordem de $70 \%$ do valor de Zyl, pelo fato deste considerar a fissuração. Entretanto se for adotado $31 \%$ da rigidez original, a diferença da deflexão no ELU em relação ao resultado de Zyl (2014) é de 7,46\% para o elemento de casca e 1,24\% para o elemento de viga.

Tabela 21 - Deflexão no topo da torre para o ELU considerando os efeitos de $2^{\mathrm{a}}$ ordem $(\mathrm{mm})$

\begin{tabular}{|c|c|c|c|c|c|c|}
\hline \multirow{2}{*}{ Carga } & \multirow{2}{*}{$\begin{array}{c}\text { Zyl (2014) } \\
\text { Casca }\end{array}$} & \multirow{2}{*}{ Casca $^{* *}$} & \multirow{2}{*}{ Viga $^{* *}$} & \multicolumn{3}{|c|}{ Diferença (\%) } \\
\hline & & & & Casca/Zyl & Viga/Zyl & Viga/Casca \\
\hline $100 \%$ & $1930^{*}$ & 608 & 573 & $-68,50$ & $-70,31$ & $-5,76$ \\
\hline $\begin{array}{c}100 \% \text { e } 0,31 \\
\text { Ec }\end{array}$ & - & 2074 & 1954 & 7,46 & 1,24 & $-5,79$ \\
\hline
\end{tabular}

*Considera a fissuração da seção. ** Análise elástica linear

Fonte: Autor

\subsubsection{Momento no ELU}

O resultado para o momento na base da torre considerando os efeitos de $2^{\mathrm{a}}$ ordem para o elemento de viga é apresentado na Tabela 22, juntamente com o de Zyl (2014) para 
comparação. O elemento de viga forneceu resultado de $-4,34 \%$ para o momento de $1^{\mathrm{a}}$ ordem e $-4,92 \%$ para o momento de $2^{\mathrm{a}}$ em relação ao resultado de Zyl (2014).

Tabela 22 - Momento na base da torre para o ELU considerando os efeitos de $2^{\mathrm{a}}$ ordem $(\mathrm{MNm})$

\begin{tabular}{cccc}
\hline Momento & $\begin{array}{c}\text { Zyl (2014) } \\
\text { Casca }\end{array}$ & Viga & ** \\
\hline $1^{\mathrm{a}}$ ordem & 220,80 & 211,22 & $\begin{array}{c}\text { Diferença (\%) } \\
\text { Viga / Casca }\end{array}$ \\
\hline $2^{\mathrm{a}}$ ordem & 237,82 & 226,13 & $-4,34$ \\
\hline${ }^{*}$ rom & & $-4,92$ \\
\hline
\end{tabular}

*Considera a fissuração da seção. ** Análise elástica linear

Fonte: Autor

\subsubsection{Análise de vibração livre}

A frequência natural da torre foi calculada usando os elementos de viga e de casca no programa de análise estrutural SAP2000, considerando a massa distribuída da torre e uma massa concentrada na parte superior da estrutura representando o efeito da massa da turbina. Os resultados para a frequência com elementos de casca e de viga são apresentados na Tabela 23, juntamente com o de Zyl (2014) para comparação. A frequência fundamental é calculada com diferença de $-6,74 \%$ para o elemento de casca e $-4,49 \%$ para o elemento de viga em relação ao resultado de Zyl (2014) considerando o estado não fissurado do concreto. Para analisar o efeito da fissuração na frequência da torre, é considerada a situação anterior com reduções na rigidez para $31 \%$ e $41 \%$ da original, respectivamente para o ELU e ELS. Considerando o ELU, a frequência obtida é calculada com diferença de 1,32\% para o elemento de casca e 3,51\% para o elemento de viga em relação ao resultado de Zyl (2014). Em relação ao ELS a frequência obtida é calculada com diferença de 9,96\% para o elemento de casca e 12,86\% para o elemento de viga em relação ao resultado de Zyl (2014).

Conforme descrito no Capítulo 3, a solução analítica para a frequência fundamental da torre modelada como uma viga engastada na base e com massa concentrada no topo é de 0,43 Hz. Assim, a frequência fundamental é calculada com diferença de $-3,49 \%$ para o elemento de casca e $-1,16 \%$ para o elemento de viga em relação ao resultado da solução analítica de um elemento de viga com massa concentrada no topo.

Analisando os resultados, observa-se que a frequência fundamental da torre é significativamente reduzida pela formação de fissuras no concreto e a redução apropriada na rigidez fornece bons resultados. 
Os modos de vibração considerando o modelo de viga com a base engastada e o concreto não fissurado são apresentados na Figura 12 e na Tabela 24 é feito uma análise comparativa dos seis primeiros modos de vibração com os resultados obtidos por Zyl (2014). Tabela 23 - Análise de vibração livre da torre para o estado não fissurado e fissurado do concreto $(\mathrm{Hz})$

\begin{tabular}{|c|c|c|c|c|c|c|}
\hline \multirow{2}{*}{ Concreto } & \multirow{2}{*}{$\begin{array}{c}\text { Zyl (2014) } \\
\text { Casca }\end{array}$} & \multirow{2}{*}{ Casca ${ }^{* *}$} & \multirow{2}{*}{ Viga $^{* *}$} & \multicolumn{3}{|c|}{ Diferença $(\%)$} \\
\hline & & & & Casca/Zyl & Viga/Zyl & $\begin{array}{l}\text { Viga/ } \\
\text { Casca }\end{array}$ \\
\hline Não fissurado & $0,445^{*}$ & 0,415 & 0,425 & $-6,74$ & $-4,49$ & 2,41 \\
\hline $\begin{array}{l}\text { Fissurado/ELU } \\
(0,31 \mathrm{Ec})\end{array}$ & $0,228^{*}$ & 0,231 & 0,236 & 1,32 & 3,51 & 2,16 \\
\hline $\begin{array}{l}\text { Fissurado/ELS } \\
(0,41 \mathrm{Ec})\end{array}$ & $0,241^{*}$ & 0,265 & 0,272 & 9,96 & 12,86 & 2,64 \\
\hline
\end{tabular}

*Considera a fissuração da seção. ** Análise elástica linear Fonte: Autor 
Figura 12 - Modos de vibração considerando o modelo de viga com a base engastada e o concreto não fissurado

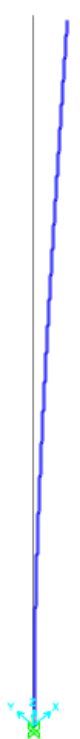

Modo 1: 0,425 Hz

Modo 2: $0,425 \mathrm{~Hz}$

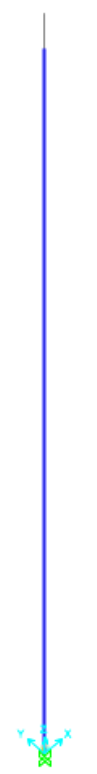

Modo 7: 9,698 Hz

Fonte: Autor

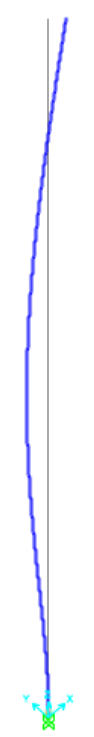

Modo 3: 2,278 Hz

Modo 4: $2,278 \mathrm{~Hz}$

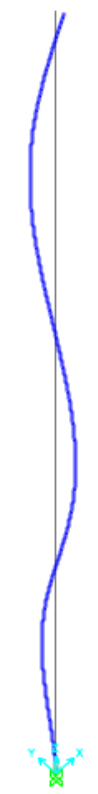

Modo 8: $11,814 \mathrm{~Hz}$

Modo 9: 11,814 Hz

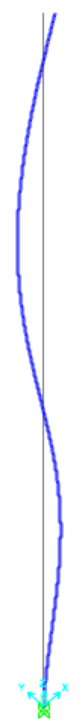

Modo 5: 6,158 Hz

Modo 6: 6,158 Hz

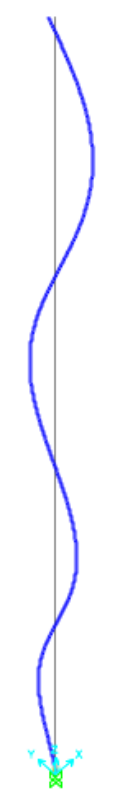

Modo 10: 18,880 Hz

Modo 11: 18,880 Hz 
Tabela 24 - Frequência para os 6 primeiros modos considerando a base engastada e o concreto não fissurado

\begin{tabular}{cccc}
\hline Modo & $\begin{array}{c}\text { Zyl (2014) } \\
\text { Casca }\end{array}$ & Viga & $\begin{array}{c}\text { Diferença (\%) } \\
\text { Viga / Casca }\end{array}$ \\
\hline 1 & 0,445 & 0,425 & $-4,49$ \\
\hline 2 & 0,446 & 0,425 & $-4,71$ \\
\hline 3 & 2,418 & 2,278 & $-5,79$ \\
\hline 4 & 2,423 & 2,278 & $-5,98$ \\
\hline 6 & 6,490 & 6,158 & $-5,11$ \\
\hline
\end{tabular}

Fonte: Autor

\subsection{Torre engastada e modelo da ABNT NBR 6118 e ABNT NBR 6123}

Nesta seção analisaremos o modelo da torre elaborado no SAP2000 de acordo com a ABNT NBR 6118 (2014) e a ABNT NBR 6123 (1988) e verificaremos que as deflexões e as frequências obtidas apresentam mudanças em relação ao modelo de Zyl, ocasionadas pela modelagem da ação do vento, as propriedades do módulo de Young e combinação de carga.

A torre está sujeita aos carregamentos provenientes do vento para o local de instalação (litoral do Ceará) e as mesmas cargas da turbina utilizada por Zyl (2014). Na determinação do carregamento do vento, tomou-se como velocidade básica $30,0 \mathrm{~m} / \mathrm{s}$, conforme indica o mapa das isopletas (ABNT NBR 6123, 1988). Para o coeficiente do Fator Topográfico, S1, utilizou-se o valor de 1 , correspondente a terrenos planos ou fracamente acidentados. Para S2, utilizou-se a Categoria II, que corresponde a terrenos abertos aproximadamente em nível, e a Classe $\mathrm{C}$, que está relacionada para edificações que possuem a sua maior dimensão horizontal ou vertical da superfície frontal maior que $50 \mathrm{~m}$. Assim, por meio dos parâmetros meteorológicos referentes à classe II da ABNT NBR 6123 (Tabela 8), extraiu-se o valor correspondente a cada faixa de altura da torre. Para o Fator Estatístico S3, considerou-se o Grupo 3, no qual estão enquadradas as instalações com baixo fator de ocupação, assumindo valor de 0,95 .

\subsubsection{Deflexão no ELS}

A ABNT NBR 6118 (2014) não possui nenhuma recomendação específica para deslocamentos máximos admissíveis em torres como no modelo proposto, porém recomenda valores-limites de deslocamentos que visam proporcionar um adequado comportamento da 
estrutura em serviço. Em relação ao grupo de aceitabilidade sensorial a ABNT NBR 6118 (2014) recomenda os seguintes limites para deslocamentos de acordo Tabela 25:

Tabela 25 - Limites para deslocamentos de aceitabilidade sensorial

\begin{tabular}{cccc}
\hline \multirow{2}{*}{ Tipo de efeito } & Razão da limitação & $\begin{array}{c}\text { Deslocamento a } \\
\text { considerar }\end{array}$ & Deslocamento-limite \\
\hline \multirow{2}{*}{ Aceitabilidade sensorial } & Visual & Devido a carga total & $\frac{h}{250}$ \\
\cline { 2 - 4 } & Outro & Devido a cargas & $h$ \\
\end{tabular}

Fonte: Autor

Analisando a Tabela 26, observa-se que a deflexão obtida, tanto no modelo de casca como de viga, não excede os limites para deslocamentos de aceitabilidade sensorial prescritos pela ABNT NBR 6118 (2014), que é $400 \mathrm{~mm}$ para a limitação visual e 285,71 mm para qualquer outra razão de limitação, quando se considera $100 \%$ da carga e a rigidez de 0,41Ec. Observa-se também que os limites para deslocamentos são distintos para as normas ABNT NBR 6118 (2014) e ACI 307-98 do American Concrete Institute.

Tabela 26 - Deflexão no topo da torre para o ELS (mm) considerando a ABNT NBR 6118 (2014) e ABNT NBR 6123 (1988)

\begin{tabular}{cccc}
\hline Carga & Casca & Viga & $\begin{array}{c}\text { Diferença (\%) } \\
\text { Viga / Casca }\end{array}$ \\
\hline $75 \%$ - início da fissuração & 87 & 83 & $-4,60$ \\
\hline $100 \%$ e $0,41 E_{c}$ & 282 & 270 & $-4,26$ \\
\hline
\end{tabular}

Fonte: Autor

\subsubsection{Deflexão no ELU}

O ELU está relacionado com o colapso, ou a qualquer outra forma de ruína estrutural, que determine a paralisação do uso da estrutura, contanto como mencionado anteriormente não há limite de deflexão, desde que a estrutura tenha resistência suficiente para evitar o colapso. Os resultados para a deflexão no topo dos elementos de casca e viga para o ELU considerando a ABNT NBR 6118 (2014) e ABNT NBR 6123 (1988) são apresentadas na Tabela 27. O início da fissuração ocorre com $30 \%$ da carga, considerando a combinação proposta para o ELU, porém observa-se que o deslocamento ainda encontra-se dentro do limite para deflexão do ELS de acordo com a ABNT NBR 6118 (2014). 
Tabela 27 - Deflexão no topo da torre para o ELU (mm) considerando a ABNT NBR 6118 (2014) e ABNT NBR 6123 (1988)

\begin{tabular}{cccc}
\hline Carga & Casca & Viga & $\begin{array}{c}\text { Diferença (\%) } \\
\text { Viga / Casca }\end{array}$ \\
\hline $30 \%$ - início da fissuração & 164 & 156 & $-4,88$ \\
\hline $100 \%$ e $0,31 E_{c}$ & 1764 & 1681 & $-4,71$ \\
\hline
\end{tabular}

Fonte: Autor

\subsubsection{Análise não linear}

Os resultados para a deflexão no topo são apresentados na Tabela 28 para o ELS e na Tabela 29 para o ELU, considerando os efeitos de segunda ordem por meio do efeito PDelta, para a não linearidade geométrica, e a redução da rigidez, para a não linearidade do material, de acordo com a ABNT NBR 6118 (2014) e ABNT NBR 6123 (1988).

\subsubsection{Deflexão no ELS}

O resultado para a deflexão no topo do elemento de casca considerando os efeitos de segunda ordem excede o limite para deslocamento de aceitabilidade sensorial prescrito pela ABNT NBR 6118 (1988), que é 285,71 mm para qualquer outra razão de limitação. Observa-se também na Tabela 28, que a deflexão da torre apresenta um aumento de 3,55\% em relação a deflexão do caso linear geométrico no ELS para o elemento de casca e de 3,33\% para o elemento de viga.

Tabela 28 - Deflexão no topo da torre para o ELS (mm), considerando os efeitos de $2^{\mathrm{a}}$ ordem de acordo com a ABNT NBR 6118 (2014) e ABNT NBR 6123 (1988)

\begin{tabular}{cccc}
\hline & Casca & Viga & Diferença (\%) \\
Viga / Casca
\end{tabular}

Fonte: Autor 


\subsubsection{Deflexão no ELU}

Observa-se na Tabela 29, que a deflexão da torre apresenta um aumento de 8,96\% em relação a deflexão do caso linear geométrico no ELU para o elemento de casca e de 8,57\% para o elemento de viga.

Tabela 29 - Deflexão no topo da torre para o ELU (mm), considerando os efeitos de $2^{\mathrm{a}}$ ordem de acordo com a ABNT NBR 6118 (2014) e ABNT NBR 6123 (1988)

\begin{tabular}{cccc}
\hline & Casca & Viga & Diferença (\%) \\
Viga / Casca
\end{tabular}

Fonte: Autor

\subsubsection{Análise de vibração livre}

A frequência natural da torre foi calculada usando os elementos de viga e de casca no programa de análise estrutural SAP2000, considerando uma massa distribuída ao longo da torre e uma massa concentrada na parte superior da estrutura representando a massa da turbina. A norma utilizada para a modelagem da torre de concreto foi a ABNT NBR 6118 (2014) - Projeto de Estruturas de Concreto. Apresentam-se a seguir as frequências naturais para o ELU (Tabela 30) e para o ELS (Tabela 31)), considerando o estado não fissurado e o estado fissurado.

Tabela 30 - Frequência natural da torre/engastada/NBR's para o ELU (Hz)

\begin{tabular}{cccc}
\hline Concreto & Casca & Viga & Diferença (\%) \\
\hline Não fissurado $-E_{c}$ & 0,418 & 0,428 & 2,39 \\
\hline Fissurado $-031 E_{c}$ & 0,233 & 0,238 & 2,15
\end{tabular}

Fonte: Autor 
Tabela 31 - Frequência natural da torre/engastada/NBR's para o ELS (Hz)

\begin{tabular}{cccc}
\hline Concreto & Casca & Viga & Diferença (\%) \\
\hline Não fissurado $-E_{c}$ & 0,418 & 0,428 & 2,39 \\
\hline Fissurado - 041 $E_{c}$ & 0,268 & 0,274 & 2,24 \\
\hline
\end{tabular}

Fonte: Autor

A diferença na frequência natural da torre engastada com o modelo de Zyl (2014) quando comparada com a frequência natural da torre de acordo com a ABNT NBR 6118 (2014) deve-se a expressões distintas para o cálculo do módulo de elasticidade, que altera a rigidez da torre.

\subsection{Torre com interação solo-estrutura e modelo de Zyl}

A interação solo-estrutura de acordo com o método de Gazetas (1983) será representada no elemento de viga, pois os resultados das deflexões e frequências da torre engastada apresentaram resultados satisfatórios para este elemento.

\subsubsection{Análise de vibração livre - concreto não fissurado}

Uma análise de sensibilidade foi realizada por Zyl (2014) para determinar o efeito da rigidez do solo sobre a freqüência fundamental da torre, estando as propriedades dos solos utilizadas nesta análise apresentadas na Tabela 32.

Os valores do coefiente de Poisson adotados por Zyl (2014) foram de 0,40 para areia e 0,35 para argila, entretanto os mesmos estão discordantes do coeficiente de Poisson, quando considera-se o solo como material isotrópico.

Tabela 32 - Propriedades de solos típicos

\begin{tabular}{ccccc}
\hline & \multicolumn{3}{c}{ Rigidez } \\
\cline { 2 - 5 } Tipo de solo & Vertical & Horizontal & Oscilatória & Torção \\
& $(\mathrm{N} / \mathrm{m})$ & $(\mathrm{N} / \mathrm{m})$ & $(\mathrm{N} . \mathrm{m})$ & $5,05 \times 10^{10}$ \\
\hline Argila mole & $7,16 \times 10^{8}$ & $5,66 \times 10^{8}$ & $3,87 \times 10^{10}$ & $9,72 \times 10^{10}$ \\
\hline Argila média & $1,50 \times 10^{9}$ & $1,13 \times 10^{9}$ & $8,10 \times 10^{10}$ & $1,59 \times 10^{11}$ \\
\hline Areia fina & $2,24 \times 10^{9}$ & $1,78 \times 10^{9}$ & $1,21 \times 10^{11}$ & $2,45 \times 10^{11}$ \\
\hline Areia média & $3,48 \times 10^{9}$ & $2,75 \times 10^{9}$ & $1,88 \times 10^{11}$ & $2,88 \times 10^{11}$ \\
\hline Areia grossa & $4,11 \times 10^{9}$ & $3,23 \times 10^{9}$ & $2,22 \times 10^{11}$ & $4,32 \times 10^{11}$ \\
\hline Cascalho & $6,16 \times 10^{9}$ & $4,85 \times 10^{9}$ & $3,33 \times 10^{11}$ &
\end{tabular}

Fonte: Autor

Um tamanho de fundação típica para uma turbina de 3,6 MW apoiada numa torre de concreto foi utilizada por Zyl (2014). Justifica-se o uso de uma fundação genérica devido 
ao fato de que a fundação é usada apenas para uma análise de sensibilidade da rigidez do solo. A fundação deve ser projetada de acordo com a torre e turbina específicas, caso a fundação seja usada nos cálculos de deflexão.

Para avaliar o efeito da rigidez da fundação, a frequência natural da torre foi calculada para o modelo com elementos de casca sem considerar a fundação (base da torre engastada) e para um modelo incluindo a fundação, agora com elementos sólidos (3D), no programa de análise estrutural SAP2000. Foi considerada uma massa distribuída ao longo da torre relativo ao peso próprio e uma massa concentrada de $314912 \mathrm{~kg}$ na parte superior da estrutura representando a massa da turbina. A frequência fundamental obtida na análise modal considerando o estado não fissurado foi de $0,415 \mathrm{~Hz}$ para o elemento de casca sem fundação (Figura 13) e de 0,412 Hz para o elemento de casca com a fundação (Figura 14), apresentando uma diferença de $0,72 \%$, confirmando, conforme DNV e RISO (2002), que o efeito da rigidez da fundação sobre a frequência fundamental da torre é pequeno. 
Figura 13 - Modos de vibração considerando o modelo de casca com a base engastada e o concreto não fissurado

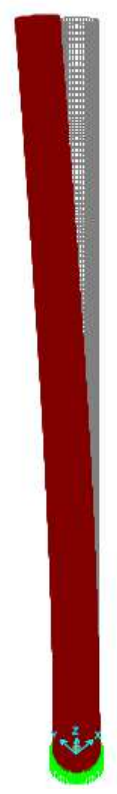

Modo 1: 0,415 Hz

Modo 2: 0,415 Hz

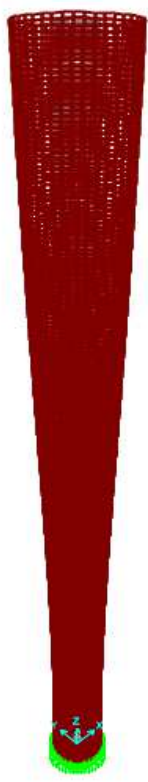

Modo 7: 7,898 Hz

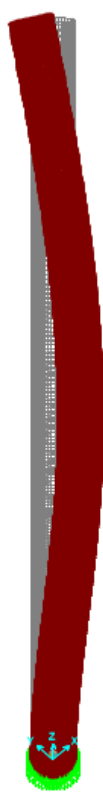

Modo 3: 2,246 Hz

Modo 4: $2,246 \mathrm{~Hz}$

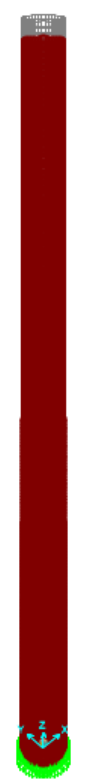

Modo 8: $9,561 \mathrm{~Hz}$

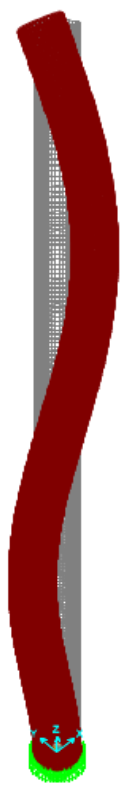

Modo 5: 6,050 Hz

Modo 6: 6,050 Hz

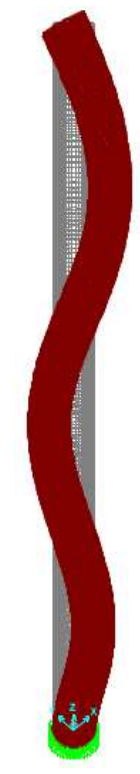

Modo 9: 11,538 Hz

Modo 10: 11,538 Hz

Fonte: Autor 
Figura 14 - Modos de vibração considerando o modelo de casca com a fundação engastada e o concreto não fissurado

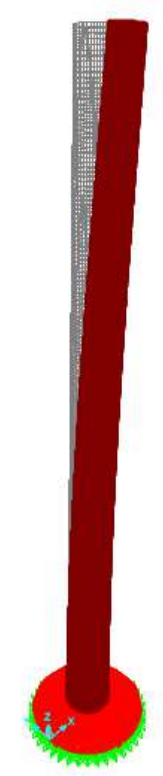

Modo 1: 0,412 Hz

Modo 2: 0,412 Hz

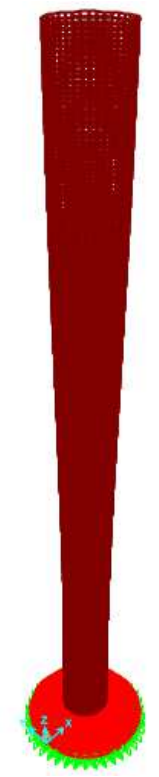

Modo 7: 7,886 Hz

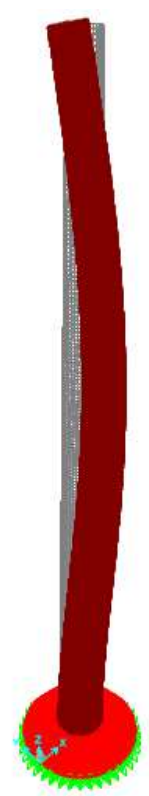

Modo 3: 2,227 Hz

Modo 4: 2,227 Hz

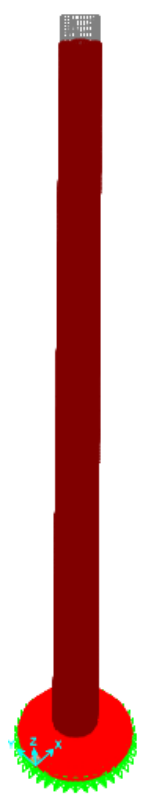

Modo 8: 9,523 Hz

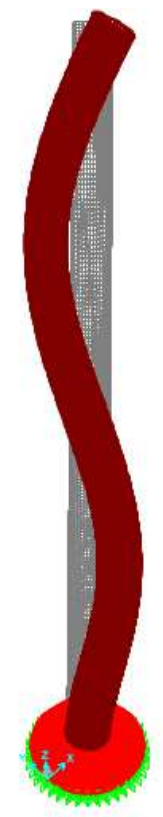

Modo 5: 6,000 Hz

Modo 6: 6,000 Hz

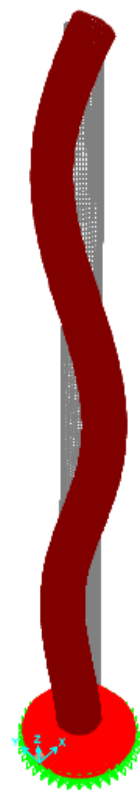

Modo 9: 11,453 Hz

Modo 10: 11,453 Hz

Fonte: Autor

A redução da frequência fundamental da torre devida a diferentes tipos de solos que é apresentada na Tabela 33 é bastante grave e enfatiza a importância de um estudo 
geotécnico detalhado para determinar a rigidez do solo, pois uma superestimação da rigidez do solo pode causar graves vibrações e/ou mesmo ressonância da estrutura.

Tabela 33 - Redução da frequência fundamental $(\mathrm{Hz})$ da torre devida a diferentes tipos de solos

\begin{tabular}{|c|c|c|c|c|c|c|}
\hline & \multicolumn{3}{|c|}{ Zyl (2014) } & \multicolumn{3}{|c|}{ Presente trabalho (modelo de viga) } \\
\hline $\begin{array}{l}\text { Tipo de } \\
\text { solo }\end{array}$ & $\begin{array}{c}\text { Fundação } \\
\text { rígida }\end{array}$ & $\begin{array}{l}\text { Modelo com } \\
\text { molas }\end{array}$ & $\begin{array}{l}\% \text { de } \\
\text { redução }\end{array}$ & $\begin{array}{c}\text { Fundação } \\
\text { rígida }\end{array}$ & $\begin{array}{l}\text { Modelo com } \\
\text { molas }\end{array}$ & $\begin{array}{l}\% \text { de } \\
\text { redução }\end{array}$ \\
\hline Argila mole & 0,445 & 0,273 & 38,65 & 0,425 & 0,281 & 33,88 \\
\hline $\begin{array}{l}\text { Argila } \\
\text { média }\end{array}$ & 0,445 & 0,320 & 28,09 & 0,425 & 0,335 & 21,18 \\
\hline Areia fina & 0,445 & 0,343 & 22,92 & 0,425 & 0,358 & 15,76 \\
\hline $\begin{array}{l}\text { Areia } \\
\text { média }\end{array}$ & 0,445 & 0,361 & 18,88 & 0,425 & 0,378 & 11,06 \\
\hline $\begin{array}{l}\text { Areia } \\
\text { Grossa }\end{array}$ & 0,445 & 0,367 & 17,53 & 0,425 & 0,384 & 9,65 \\
\hline Cascalho & 0,445 & 0,378 & 15,06 & 0,425 & 0,397 & 6,59 \\
\hline
\end{tabular}

Um aumento gradual dos parâmetros de rigidez usando um fator $\lambda$, partindo-se da areia fina como referência $(\lambda=1)$, mostra, para a frequência da torre no estado não fissurado, o comportamento não linear apresentado na Figura 15. Quando $\lambda$ se torna grande, a frequência tende para a situação de engaste na base. $O$ gráfico sugere que qualquer melhoramento no solo, aumentando a sua rigidez, tem um efeito significativo no aumento da frequência. A Figura 16 apresenta os modos de vibração considerando o modelo de viga com a base apoiada na areia fina e o concreto não fissurado.

Figura 15 - Variação da frequência natural da torre no estado não fissurado com a rigidez

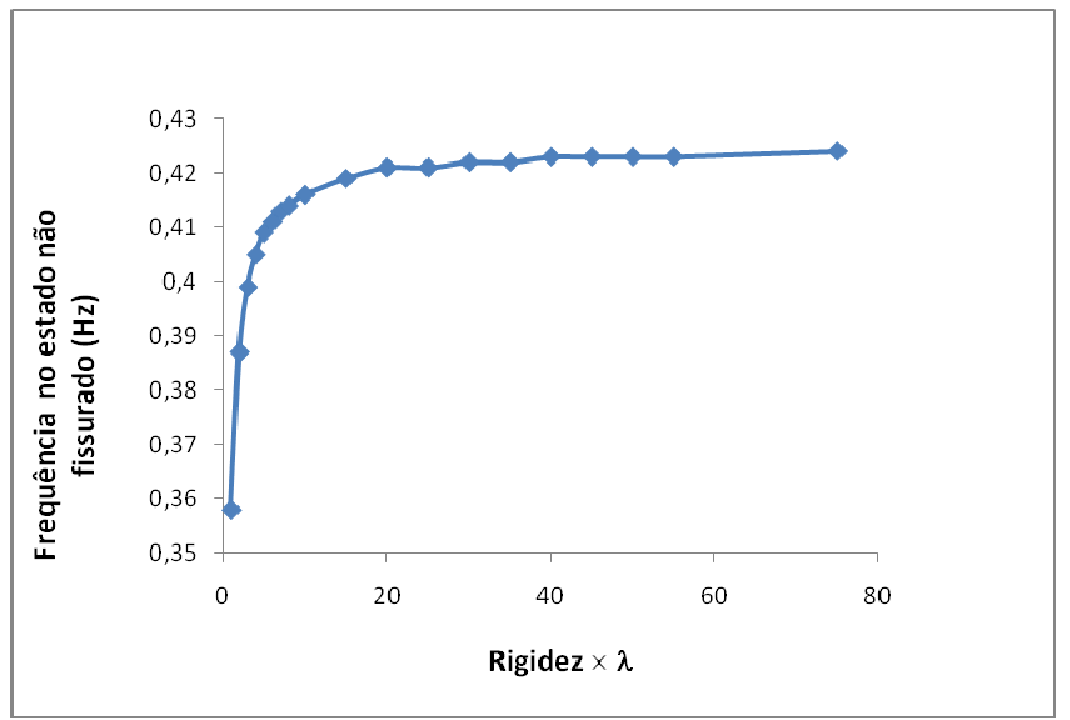

Fonte: Autor 
Figura 16 - Modos de vibração considerando o modelo de viga com a base apoiada na areia fina e o concreto não fissurado

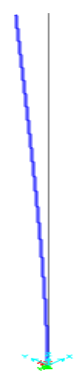

Modo 1: 0,358 Hz

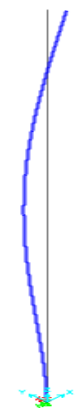

Modo 4: 2,278 Hz

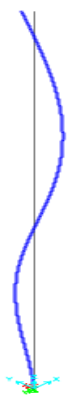

Modo 7: 6,158 Hz

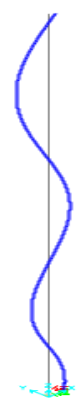

Modo 10: 15,363 Hz

Fonte: Autor

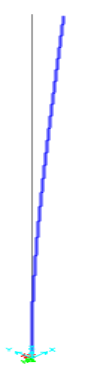

Modo 2: $0,425 \mathrm{~Hz}$

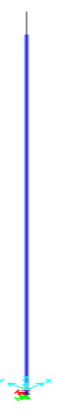

Modo 5: 4,987 Hz

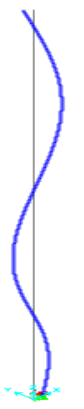

Modo 8: 9,833 Hz

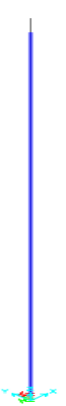

Modo 11: 17,646 Hz
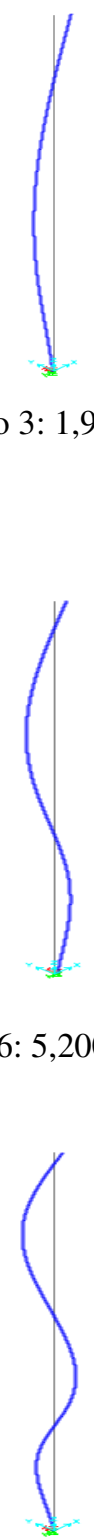

Modo 3: 1,903 Hz

Modo 6: 5,200 Hz

Modo 9: 11,814 Hz

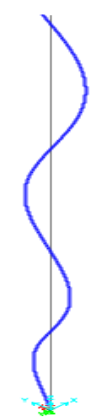

Modo 12: 18,880 Hz 


\subsubsection{Análise de vibração livre no ELS - concreto fissurado}

Esta seção calcula a redução na frequência fundamental, quando o concreto está fissurado no ELS e considera-se a interação solo-estrutura. A Tabela 34 mostra que, neste caso, a frequência fundamental da torre pode ser reduzida em até $48,24 \%$ no caso da argila mole, fazendo com que a frequência da torre fique fora da frequência de trabalho da turbina que está compreendido entre 0,242 e 0,594.

Tabela 34 - Influência da fissuração do concreto na frequência $(\mathrm{Hz})$ da torre para diferentes tipos de solos no ELS

\begin{tabular}{|c|c|c|c|c|c|}
\hline \multirow{2}{*}{ Tipo de solo } & \multirow{2}{*}{$\begin{array}{l}\text { Fundação rígida } \\
\text { (concreto não } \\
\text { fissurado) }\end{array}$} & \multicolumn{2}{|c|}{ Modelo com molas } & \multicolumn{2}{|c|}{ \% de redução } \\
\hline & & $\begin{array}{l}\text { Estado não } \\
\text { fissurado }\end{array}$ & $\begin{array}{c}\text { Estado } \\
\text { fissurado }\end{array}$ & $\begin{array}{l}\text { Estado não } \\
\text { fissurado }\end{array}$ & Estado fissurado \\
\hline Argila mole & 0,425 & 0,281 & 0,220 & 33,88 & 48,24 \\
\hline Argila média & 0,425 & 0,335 & 0,243 & 21,18 & 42,82 \\
\hline Areia fina & 0,425 & 0,358 & 0,252 & 15,76 & 40,71 \\
\hline Areia média & 0,425 & 0,378 & 0,259 & 11,06 & 39,06 \\
\hline Areia Grossa & 0,425 & 0,384 & 0,260 & 9,65 & 38,82 \\
\hline Cascalho & 0,425 & 0,397 & 0,264 & 6,59 & 37,88 \\
\hline
\end{tabular}

Fonte: Autor

\subsubsection{Análise de vibração livre no ELU - concreto fissurado}

Esta seção calcula a redução na frequência fundamental, quando o concreto está fissurado no ELU e considera-se a interação solo-estrutura. A Tabela 35 mostra que, neste caso, a frequência fundamental da torre pode ser reduzida em até 52,94\% no caso da argila mole. Esta redução na frequência fundamental da torre poderá levar à ressonância com as frequências de excitação da turbina em operação e em última análise à falha estrutural. Observa-se também que a frequência da torre fica fora da frequência de trabalho da turbina que está compreendido entre 0,242 e 0,594 para todos os tipos de solo. 
Tabela 35 - Influência da fissuração do concreto na frequência $(\mathrm{Hz})$ da torre para diferentes tipos de solos no ELU

\begin{tabular}{|c|c|c|c|c|c|}
\hline \multirow{2}{*}{ Tipo de solo } & \multirow{2}{*}{$\begin{array}{l}\text { Fundação rígida } \\
\text { (concreto não } \\
\text { fissurado) }\end{array}$} & \multicolumn{2}{|c|}{ Modelo com molas } & \multicolumn{2}{|c|}{ \% de redução } \\
\hline & & $\begin{array}{c}\text { Estado não } \\
\text { fissurado }\end{array}$ & $\begin{array}{c}\text { Estado } \\
\text { fissurado }\end{array}$ & $\begin{array}{c}\text { Estado não } \\
\text { fissurado }\end{array}$ & Estado fissurado \\
\hline Argila mole & 0,425 & 0,281 & 0,200 & 33,88 & 52,94 \\
\hline Argila média & 0,425 & 0,335 & 0,217 & 21,18 & 48,94 \\
\hline Areia fina & 0,425 & 0,358 & 0,223 & 15,76 & 47,53 \\
\hline Areia média & 0,425 & 0,378 & 0,228 & 11,06 & 46,35 \\
\hline Areia Grossa & 0,425 & 0,384 & 0,229 & 9,65 & 46,12 \\
\hline Cascalho & 0,425 & 0,397 & 0,231 & 6,59 & 45,65 \\
\hline
\end{tabular}

Fonte: Autor

\subsection{Torre com interação solo-estrutura e modelo da ABNT NBR 6118 e ABNT NBR 6123}

Nesta seção analisaremos a interação solo-estrutura da torre de Zyl com o método de Gazetas (1983) de acordo com a ABNT NBR 6118 (2014) e a ABNT NBR 6123 (1988).

\subsubsection{Deflexão no ELS - concreto fissurado}

Os resultados para a deflexão no topo da torre para diferentes tipos de solos são apresentados na Tabela 36. Os resultados mostram que os solos com exceção do cascalho, excedem o limite para deslocamento de aceitabilidade sensorial prescrito pela ABNT NBR 6118 (2014), que é 285,71 mm para qualquer outra razão de limitação, quando se considera $100 \%$ da carga e a rigidez de 0,41Ec. Vale ressaltar que os limites da ABNT NBR 6118 (2014) são aplicáveis a edifícios, pontes, obras hidráulicas, portos ou aeroportos etc. 
Tabela 36 - Deflexão $(\mathrm{mm})$ no topo da torre para diferentes tipos de solos, considerando o concreto fissurado

\begin{tabular}{cccc}
\hline Tipo de solo & Base engastada & Modelo de molas & \% de aumento \\
\hline Argila mole & 270 & 379 & 40,37 \\
\hline Argila média & 270 & 322 & 19,26 \\
\hline Areia fina & 270 & 305 & 12,96 \\
\hline Areia média & 270 & 293 & 8,52 \\
\hline Areia Grossa & 270 & 289 & 7,04 \\
\hline Cascalho & 270 & 283 & 4,81 \\
\hline
\end{tabular}

Fonte: Autor

\subsubsection{Deflexão no ELS - concreto fissurado e efeitos de segunda ordem}

Os resultados para a deflexão no topo da torre para diferentes tipos de solos considerando os efeitos de segunda ordem são apresentados na Tabela 37. Os resultados mostram que os solos, excedem o limite para deslocamento de aceitabilidade sensorial prescrito pela ABNT NBR 6118 (2014), que é 285,71 mm para qualquer outra razão de limitação, quando se considera $100 \%$ da carga e a rigidez de $0,41 E c$.

Tabela 37 - Deflexão (mm) no topo da torre para diferentes tipos de solos: concreto fissurado e efeitos de $2^{\mathrm{a}}$ ordem

\begin{tabular}{|c|c|c|c|}
\hline \multirow{2}{*}{ Tipo de solo } & \multicolumn{2}{|c|}{ Modelo de molas } & \multirow{2}{*}{$\%$ de aumentc } \\
\hline & $1^{\mathrm{a}}$ ordem & $2^{\mathrm{a}}$ ordem & \\
\hline Argila mole & 379 & 397 & 4,75 \\
\hline Argila média & 322 & 335 & 4,04 \\
\hline Areia fina & 305 & 316 & 3,61 \\
\hline Areia média & 293 & 302 & 3,07 \\
\hline Areia Grossa & 289 & 299 & 3,46 \\
\hline Cascalho & 283 & 292 & 3,18 \\
\hline
\end{tabular}

Fonte: Autor

\subsection{Torre engastada e modelo de Zyl incorporando a armadura}

A torre de concreto proposta por Zyl (2014) é reforçada por quatro camadas de aço (Tabela 16), sendo duas camadas verticais e duas horizontais, conforme mostrado na Figura 17. 
Figura 17 - Detalhe da armadura da torre de concreto

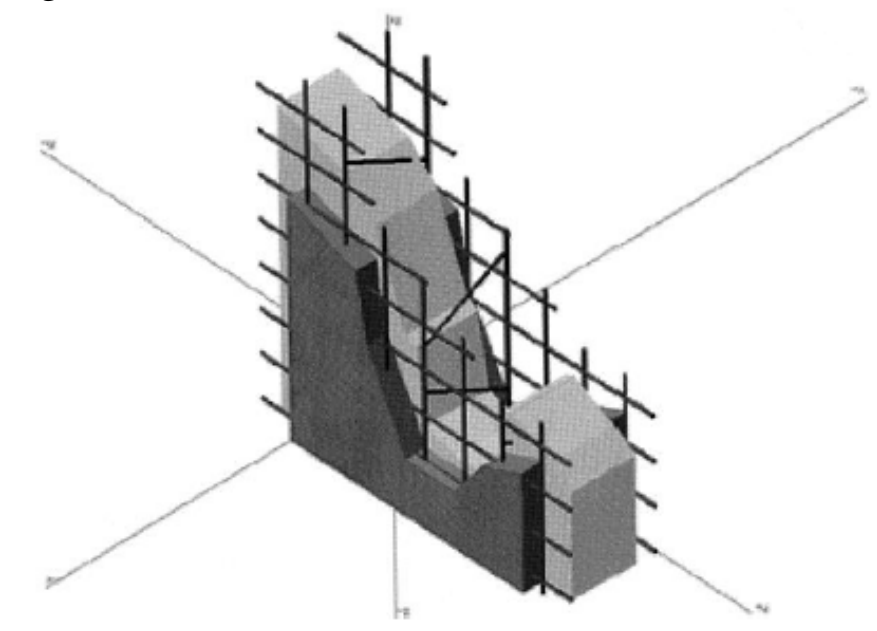

Fonte: Zyl (2014)

As resistências de projeto do concreto à compressão e do aço à tração são calculadas na forma

$$
R_{d}=\frac{\mathrm{f}_{\mathrm{k}}}{\gamma_{\mathrm{m}}}
$$

e a resistência de projeto do aço à compressão é dada por

$$
R_{\text {compressão do aço }}=\frac{\mathrm{f}_{\mathrm{y}}}{\gamma_{\mathrm{m}}+\frac{\mathrm{f}_{\mathrm{y}}}{2000}}
$$

onde $\mathrm{f}_{\mathrm{k}}$ é a resistência característica do material, $R_{d}$ é a resistência de projeto do material, $\mathrm{f}_{\mathrm{y}}$ é

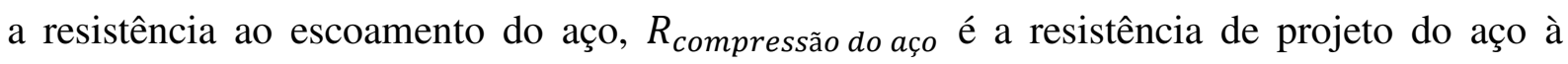
compressão e $\gamma_{m}$ é o coeficiente de ponderação da resistência do material (Tabela 6).

Ao contrário da resistência característica de um material que deverá ser minorada pelo coeficiente de ponderação da resistência do material, a carga característica deverá ser majorada pelo coeficiente de ponderação das ações. Este coeficiente é responsável por qualquer incerteza na carga característica aplicada à estrutura. A carga de projeto é dada por:

$$
Q_{d}=\gamma_{\mathrm{f}} \mathrm{Q}_{\mathrm{n}}
$$

onde:

$\gamma_{\mathrm{f}}$ é o coeficiente de ponderação das ações; 
$\mathrm{Q}_{\mathrm{n}}$ é a carga característica.

A modelagem da estrutura de concreto armado como elemento de área no SAP2000 foi feita através do tipo Shell - Layered/Nonlinear de seção heterogênea que é composta ao longo da espessura da Shell por várias camadas independentes (APÊNDICE A). A deflexão no topo da torre foi calculada considerando as cargas da turbina, cargas do vento, massa distribuída ao longo da torre e uma massa concentrada na parte superior da estrutura representando a massa da turbina.

\subsubsection{Deflexão, análise de vibração livre e efeitos de segunda ordem no ELU}

A resistência característica do material foi minorada e as ações características majoradas, obtendo um deslocamento no topo da torre considerando a seção fissurada de 1708 $\mathrm{mm}$, apresentando uma diferença de $-5,53 \%$ em relação ao resultado de Zyl (2014), que foi $1808 \mathrm{~mm}$. Analisando a magnitude dos efeitos de segunda ordem determinado pelo efeito PDelta, foi obtido uma deflexão no topo da torre igual a $1943 \mathrm{~mm}$ considerando a seção fissurada, apresentando uma diferença de 0,67 \% em relação ao resultado de Zyl (2014), que foi de $1930 \mathrm{~mm}$.

A frequência fundamental é calculada com diferença de $-3,82 \%$ para o elemento de casca sem fundação (Figura 18) e -4,49\% para o elemento de casca com fundação (Figura 19) em relação ao resultado de Zyl (2014), que foi $0,445 \mathrm{~Hz}$, considerando o estado não fissurado do concreto. 
Figura 18 - Modos de vibração considerando o modelo de casca com a base engastada e o concreto armado não fissurado

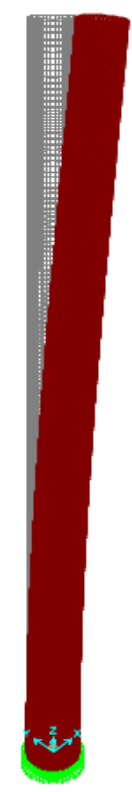

Modo 1: 0,428 Hz

Modo 2: 0,428 Hz

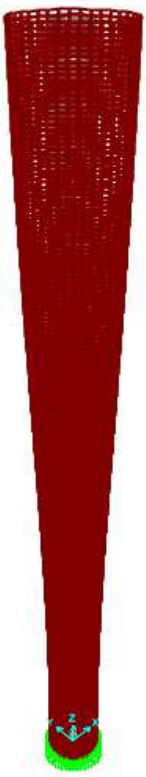

Modo 7: 8,681 Hz

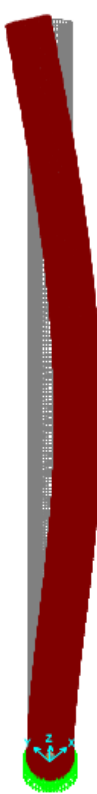

Modo 3: 2,279 Hz

Modo 4: 2,279 Hz

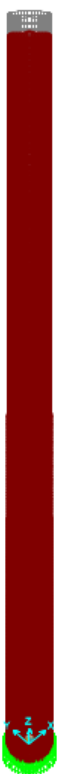

Modo 8: 9,799 Hz

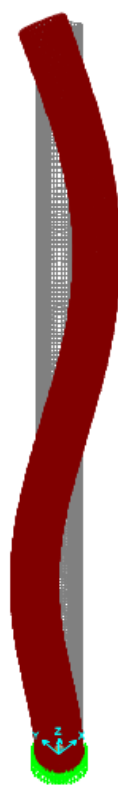

Modo 5: 6,122 Hz

Modo 6: 6,122 Hz

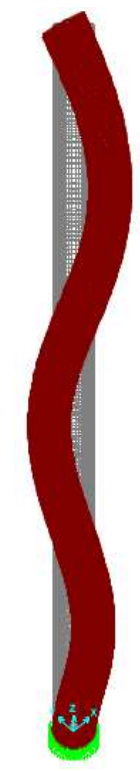

Modo 9: 11,682 Hz

Modo 10: 11,682 Hz

Fonte: Autor 
Figura 19 - Modos de vibração considerando o modelo de casca com a fundação engastada e o concreto armado não fissurado

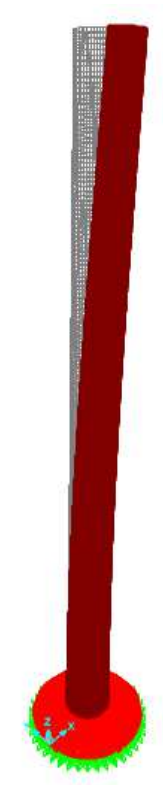

Modo 1: 0,425 Hz

Modo 2: 0,425 Hz

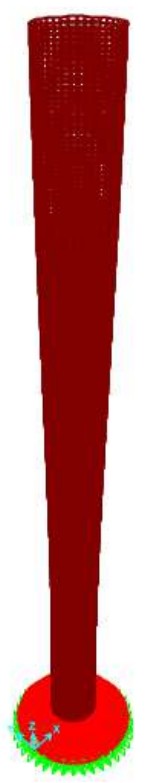

Modo 7: 8,671 Hz

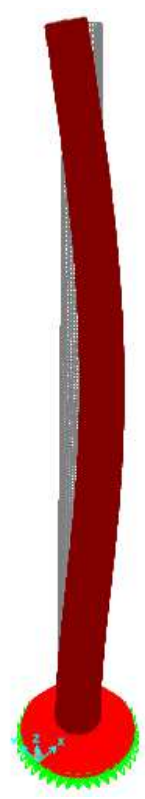

Modo 3: 2,257 Hz

Modo 4: $2,257 \mathrm{~Hz}$

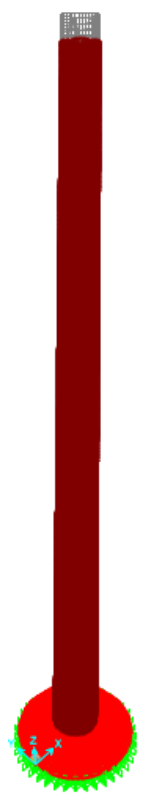

Modo 8: 9,757 Hz

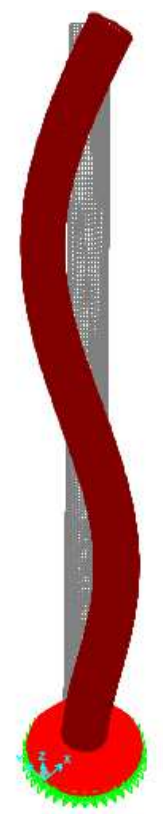

Modo 5: 6,065 Hz

Modo 6: 6,065 Hz

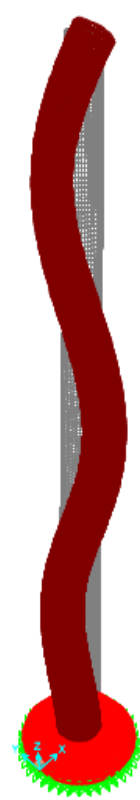

Modo 9: 11,585 Hz

Modo 10: 11,585 Hz

Fonte: Autor 
A Figura 20 apresenta o gráfico da porcentagem da ação do vento $\times$ deslocamento, que foi realizado variando a carga do vento da torre e a carga de turbina induzida pelo vento, sendo aplicada a carga permanente na sua totalidade no início da análise.

Figura 20 - Máxima deflexão em função da carga de vento aplicada no ELU

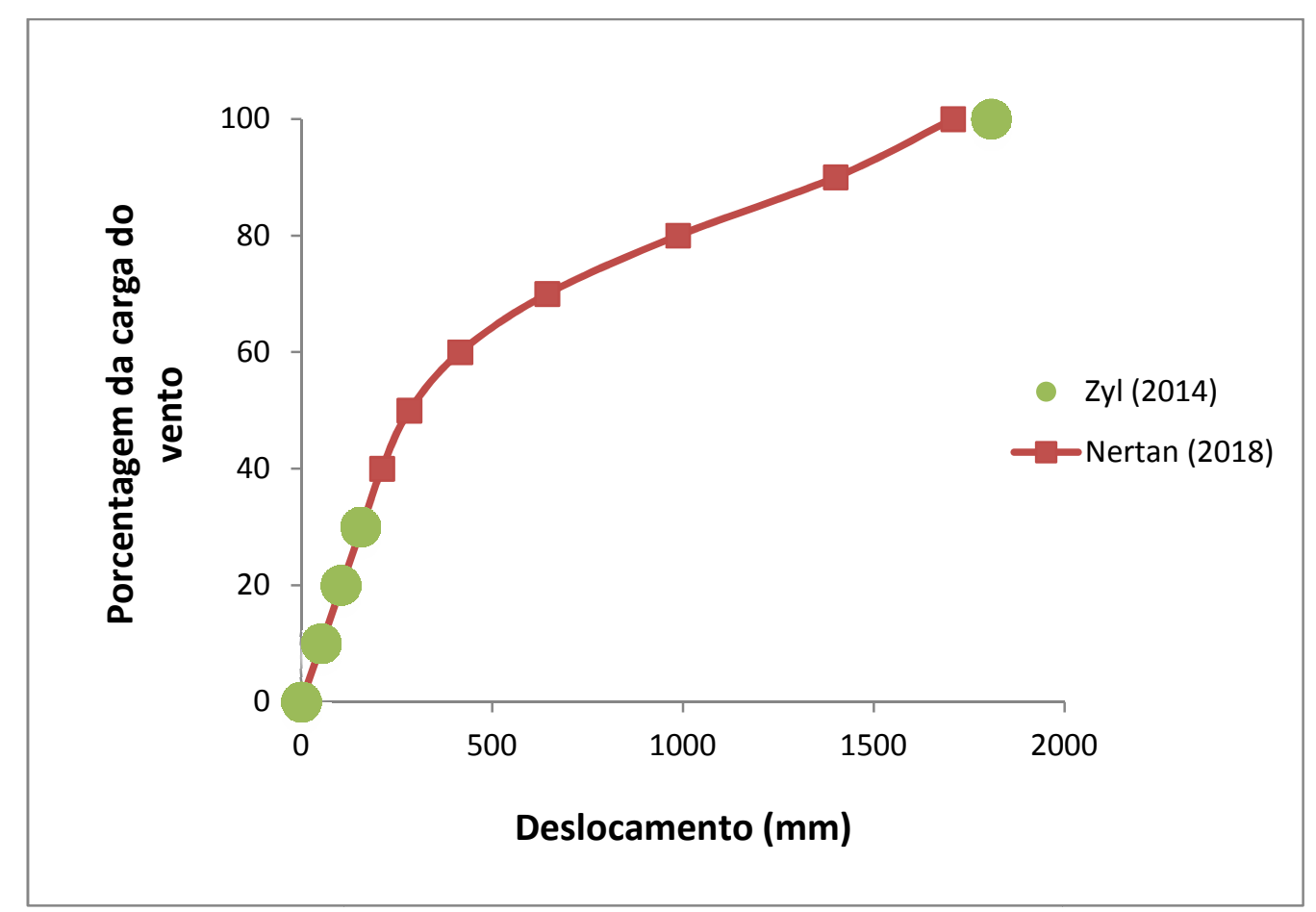

Fonte: Autor

\subsubsection{Deflexão no ELS}

No ELS a resistência característica à compressão do aço foi minorada e as ações adotadas foram $60 \%$ da carga característica extrema, obtendo um deslocamento no topo da torre para $75 \%$ da carga com a seção não fissurada de $157 \mathrm{~mm}$, apresentando uma diferença de -6,55\% quando comparado com o resultado de Zyl (2014), que foi $168 \mathrm{~mm}$ com a seção não fissurada. Entretanto se for aplicado $100 \%$ da carga a deflexão obtida no topo da torre é de $210 \mathrm{~mm}$ com a seção não fissurada, apresentando uma diferença de $-61,75 \%$ quando comparado com o resultado de Zyl (2014), que foi $549 \mathrm{~mm}$ com a seção fissurada.

Através da Figura 21, observa-se que o efeito da não linearidade no SAP2000 somente aparece para um fator de carga acima de 0,77 . Como a carga vai até 0,60 , a resposta é toda linear. Já no programa Diana $(Z y l, 2014)$, a não linearidade aparece para um fator de carga de 0,45. 
Figura 21 - Máxima deflexão em função do fator de carga do vento no ELS

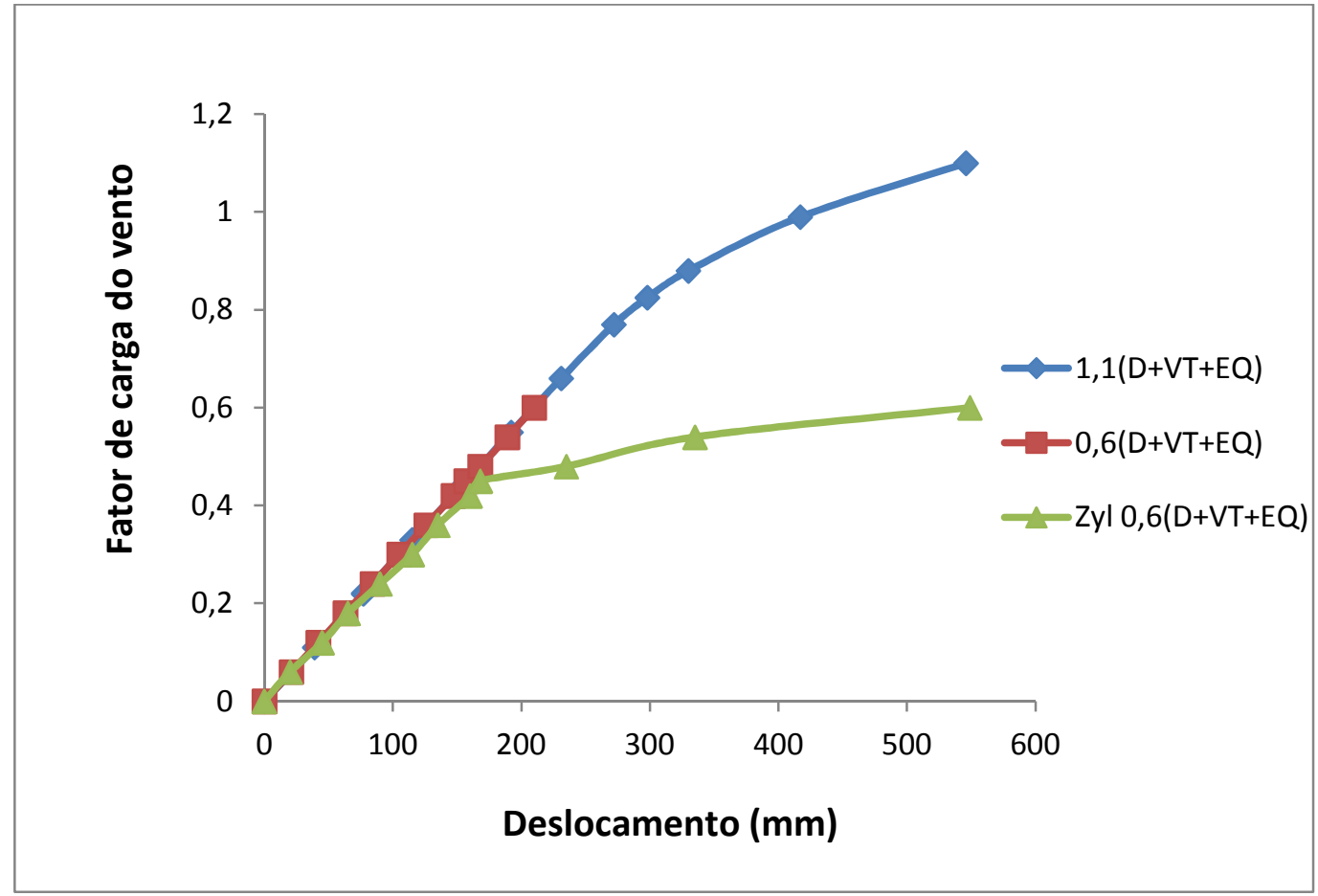

Fonte: Autor 


\section{ANÁLISE PARAMÉTRICA}

Visando avaliar a influência de alguns parâmetros no comportamento da torre, em particular na frequência fundamental e no deslocamento no topo, foram realizadas variações na resistência característica do concreto à compressão, na espessura e no diâmetro externo. Uma vez que os resultados para o elemento de viga foram satisfatórios e objetivando a sua utilização num futuro modelo de otimização, este elemento é usado nas análises. Nas análises executadas a seguir, adotou-se a torre engastada na base e o modelo de Zyl.

\subsection{Variação da resistência característica do concreto à compressão}

A frequência natural da estrutura da torre deve ser tal que atenda as condições especificadas pelo fabricante da turbina, de forma que o seu regime de trabalho seja o ideal (SILVEIRA, 2017). Analisando a Tabela 38 e a Figura 22, observa-se que, variando a resistência do concreto à compressão, as frequências obtidas para a torre com o modelo de Zyl (2014) e o concreto não fissurado se encontram dentro da faixa de frequência de trabalho da turbina que está compreendida entre 0,242 e 0,594. A frequência aumenta com a resistência de forma não linear, mas com uma taxa muito baixa, com um valor médio da ordem de $8 \times 10^{-4}$ $\mathrm{Hz} / \mathrm{MPa}$. Assim, a variação da frequência fundamental da torre devida à variação da resistência do concreto é pequena, quando comparada com a variação de frequência ocasionada pelos diferentes tipos de solos.

Em relação ao deslocamento no topo da torre no estado não fissurado causado pela variação da resistência do concreto, observa-se na Figura 23 que ocorre uma variação não linear. Não é importante o valor do deslocamento do topo da torre, sendo parâmetro determinante a frequência da torre para o bom funcionamento da turbina (SILVEIRA, 2017).

Tabela 38 - Análise paramétrica da frequência da torre engastada de Zyl (2014) no estado não fissurado, em função da resistência do concreto $(\mathrm{Hz})$

\begin{tabular}{ccc}
\hline $\begin{array}{c}\text { Resistência característica do } \\
\text { concreto à compressão }(\mathrm{MPa})\end{array}$ & $\begin{array}{c}\text { Frequência no estado não fissurado } \\
(\mathrm{Hz})\end{array}$ & $\begin{array}{c}\text { Deslocamento no topo da torre no } \\
\text { estado não fissurado (mm) }\end{array}$ \\
\hline 50 & 0,396 & 194 \\
\hline 60 & 0,407 & 184 \\
\hline 70 & 0,416 & 176 \\
\hline 80 & 0,425 & 169 \\
\hline 90 & 0,432 & 163 \\
\hline 100 & 0,439 & 157 \\
\hline 110 & 0,446 & 153 \\
\hline
\end{tabular}

Fonte: Autor 
Figura 22 - Variação da frequência da torre no estado não fissurado com a resistência do concreto

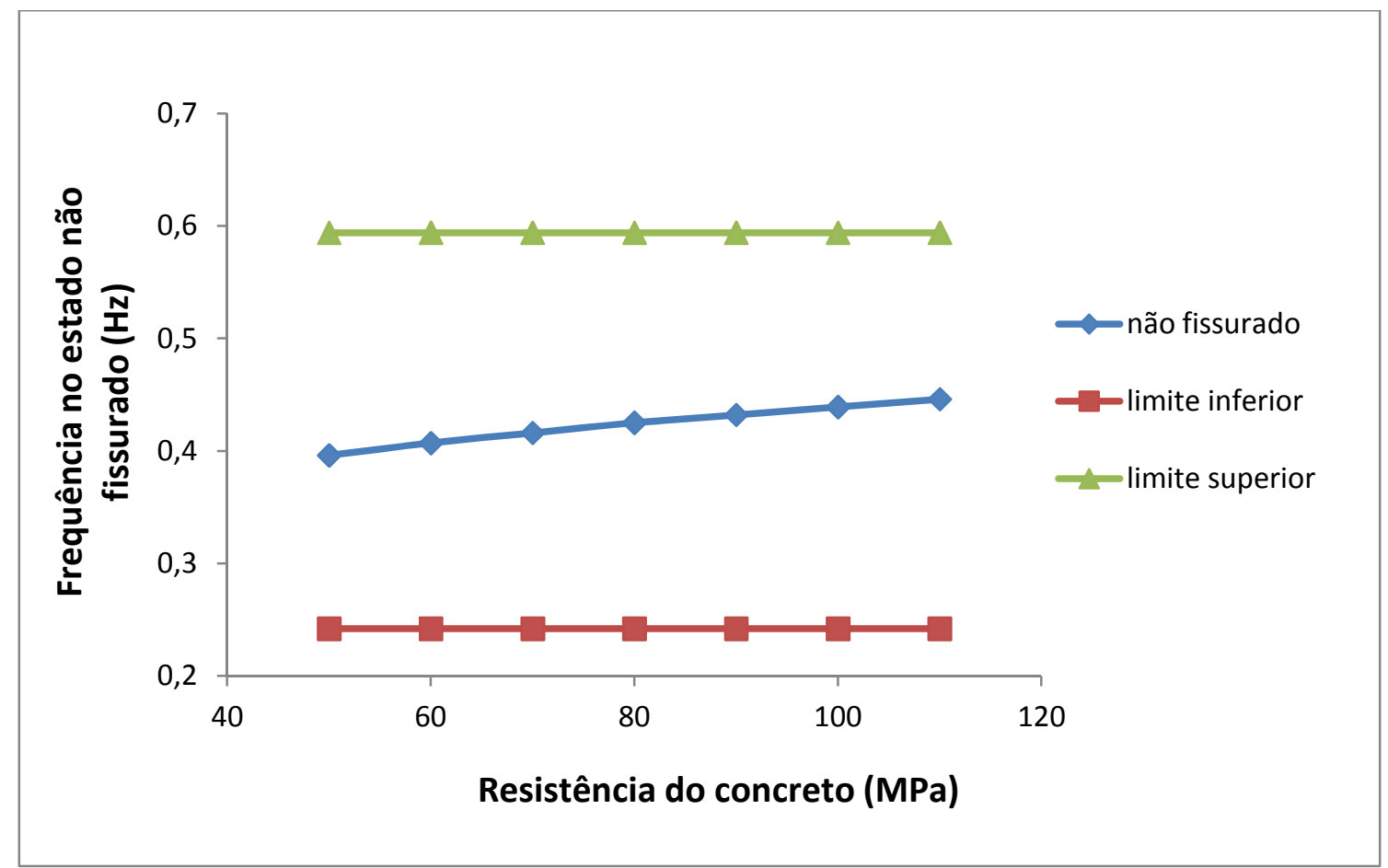

Fonte: Autor

Figura 23 - Variação do deslocamento no topo da torre no estado não fissurado com a resistência do concreto

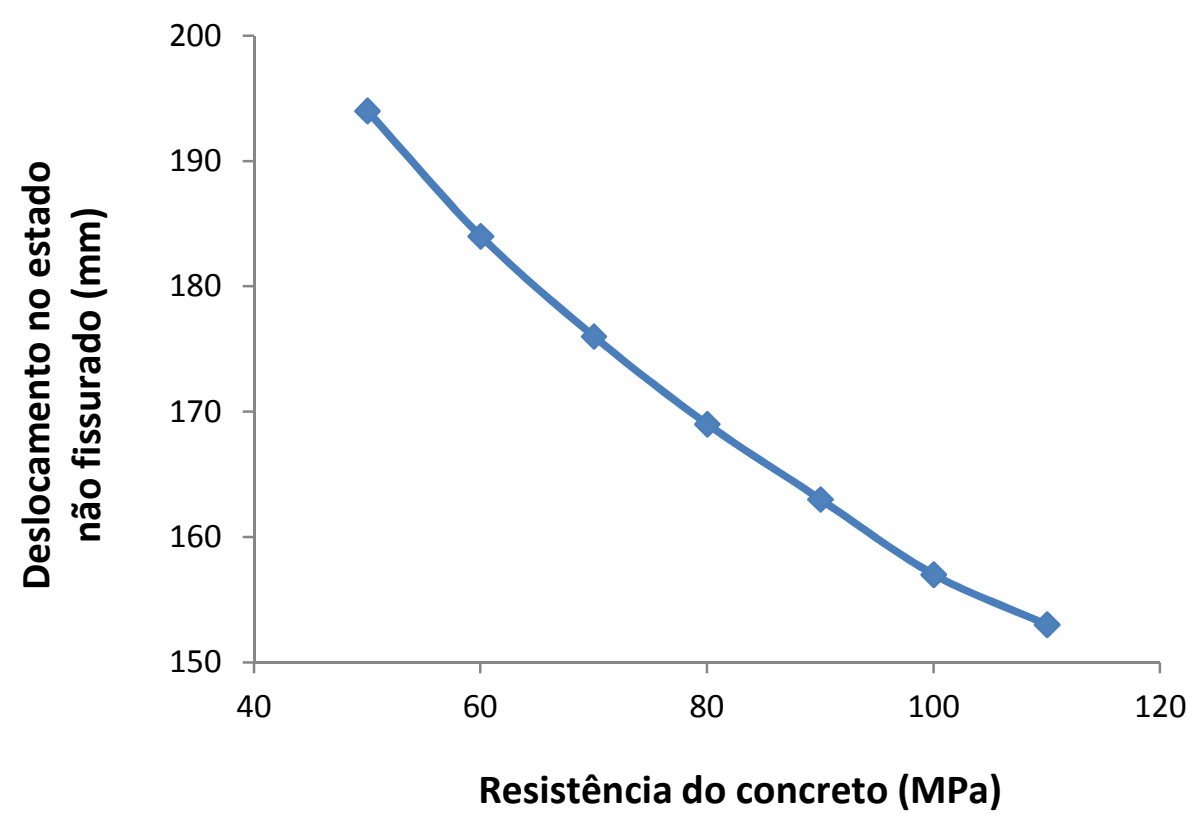

Fonte: Autor 


\subsection{Variação da espessura}

A análise paramétrica foi modelada considerando constantes os diâmetros externos na base e no topo da torre de Zyl (2014) e a espessura da parede no topo da torre, variando a espessura da parede na base da torre e mantido o formato tronco de cone com variação linear da geometria. Analisando a Tabela 39 e Figura 24, observa-se que as frequências obtidas para o modelo de Zyl variando a espessura se encontram dentro da frequência de trabalho da turbina que está compreendido entre 0,242 e 0,594. Em relação a deflexão obtida (Figura 25), as mesmas excedem a deflexão lateral máxima prescrita pelo American Concrete Institute (ACI) 307-98, que é $333 \mathrm{~mm}$ para o ELS, quando se considera $100 \%$ da carga e a rigidez de $0,41 E c$.

A frequência fundamental da torre devido a variação da espessura da parede apresenta diferença de até $8 \%$ no estado não fissurado e de até 7,72\% no estado fissurado quando comparado com os resultados do modelo de viga da torre de $\mathrm{Zyl}$, em relação aos deslocamentos apresenta diferença de até $20,62 \%$.

Tabela 39 - Análise paramétrica da torre de acordo com o modelo de Zyl (2014) com a base engastada considerando a variação da espessura da parede

\begin{tabular}{cccc}
\hline Espessura da parede $(\mathrm{cm})$ & $\begin{array}{c}\text { Frequência no estado não } \\
\text { fissurado }(\mathrm{Hz})\end{array}$ & $\begin{array}{c}\text { Frequência no estado } \\
\text { fissurado }(\mathrm{Hz})\end{array}$ & $\begin{array}{c}\text { Deslocamento no topo da } \\
\text { torre }(\mathrm{mm})\end{array}$ \\
\hline 30 & 0,391 & 0,251 & 661 \\
\hline 32,5 & 0,401 & 0,257 & 527 \\
\hline 35 & 0,409 & 0,262 & 571 \\
\hline 37,5 & 0,417 & 0,267 & 548 \\
\hline 40 & 0,425 & 0,272 & 527 \\
\hline 42,5 & 0,432 & 0,276 & 509 \\
\hline 50 & 0,438 & 0,280 & 492 \\
\hline
\end{tabular}

Fonte: Autor 
Figura 24 - Variação da frequência da torre com a espessura da parede

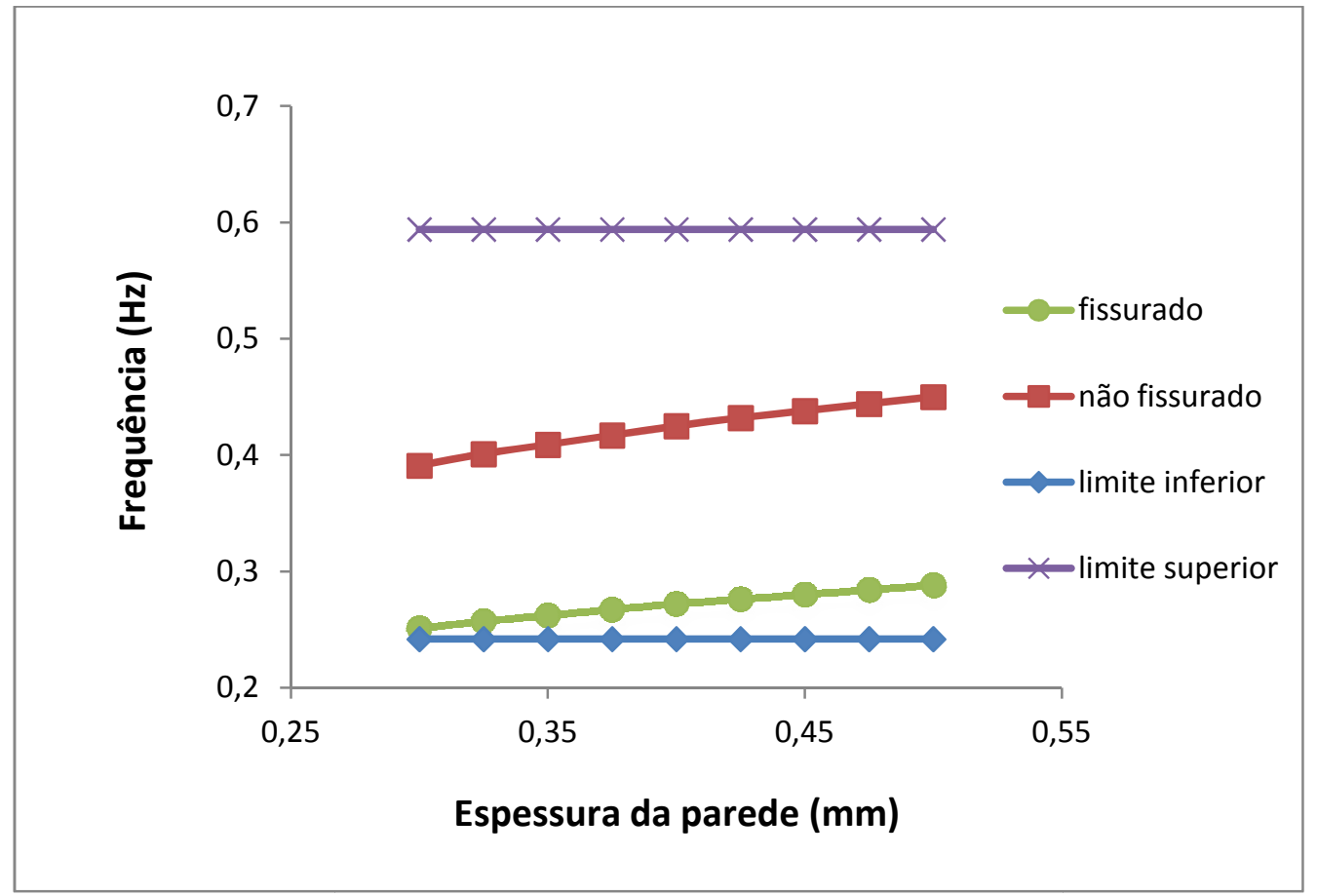

Fonte: Autor

Figura 25 - Variação do deslocamento no topo da torre no estado fissurado com a espessura da parede

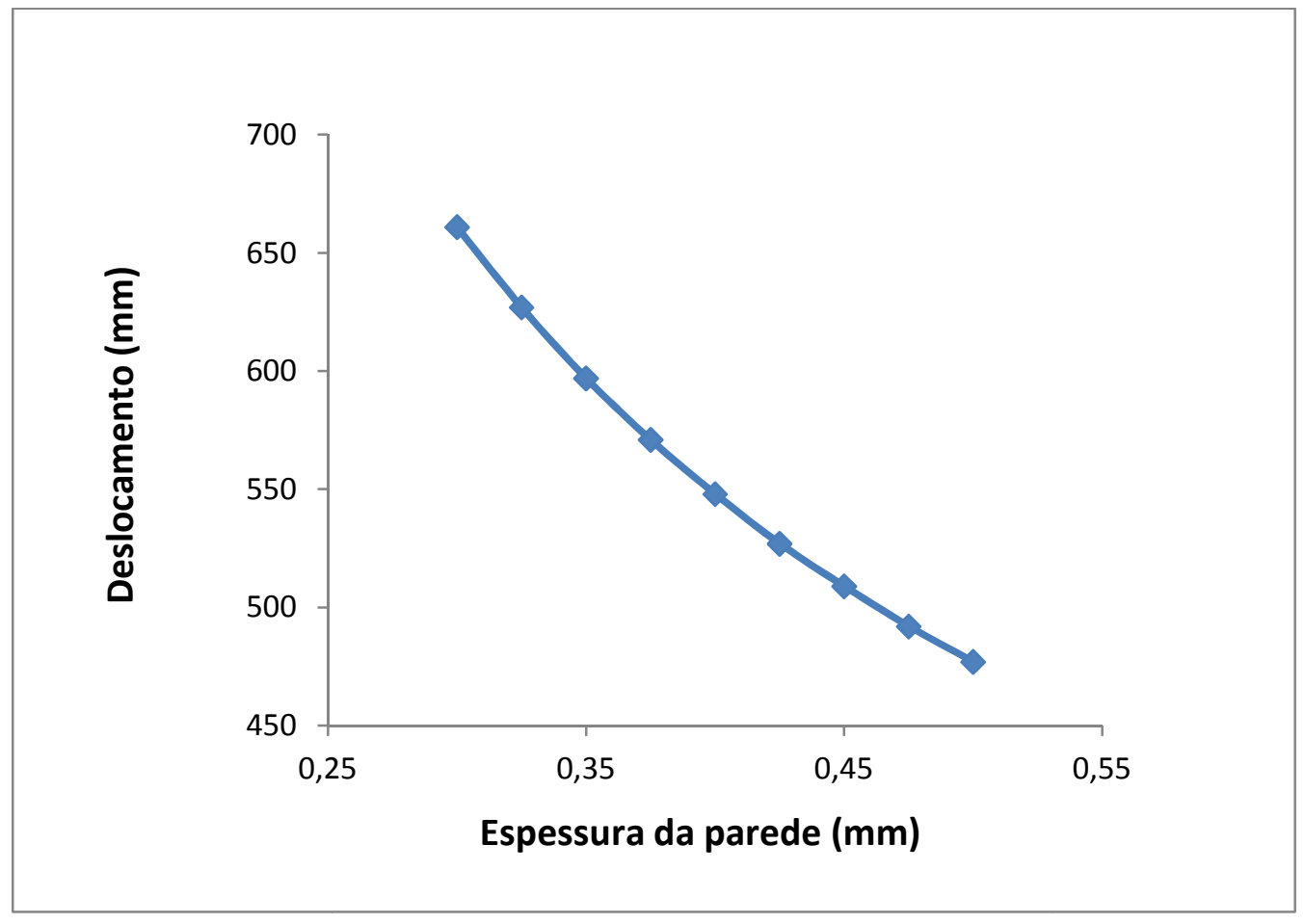

Fonte: Autor 


\subsection{Variação do diâmetro externo}

A análise paramétrica foi modelada considerando constante o diâmetro externo no topo da torre e a espessura da parede ao logo da torre, variando o diâmetro inferior externo e interno e os diâmetros intermediários linearmente com a altura.

Analisando a Tabela 40 e Figura 26, observa-se que as frequências obtidas para a torre variando o diâmetro externo não se encontram dentro da frequência de trabalho da turbina que está compreendido entre 0,242 e 0,594 para os diâmetros externos de 5600 e 6100mm. Em relação a deflexão obtida (Figura 27), as mesmas excedem a deflexão lateral máxima prescrita pelo ACI 307-98, que é $333 \mathrm{~mm}$ para o ELS, quando se considera $100 \%$ da carga e a rigidez de $0,41 E c$.

A frequência fundamental da torre devido a variação do diâmetro externo apresenta diferença de até $25,88 \%$ no estado não fissurado e de até $25,74 \%$ no estado fissurado quando comparado com os resultados do modelo de viga de Zyl, em relação aos deslocamentos apresenta diferença de até 77,00\%.

Tabela 40 - Análise paramétrica da torre de acordo com o modelo de Zyl (2014) com a base engastada considerando a variação do diâmetro externo

\begin{tabular}{cccc}
\hline $\begin{array}{c}\text { Diâmetro inferior externo } \\
(\mathrm{mm})\end{array}$ & $\begin{array}{c}\text { Frequência no estado não } \\
\text { fissurado }(\mathrm{Hz})\end{array}$ & $\begin{array}{c}\text { Frequência no estado } \\
\text { fissurado (Hz) }\end{array}$ & $\begin{array}{c}\text { Deslocamento no topo da } \\
\text { torre }(\mathrm{mm})\end{array}$ \\
\hline 5600 & 0,319 & 0,204 & 970 \\
\hline 6100 & 0,353 & 0,226 & 653 \\
\hline 6600 & 0,389 & 0,249 & 548 \\
\hline 7100 & 0,425 & 0,272 & 465 \\
\hline 7600 & 0,461 & 0,295 & 399 \\
\hline 8100 & 0,498 & 0,319 & 346
\end{tabular}

Fonte: Autor 
Figura 26 - Variação da frequência da torre com o diâmetro externo

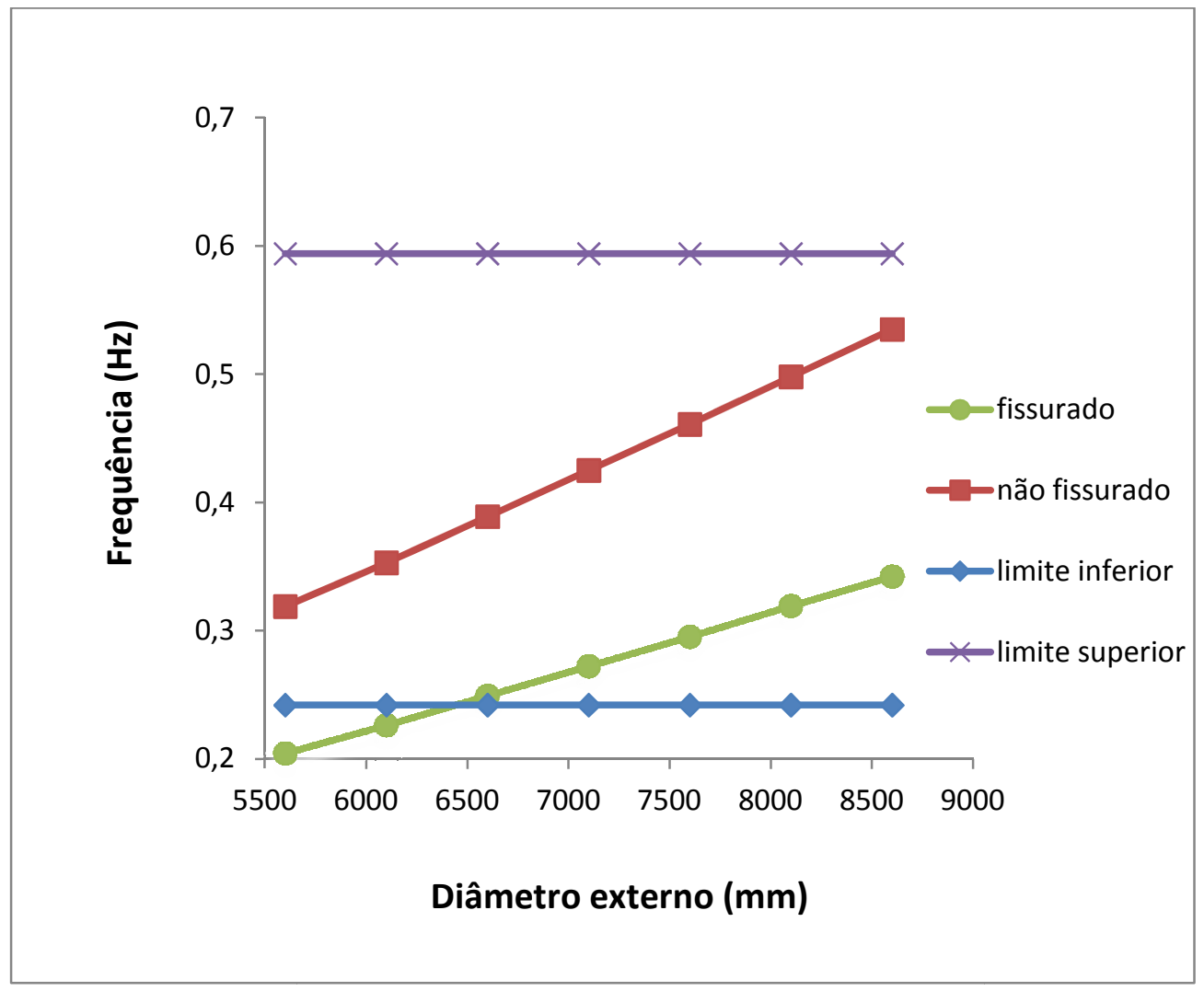

Fonte: Autor

Figura 27 - Variação do deslocamento no topo da torre no estado fissurado com o diâmetro externo

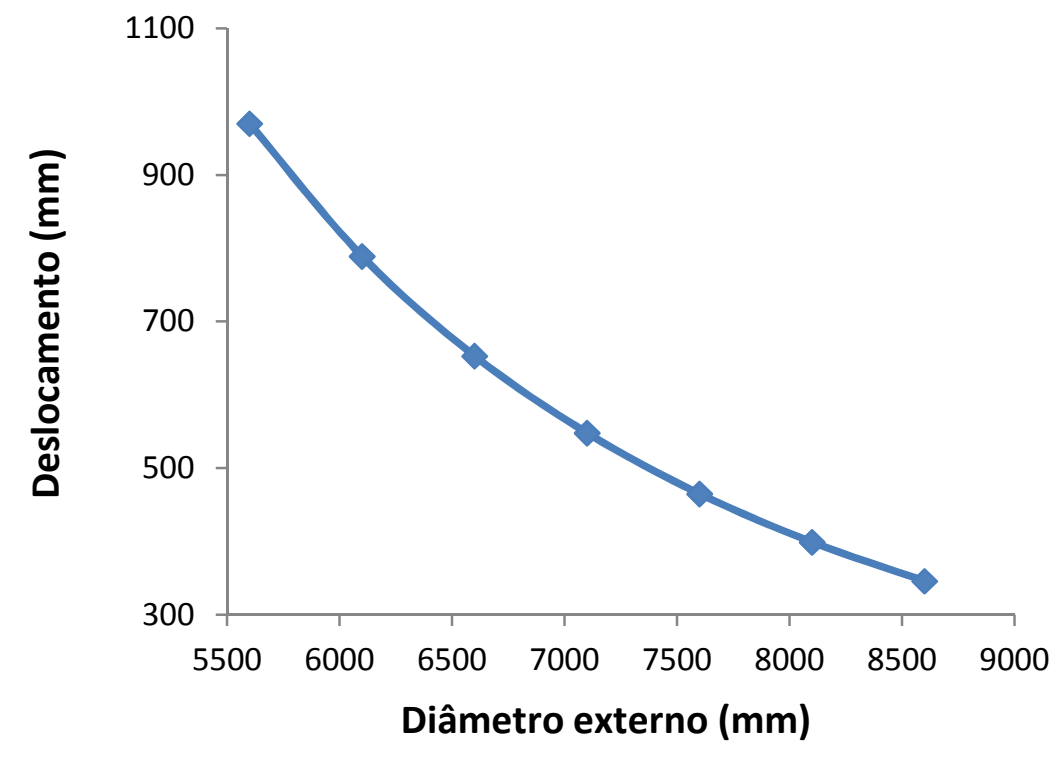

Fonte: Autor 


\section{COMENTÁRIOS FINAIS}

A torre eólica analisada neste trabalho através do programa de análise estrutural SAP2000 possui $100 \mathrm{~m}$ de altura com uma turbina de 3,6 MW, cujas ações foram obtidas da literatura e os resultados validados com modelo da literatura. Os modelos de análise foram comparados através dos métodos dos elementos finitos com consideração dos elementos finitos unidimensionais e bidimensionais. A modelagem da ação do vento ao longo da torre foi tratada como estática. Foram avaliadas as influências de não linearidades física e geométrica, interação solo-estrutura e o seu efeito nos deslocamentos e nas frequências naturais da torre.

Os resultados indicam que o modelo de viga é promissor para a sua utilização em um modelo de otimização de projeto preliminar de torres de concreto armado, apresentando valores para o modelo de viga em relação ao modelo de casca com diferença menor que $6 \%$. A não linearidade geométrica pode ser representada pelo efeito P-delta e a do material pela redução da rigidez. Por ser mais simples, a sua utilização não tornará a otimização tão onerosa computacionalmente. Obviamente que a solução obtida deverá ser avaliada com um modelo mais refinado de análise. Os elementos de casca também produziram resultados satisfatórios, mas apresentam um custo computacional mais elevado.

$\mathrm{Na}$ otimização usando algoritmos bio-inspirados, como os algoritmos genéticos, muitas análises são necessárias. O uso de um modelo mais simples de análise pode ser útil e evitaria a necessidade de utilização de modelos substitutos.

A interação solo-estrutura mostrou-se importante para a avaliação da frequência fundamental da torre analisada, assim como o tipo de solo. A frequência sofre uma redução significativa quando a interação solo-estrutura é considerada por meio de molas no elemento de viga, considerando o modelo de Zyl, chegando a reduções entre 6,59\% e 52,94\% para o ELU e $6,59 \%$ e $48,24 \%$ para o ELS, dependendo do tipo de solo. Na prática, este problema pode ser amenizado fazendo-se tratamentos no solo e alerta-se para a importância do estudo geotécnico para estimativa da rigidez do solo. Já a incorporação da fundação no modelo, considando-a engastada no solo, não produziu efeitos significativos.

Outro aspecto de igual importância é o efeito da fissuração do concreto na rigidez e, consequentemente, nas frequências. Este efeito foi representado considerando-se a rigidez secante do material, resultando em reduções drásticas do módulo de elasticidade de $31 \%$ e $41 \%$ do valor original para, respectivamente, o ELU e ELS. 
$\mathrm{Na}$ análise paramétrica, a variação da resistência do concreto mostra que ocorre pequena variação na frequência da torre no estado não fissurado, a variação da espessura da parede mostra que ocorre grande variação nos deslocamentos, em relação a variação do diâmetro externo os resultados mostram que ocorre grande variação na frequência da torre e nos deslocamentos.

Deixamos como sugestões para continuidade do desenvolvimento deste estudo identificar as cargas reais da trubina e realizar uma análise de fadiga da torre e aplicação do modelo de viga para formulação de um modelo de otimização da torre. 


\section{REFERÊNCIAS}

[AEROGERADOR de eixo vertical e horizontal]. In: Sustentabilidade e novas tendências, 2012. 1 fotografia, $279 \times 256$ pixels, $12 \mathrm{~KB}$, formato jpeg. Disponível em: https://axionconstrucoes.files.wordpress.com/2012/10/eixo-vert-x-horiz.jpeg. Acesso em: 14 ago. 2017.

AMERICAN CONCRETE INSTITUTE. Design and Construction of Reinforced Concrete Chimneys (ACI 307-98). [S.l.]: American Concrete Institute, 1998. Disponível em: http://www.uomisan.edu.iq/library/admin/book/14810811029.pdf. Acesso em: 03 abr. 2018.

AMERICAN SOCIETY OF CIVIL ENGINEERS. Minimum Design Loads for Buildings and Other Structures. [S.l.]: American Society of Civil Engineers, 2010. Disponível em: https://cedb.asce.org/CEDBsearch/record.jsp?dockey=0263505. Acesso em: 13 maio. 2018.

ASSOCIAÇÃO BRASILEIRA DE NORMAS TÉCNICAS. ABNT NBR 6118: projeto de estruturas de concreto - procedimento. Rio de Janeiro: ABNT, 2014.

ASSOCIAÇÃO BRASILEIRA DE NORMAS TÉCNICAS. ABNT NBR 6123: forças devido ao vento em edificações. Rio de Janeiro: ABNT, 1988.

BLESSMANN, J. Ação do vento em edifícios. 2. ed. Porto Alegre: UFRS, 1989.

BLESSMANN, J. Aerodinâmica das construções. Porto Alegre: UFRS, 1983.

BRASIL sobe no ranking mundial de capacidade instalada de energia eólica. Revista Ecoturismo, Santos, fev. 2017. Disponível em:

http://revistaecoturismo.com.br/turismo-sustentabilidade/brasil-sobe-no-rankingmundial-de-capacidade-instalada-de-energia-eolica/. Acesso em 06 maio 2017.

BRASIL, R. M. L. R. F.; PAULETTI, R. M. O.; CARRIL JÚNIOR, C. F.; LAZANHA, E. C. Efeito do vento sobre uma torre de telecomunicações em concreto pré-moldado. In: SIMPÓSIO EPUSP SOBRE ESTRUTURAS DE CONCRETO, 5. 2003. São Paulo. Anais [...] São Paulo: USP, 2003. p. 1 - 16. Disponível em:

http://www.lmc.ep.usp.br/people/pauletti/Publicacoes_arquivos/SIMP67-

Efeito\%20do\%20Vento.pdf. Acesso em: 27 maio 2018.

BRASIL, R. M. L. R. F.; SILVA, M. S. P. Análise dinâmica não-linear de torres em concreto armado submetidas ao vento sintético. Revista Interdisciplinar de pesquisa em engenharia - RIPE, Brasília, v. 2, n. 22, p. 1-16, 2016. Disponível em: http://periodicos.unb.br/index.php/ripe/article/view/20869/19239. Acesso em: 13 jun. 2018.

CHASTRE, C.; LÚCIO, V. Evolução histórica, desenvolvimento atual e potencial futuro das torres de concreto pré-moldado para suporte de aerogeradores. Concreto e Construções, [S.l.], v. 42, n. 75, p. 24-34, jul.-set. 2014. 
Berkeley: [s.n.], 2005.

DNV; RISO. Guidelines for the design of wind turbines. 2 nd ed. Denmark: Det Norske Veritas, Riso National Laboratory. 2002. 294p.

DUARTE, E. P. Evolução das torres eólicas pré-moldadas protendidas. Concreto e Construções, [S.l.], v. 42, n.75, p. 36-41, jul.-set. 2014.

ENERGIAS RENOVÁVEIS. Componentes de um aerogerador.

Apeneregiasrenovaveis, 2017. Disponível em:

https://apenergiasrenovaveis.wordpress.com/eolica/componentes-de-um-aerogerador/. Acesso em 06 maio 2017.

FEIJÓ, B. P. Otimização de torres de aço para geradores eólicos. $2010.85 \mathrm{f}$.

Dissertação (Mestrado em Engenharia Civil: Estruturas e Construção Civil)- Centro de Tecnologia, Universidade Federal do Ceará, Fortaleza, 2010.

FRANCO, M. Direct along-wind dynamic analysis of tall structures. Boletim Técnico da Escola Politécnica da Universidade de São Paulo BT/PEF/9303, São Paulo, 1993.

GAMA, P. V. C. N. Contribuições ao dimensionamento de torres eólicas de concreto. 2015. 231 f. Dissertação (Mestrado em Engenharia Civil)- Universidade de São Paulo, São Paulo, 2015.

GAZETAS, G. Analysis of machine foundation vibrations: state of the art. Journal of Soil Dynamics and Earthquake Engineering, [S.l.], v.2, n.1, p. 2-42, 1983.

GLOBAL WIND REPORT. Annual Market update 2013. [S.l.]: Gwec, 2013. Disponível em: http://www.gwec.net/wp-content/uploads/2014/04/GWEC-GlobalWind-Report_9-April-2014.pdf. Acesso em: 21 ago. 2017.

GLOBAL WIND REPORT. Annual Market update 2017. [S.l.]: Gwec, 2017.

HAU, E. Wind Turbines: fundamentals, technologies, application, economics. 3 nd ed. Springer, 2013.

INTERNATIONAL ELECTROTECHNICAL COMMISSION. IEC 61400-1: Wind turbines - part 1: design requirements. Genebra: IEC, 2005. Disponível em: https://www.saiglobal.com/pdftemp/previews/osh/iec/iec61000/61400/iec614001\%7Bed3.0\%7Den.pdf. Acesso em: 4 abr. 2017.

INTERNATIONAL FEDERATION FOR STRUCTURAL CONCRETE. Model Code 2010: final draft. CEB-FIB, Switzerland, bulletin 95, v. 1, p. 1-357, 2010.

JAMMES, F. X. Design of wind turbines with Ultra-High Performance Concrete. Massachusetts Institute of Technology, 2009. Disponível em: http://hdl.handle.net/1721.1/51574. Acesso em: 11 set. 2017.

LANIER, M. V. LWST Phase I Project Conceptual Design Study: Evaluation of 
Design and Construction Approaches for Economical Hybrid Steel/Concrete Wind Turbine Towers. Washington: National REnewable Energy Laboratory, 2005.

LEWIN, T. J. An Investigation of design alternatives for 328-ft (100-m) tall wind turbine towers. 2010. 193 f. Dissertação (Mestrado em Engenharia Civil) — Iowa State University, Ames, 2010. Disponível em:

https://lib.dr.iastate.edu/cgi/viewcontent.cgi?article=3262\&context=etd. Acesso em: 28 set. 2017.

LIMA, J. B. C. A. Contribuições para otimização estrutural de torres tubulares de aço para turbinas eólicas. 2011. 150 f. Dissertação (Mestrado em Engenharia Civil: Estruturas e Construção Civil)- Centro de Tecnologia, Universidade Federal do Ceará, Fortaleza, 2011.

MCCORMAC, C. J.; BROWN, H. R. Design of Reinforced Concrete. 9 th ed. Hoboken: [s.n], 2014.

NASCIMENTO, L. Brasil é o oitavo país do mundo em produção de energia eólica. Agência Brasil, Brasília, fev. 2018, não paginado. Disponível em:

http://agenciabrasil.ebc.com.br/economia/noticia/2018-02/brasil-e-o-oitavo-pais-domundo-em-producao-de-energia-eolica. Acesso em: 14 dez. 2018.

PINI. Construção Mercado: Negócio de Incorporação e Construção. Revista Construção Mercado, São Paulo, n. 163, p. 54-56, fev., 2015.

PROTENDIDOS DYWIDAG LTDA. [Painéis curvos de concreto]. 1 fotografia, 232 $\times 130$ pixels, $147 \mathrm{~KB}$, formato jpeg. Disponível em:

https://www.dywidag.com.br/projetos/2014-info-22/rapido-e-eficiente-tendoes-wireex-para-novos-parques-eolicos-no-rio-grande-do-norte-brasil/. Acesso em: 14 maio. 2018.

SANS 10100-1. The structural use of concrete - Part 1: Design. [S.l.]: South African National Standards: SABS, 2000.

SANS 10160-3. Basis of structural design and actions for buildings and industrial structures Part 3: Wind actions. [S.l.]: SABS, 2011.

SILVEIRA, M. C. A. Torres eólicas em concreto. Revista da Academia Cearense de Engenharia, Fortaleza, v. 2, n. 2, p. 152 - 161, 2017.

SISTEMA NACIONAL DE PESQUISA DE CUSTOS E ÍNDICES DA CONSTRUÇÃO CIVIL. Caixa Econômica Federal. Sinapi, 2014. Disponível em: http://www.caixa.gov.br/poder-publico/apoio-poderpublico/sinapi/Paginas/default.aspx. Acesso em: 07 nov. 2017.

SOUSA, J. R. Um modelo refinado para a otimização de torres de aço de turbinas eólicas. 2016. 82 f. Monografia (Bacharelado em Engenharia Civil) - Universidade Federal do Ceará. Fortaleza, 2016.

THE NETHERLANDS ORGANISATION. Diana's user manual. In: THE 
NETHERLANDS ORGANISATION. Element Library. [S.l.]: Netherlands Organisation, 2012.

ZYL, W. S. V. Concrete Wind turbine towers in Southern Africa. 2014. 129 f. Dissertação (Mestrado em Engenharia Civil)- Stellenbosch University, Stellenbosch, 2014. 


\section{APÊNDICE A - MANUAL DE UTILIZAÇÃO DE ELEMENTOS SHELL NO SOFTWARE SAP2000}

No presente apêndice é apresentado um manual de utilização de elementos Shell no software SAP2000.

\section{Propriedades dos materiais}

Para definir as propriedades do concreto e do aço é necessário seguir os seguintes passos pela ordem indicada:

1. Primeiro ir no menu Define $\rightarrow$ Material $\rightarrow$ Add New Material.

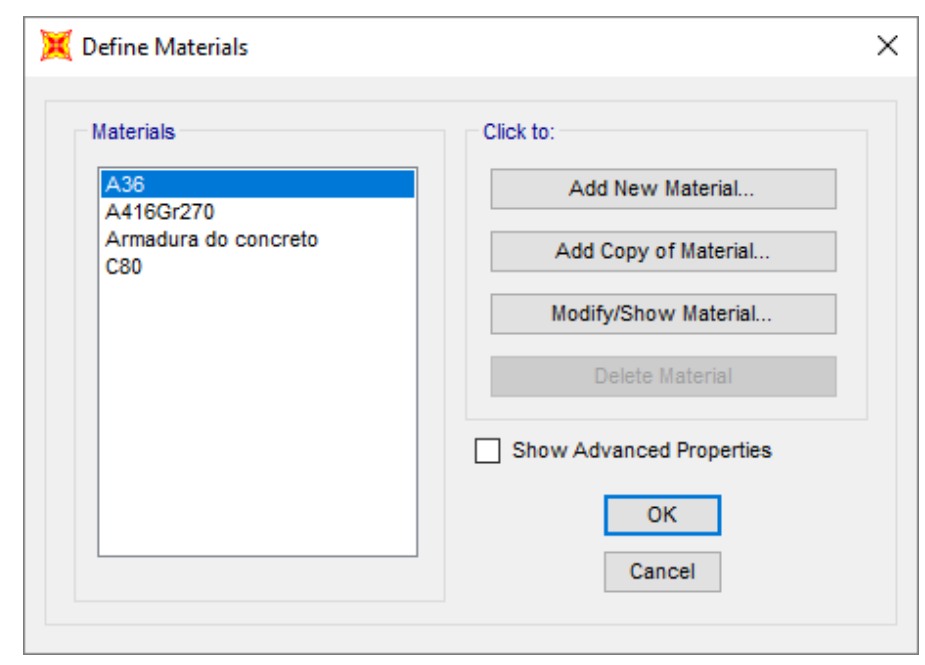

2. Em seguida adiciona as propriedades do material escolhendo o Material Type Concrete ou Rebar.

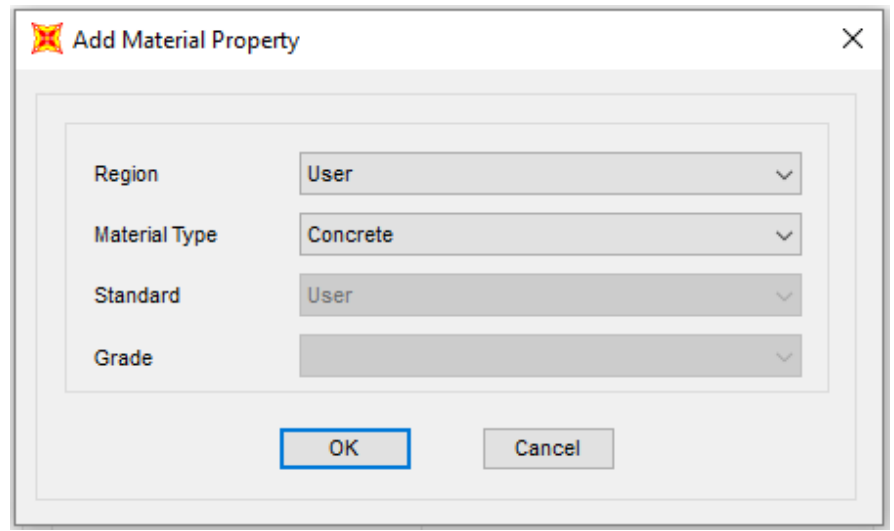


3. No menu seguinte dar um nome ao material em Material Name $\rightarrow$ na opção Directional Symmetry Type escolher Isotropic ou Uniaxial $\rightarrow$ Modify/Show Material Properties.

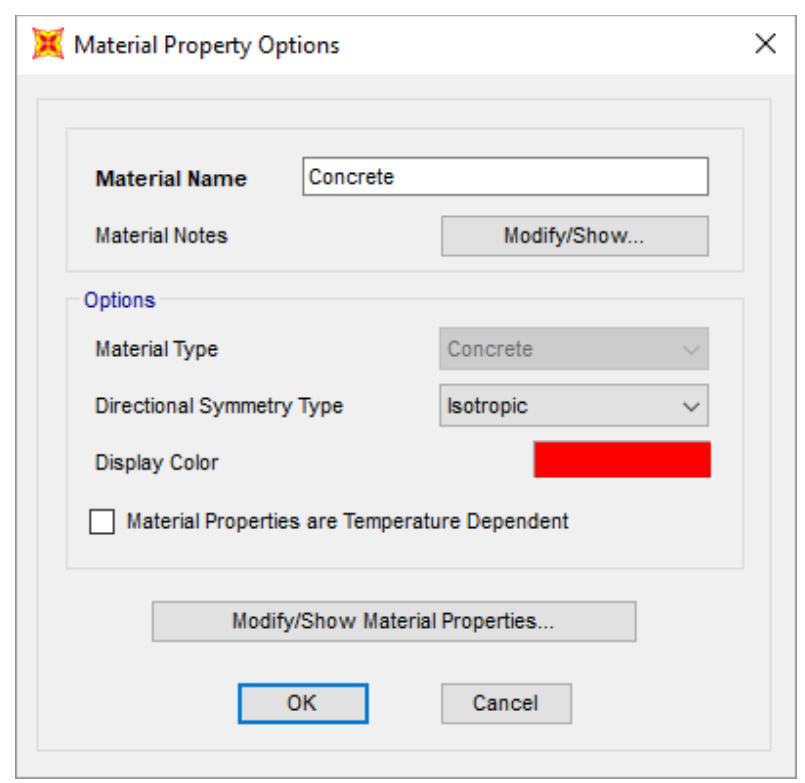

4. Em seguida alterar o valor Weight per Unit Volume (Peso Volumétrico) $\rightarrow$ alterar o Poisson's Ratio (coeficiente de Poisson) $\rightarrow$ escolher Nonlinear Material Data.

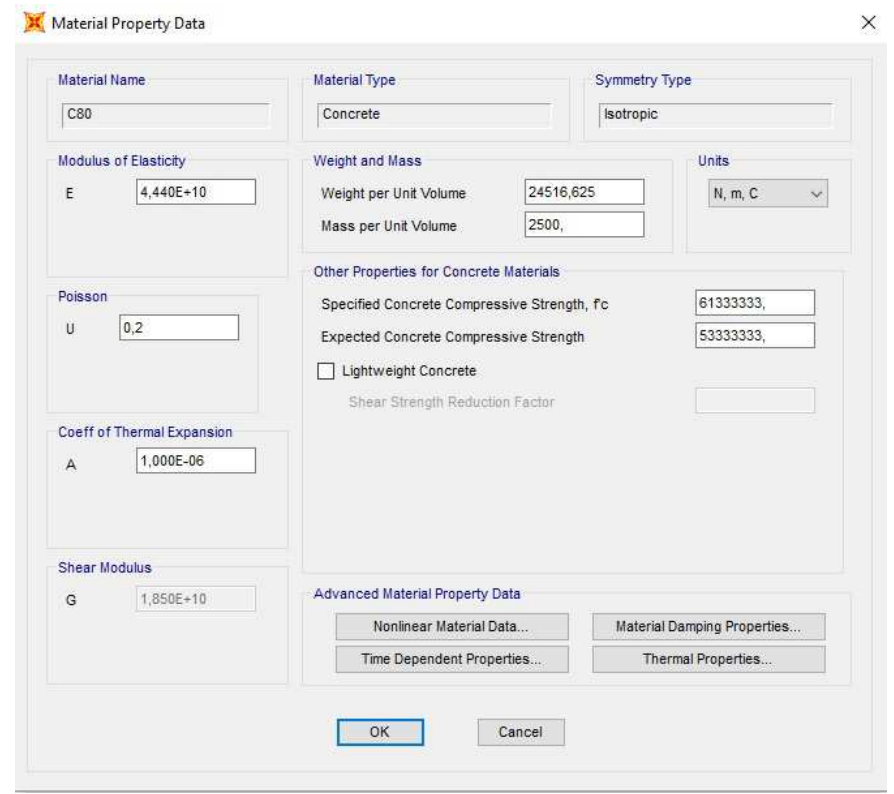

5. No menu seguinte do programa escolher o tipo de User Stress-Strain Curve Definition Options e escolher User Defined $\rightarrow$ definir o número de pontos que o gráfico 
tensão-deformação tem em Number of Points in Stress-Strain Curve $\rightarrow$ Inserir os pontos para definir a curva.

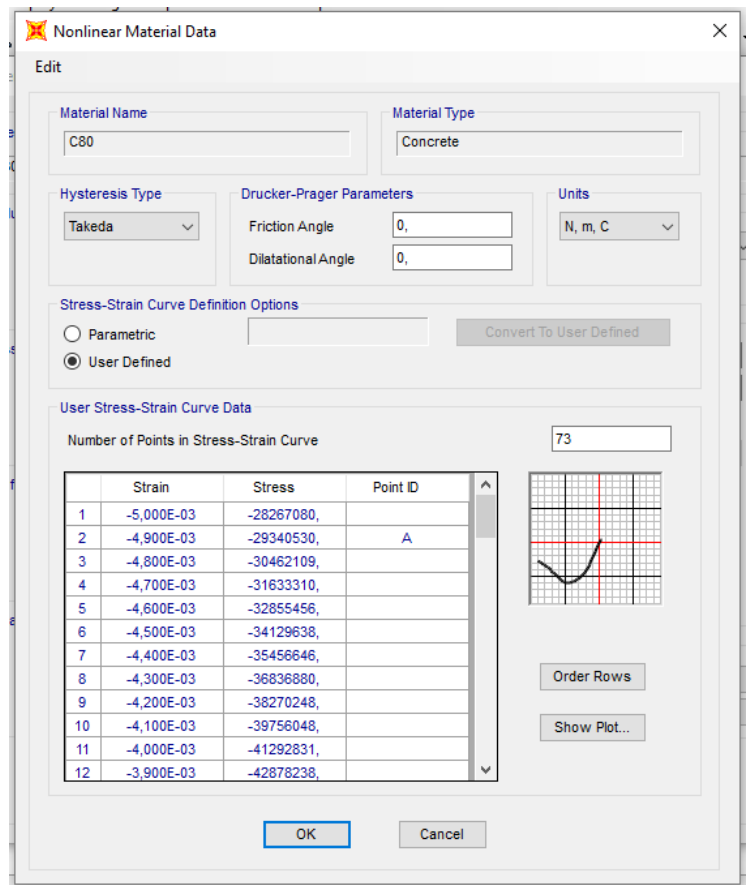

\section{Definição das cargas}

Para definir as cargas a aplicar é necessário seguir os seguintes passos:

1. No menu Define $\rightarrow$ Load Pattern $\rightarrow$ Escolher um nome para cada carga a ser aplicada (peso próprio, carga do vento e cargas da turbina).

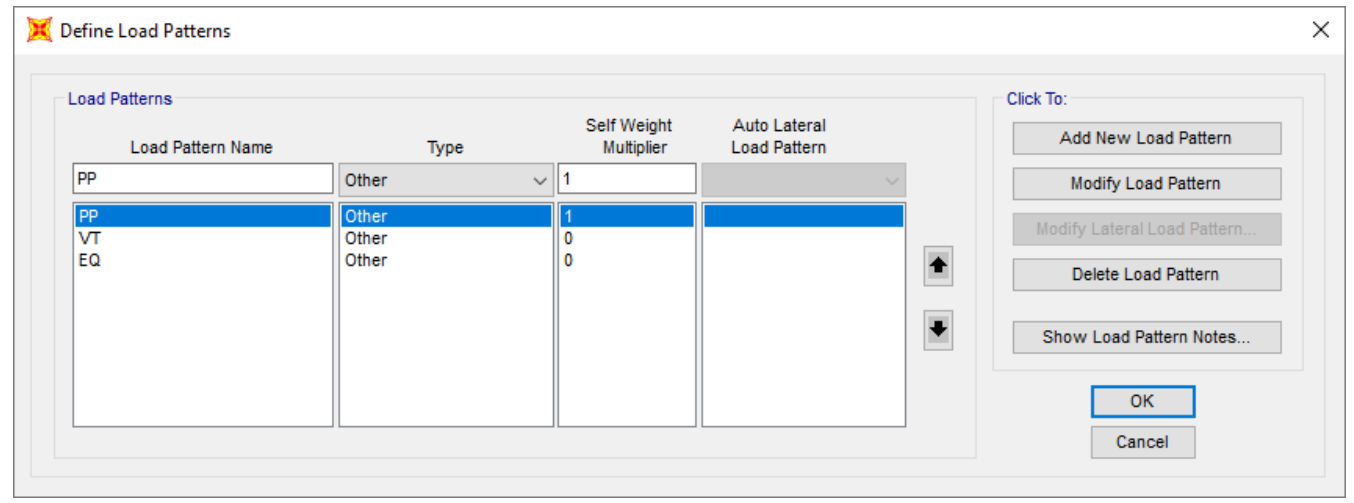

2. Em seguida é necessário definir a combinação de carga para que o programa faça uma análise não linear. Através do menu Define $\rightarrow$ Load Cases $\rightarrow$ Add New Load Case. 


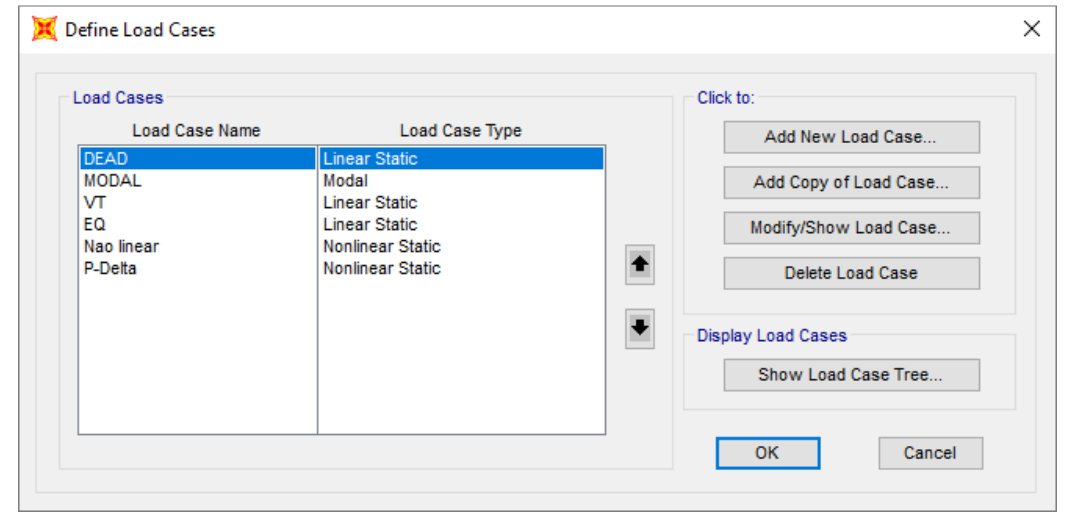

3. Escolher a Analysis Type como Nonlinear.

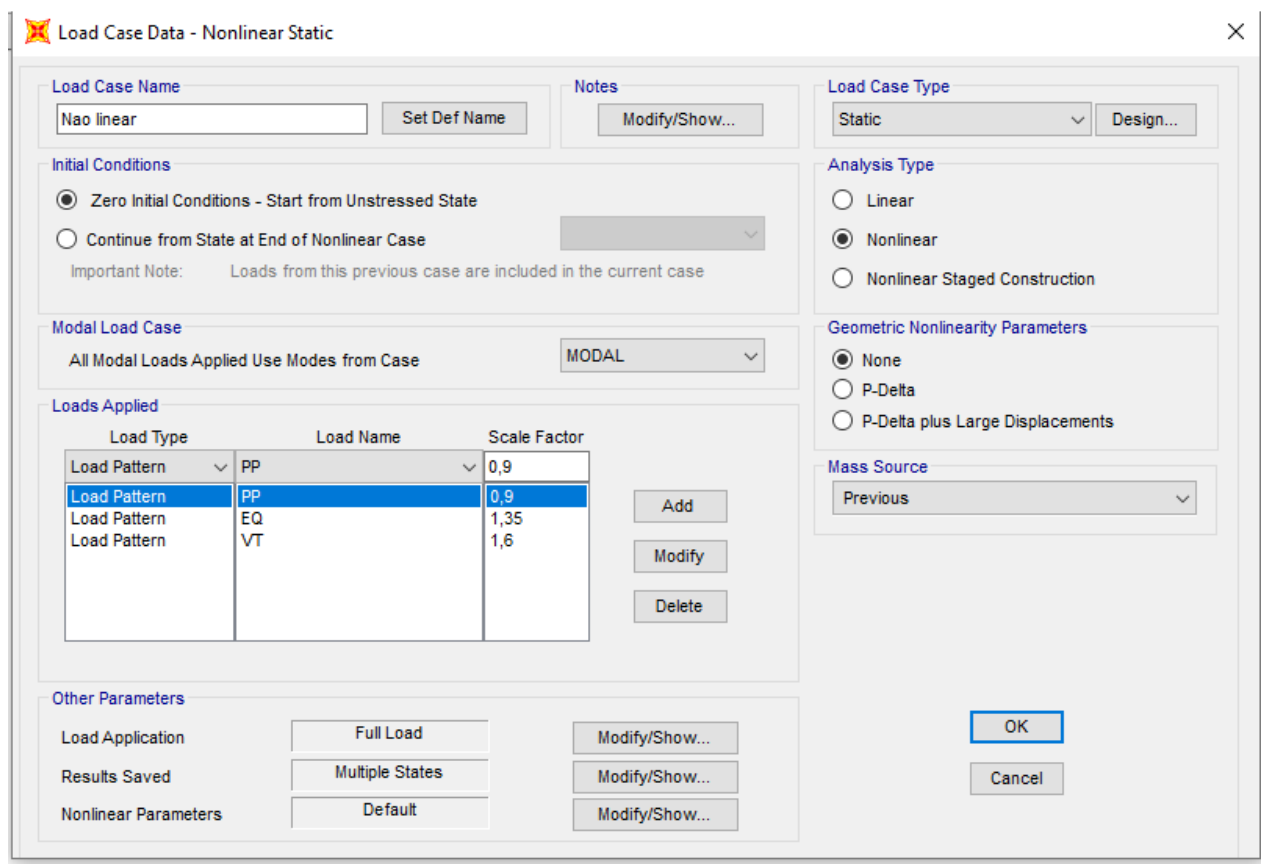

\section{Propriedades das seções}

Para definir uma seção é necessário seguir os seguintes passos.

1. Define $\rightarrow$ Section Properties $\rightarrow$ Area Sections para aparecer o menu inicial para definição das seções.

2. Adicionar uma nova seção através do menu $\rightarrow$ Add New Section. 


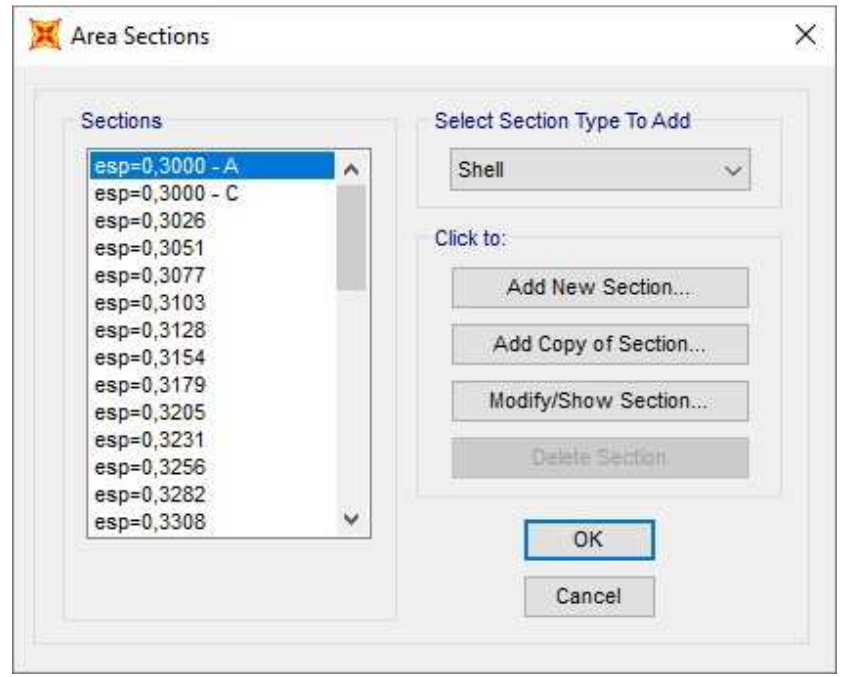

3. No menu seguinte em Section Name, é necessário atribuir um nome à seção $\rightarrow$ escolher o tipo Shell - Layered/Nonlinear $\rightarrow$ Modify/Show Layer Definition.

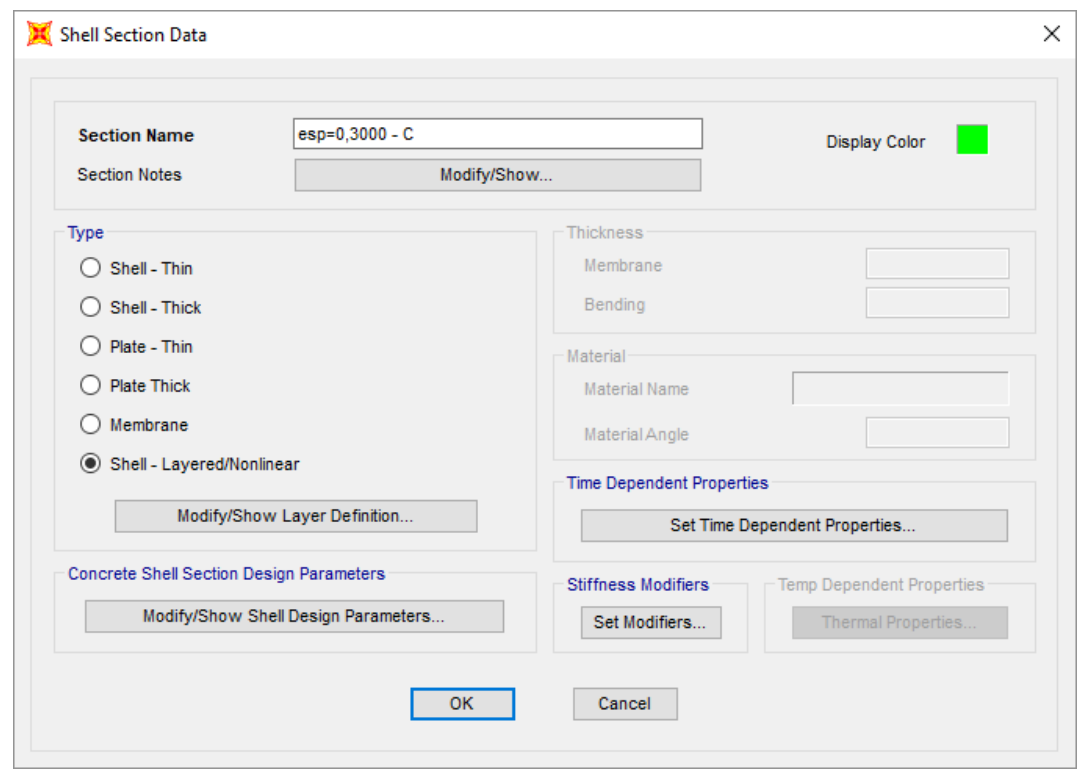

4. No menu seguinte introduzem-se os parâmetros necessários para definir a seção de concreto armado através das várias camadas que compõem a Shell. 


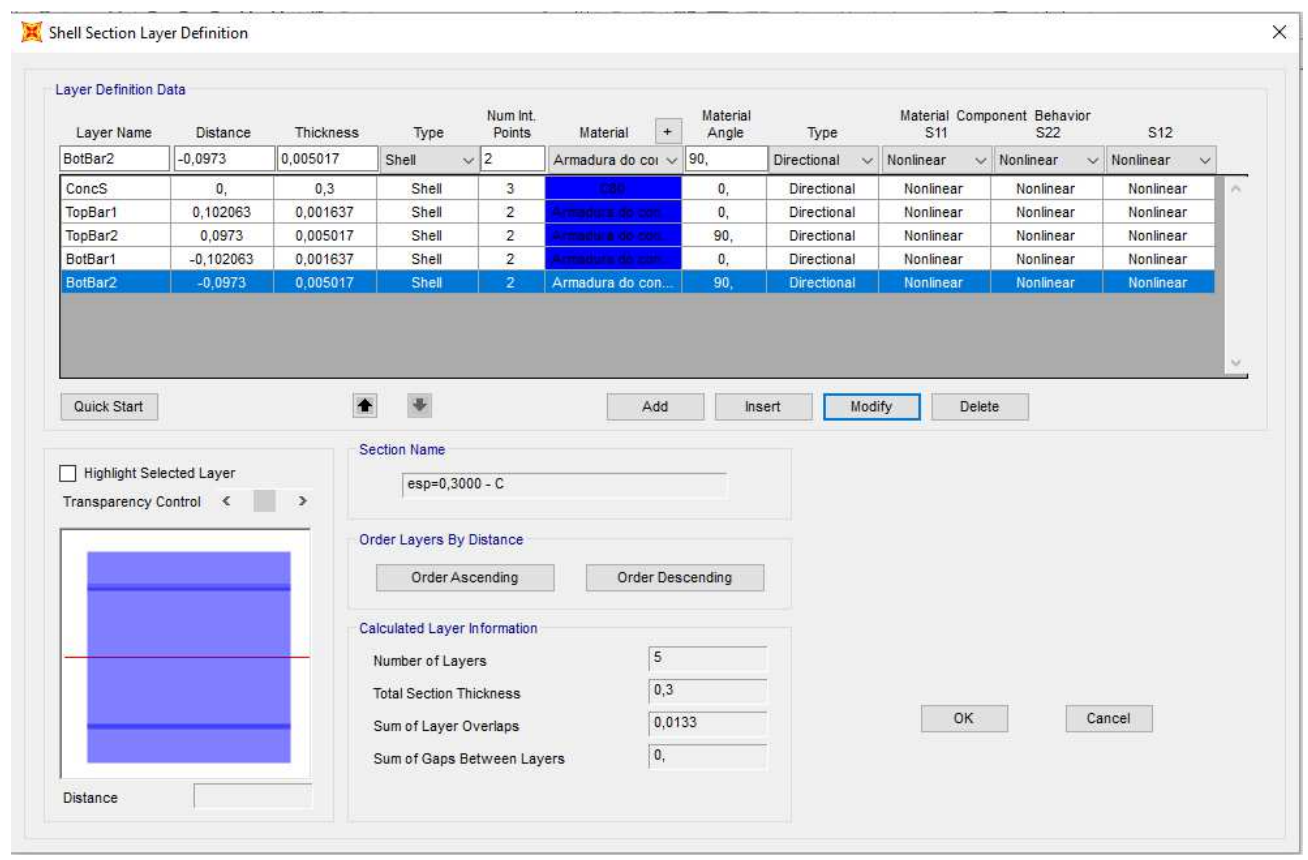




\section{APÊNDICE B - PROCEDIMENTO DE PROJETO PARA DETERMINAÇÃO DA CARGA DO VENTO}

No presente apêndice é apresentado o procedimento de projeto para determinação da carga do vento de acordo com o modelo de Zyl e de acordo com a ABNT NBR 6123 (1988).

\section{Procedimento de projeto para determinação da pressão direta do vento de acordo} com o modelo de Zyl (2014)

$1^{\text {a }}$ Etapa - Calcular a velocidade básica do vento de acordo com a IEC:

- Escolha uma classe de turbina eólica de acordo com as especificações da turbina;

- Escolha a categoria de turbulência do vento de acordo com as especificações da turbina;

- Calcular a velocidade do vento EWM;

- Calcular a velocidade do vento EOG.

$2^{\mathrm{a}}$ Etapa - Calcular a pressão do vento sobre a altura da estrutura de acordo com a ASCE 7-10:

- Converter a velocidade do vento da altura do cubo IEC para a velocidade do vento a $10 \mathrm{~m}$

- Determinar a categoria de risco da torre;

- Determinar a categoria de exposição B, C ou D de acordo com a rugosidade do terreno do local;

- Escolher o fator de direcionalidade do vento, $\mathrm{K}_{\mathrm{d}}$ de acordo com a forma da estrutura;

- Determinar o fator topográfico, $\mathrm{K}_{\mathrm{zt}}$;

- Calcular o coeficiente de exposição da pressão dinâmica, $\mathrm{K}_{\mathrm{z}}$.

- Calcular o fator de efeito de rajada, G para levar em conta a esbeltez da estrutura;

- Calcular a pressão dinâmica $q_{z}$ na altura necessária.

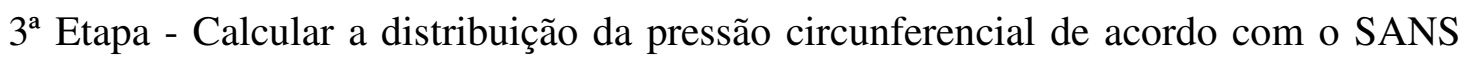
10160-3: 
- Calcule o número de Reynolds para a velocidade do vento de projeto usado na $2^{\mathrm{a}}$ etapa;

- Escolha a curva correta na Figura 5 de acordo com o número de Reynolds;

- Use a Tabela 3 para determinar com precisão os valores críticos da curva escolhida;

- Multiplique os coeficientes de pressão externas com a pressão dinâmica de projeto, $q_{z}$.

\section{Procedimento de projeto para determinação da força de arrasto do vento de} acordo com o modelo de viga de Zyl (2014)

$1^{\text {a }}$ Etapa - Calcular a velocidade básica do vento de acordo com a IEC:

- Escolha uma classe de turbina eólica de acordo com as especificações da turbina;

- Escolha a categoria de turbulência do vento de acordo com as especificações da turbina;

- Calcular a velocidade do vento EWM;

- Calcular a velocidade do vento EOG.

$2^{\text {a }}$ Etapa - Calcular a pressão do vento sobre a altura da estrutura de acordo com a ASCE 7-10:

- Converter a velocidade do vento da altura do cubo IEC para a velocidade do vento a $10 \mathrm{~m}$;

- Determinar a categoria de risco da torre;

- Determinar a categoria de exposição B, C ou D de acordo com a rugosidade do terreno do local;

- Escolher o fator de direcionalidade do vento, $K_{d}$ de acordo com a forma da estrutura;

- Determinar o fator topográfico, $\mathrm{K}_{\mathrm{zt}}$;

- Calcular o coeficiente de exposição da pressão dinâmica, $\mathrm{K}_{\mathrm{z}}$.

- Calcular o fator de efeito de rajada, G para levar em conta a esbeltez da estrutura;

- Calcular a pressão dinâmica $q_{z}$ na altura necessária. 
$3^{\text {a }}$ Etapa - Calcular a força de arrasto resultante, considerando uma área com comprimento unitário ao longo da torre, que é obtido através da multiplicação do coeficiente ABNT NBR 6123 (1988), de arrasto $C_{a}$ da com a pressão dinâmica da ASCE 7-10 (2010), com o diâmetro externo da torre.

Procedimento de projeto para determinação da pressão direta do vento acordo com o modelo de casca de ABNT NBR 6123 (1988)

$1^{\text {a }}$ Etapa - Calcular a velocidade característica do vento:

- Determinar a velocidade básica do vento $V_{o}$, através do mapa das isopletas;

- Determinar o Fator Topográfico $S_{1}$.

- Calcular o fator $S_{2}$ que combina os efeitos da rugosidade do terreno, da variação da velocidade do vento com a altura acima do terreno e das dimensões da estrutura;

- Determinar o Fator Estatístico $S_{3}$;

- Calcular a velocidade característica do vento $\left(V_{K}\right)$.

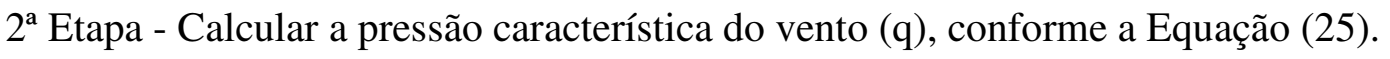

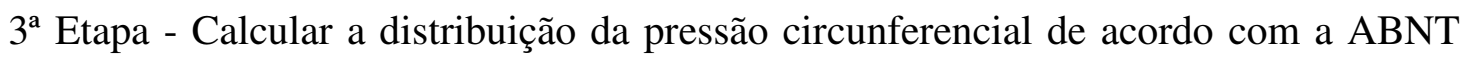
NBR 6123 (1988):

- Calcular o número de Reynolds para a velocidade característica do vento;

- Verificar se o número de Reynolds é maior que 4,20 x $10^{5}$ e se o vento está incidindo perpendicularmente ao eixo do cilindro, de diâmetro d;

- Caso o número de Reynolds seja maior, multiplique os coeficientes de pressão externas da

- $\quad$ com a pressão característica do vento (q).

Procedimento de projeto para determinação da força de arrasto do vento de acordo com o modelo de viga de ABNT NBR 6123 (1988)

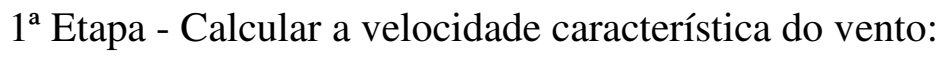

- Determinar a velocidade básica do vento $V_{o}$, através do mapa das isopletas; 
- Determinar o Fator Topográfico $S_{1}$;

- Calcular o fator $S_{2}$ que combina os efeitos da rugosidade do terreno, da variação da velocidade do vento com a altura acima do terreno e das dimensões da estrutura;

- Determinar o Fator Estatístico $S_{3}$;

- Calcular a velocidade característica do vento $\left(V_{K}\right)$.

$2^{\text {a }}$ Etapa - Calcular a pressão característica do vento (q), conforme a Equação (25).

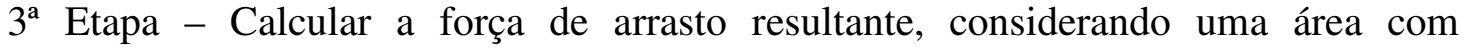
comprimento unitário ao longo da torre, que é obtido através da multiplicação do coeficiente de arrasto $C_{a}$ da ABNT NBR 6123 (1988), com a pressão característica do vento (q), com o diâmetro externo da torre. 